\title{
Quality of Life and Health Outcomes in Overweight and Non- Overweight Children with Asthma.
}

Amy Becker Manion
Loyola University Chicago

Follow this and additional works at: https://ecommons.luc.edu/luc_diss

Part of the Nursing Commons

\section{Recommended Citation}

Manion, Amy Becker, "Quality of Life and Health Outcomes in Overweight and Non-Overweight Children with Asthma." (2010). Dissertations. 145.

https://ecommons.luc.edu/luc_diss/145

This Dissertation is brought to you for free and open access by the Theses and Dissertations at Loyola eCommons. It has been accepted for inclusion in Dissertations by an authorized administrator of Loyola eCommons. For more information, please contact ecommons@luc.edu. (c) (i) $(9)$

This work is licensed under a Creative Commons Attribution-Noncommercial-No Derivative Works 3.0 License. Copyright $\odot 2010$ Amy Becker Manion 


\title{
LOYOLA UNIVERSITY CHICAGO
}

\section{QUALITY OF LIFE AND HEALTH OUTCOMES IN OVERWEIGHT AND NON-OVERWEIGHT CHILDREN WITH ASTHMA}

\author{
A DISSERTATION SUBMITTED TO \\ THE FACULTY OF THE GRADUATE SCHOOL \\ IN CANDIDACY FOR THE DEGREE OF \\ DOCTOR OF PHILOSOPHY
}

PROGRAM IN NURSING

BY

AMY BECKER MANION

CHICAGO, ILLINOIS

MAY 2010 
Copyright by Amy Becker Manion, 2010 All rights reserved. 


\section{ACKNOWLEDGEMENTS}

The completion of this doctoral work would not have been possible without the contributions of many wonderful people. First, I would like to thank my husband, Mike, for his love and support. I really could not have come this far without his help. I also want to thank my children, Molly and Finn, who have waited so patiently for mommy to

play with them. In addition, I am grateful to my parents, Fred and Jane, and my in-laws, John and Barbara for their support. I would like to especially thank my brother, Scott, for teaching me how to be a better writer, and to my sister, Jill, for babysitting and other foolishness.

I would like to acknowledge the children and caregivers who were willing to participate in this study. You have taught me so much. In addition, I would like to thank the staff at Children's Memorial Allergy Clinic, especially Dr. Rachel Story, Patty, and Michael for their assistance with data collection. In addition, I am forever indebted to Amanda Skoskiewicz for her research assistance and cheerful attitude. Also, I am grateful to my friend, Gilbert Hinojosa, at Denver Children's Hospital for his lessons in spirometry. I am also appreciative of Dr. Lou Fogg and Dr. Briana Jegier at Rush University for their statistical assistance.

I am grateful to my dissertation director and advisor, Dr. Barbara VelsorFriedrich, for her guidance and understanding. I would also like to thank the other 
members of my committee, Dr. Sue Penckofer and Dr. Gloria Jacobson for all their assistance and support.

Finally, I would like to acknowledge my coworkers and friends at Northwestern Children's Practice, who have supported me throughout this endeavor. I am especially grateful to Dr. Marc Weissbluth and his wonderful wife Linda, who have always given me the job flexibility and support to help me achieve my goals. In addition, I would also like to thank all the children and their parents, whom I have had the privilege to take care of over the last 20 years. You are the reason I enjoy being a nurse, and I am forever grateful. 
To my wonderful husband, Mike, who makes life so much easier.

To my children, Molly and Finn, whom I love so much and who make me laugh. 
Our most basic common link is that we all inhabit this small planet. We all breathe the same air. We all cherish our children's future. And we are all mortal.

John F. Kennedy, American University, Washington DC, June 10, 1963. 
TABLE OF CONTENTS

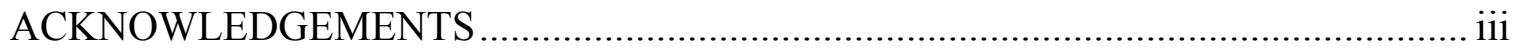

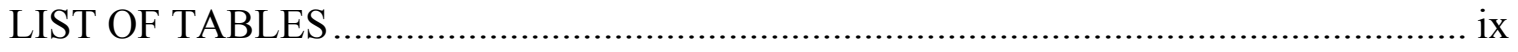

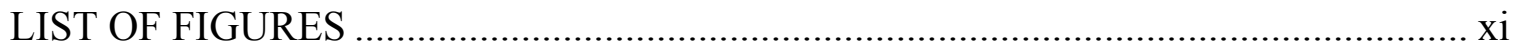

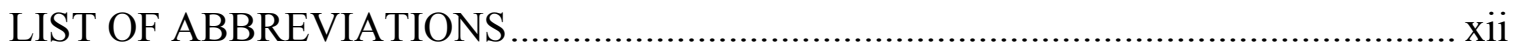

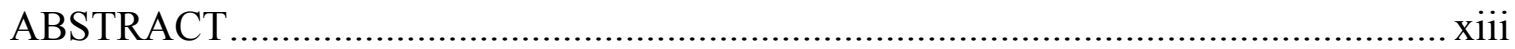

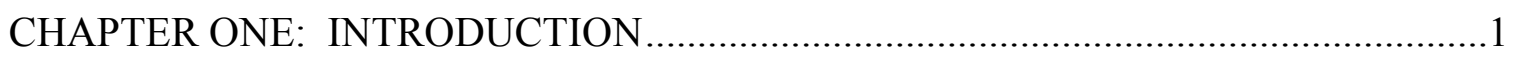

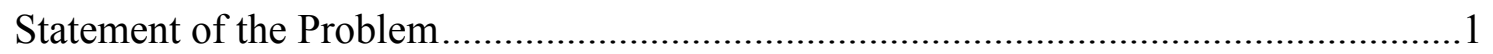

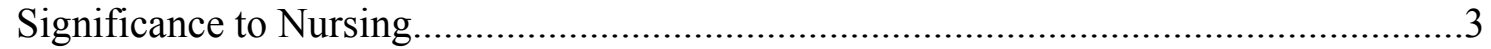

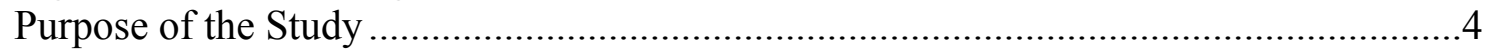

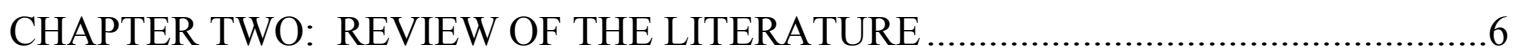

Background and Significance of Asthma ................................................................

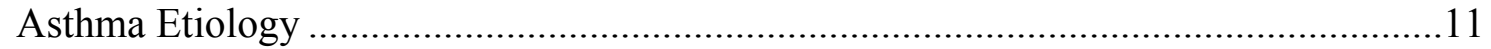

Background and Significance of Obesity ……………............................................17

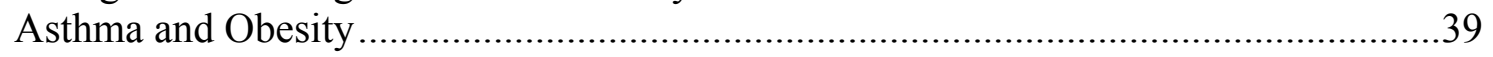

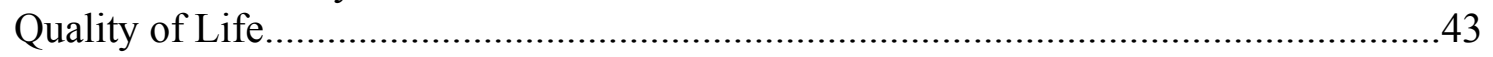

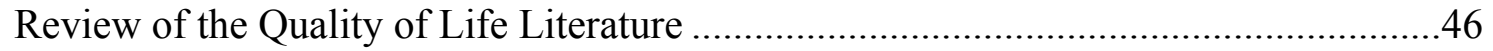

Gaps in the Literature........................................................................................6

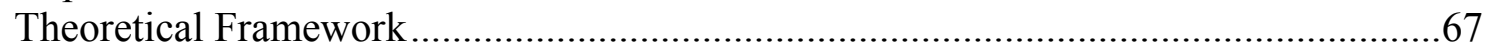

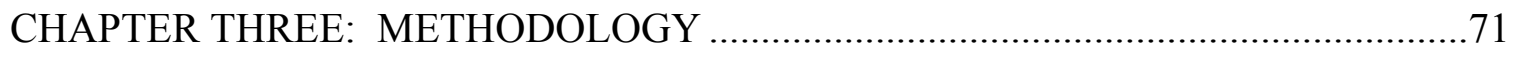

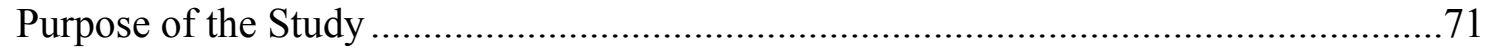

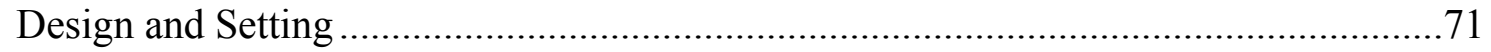

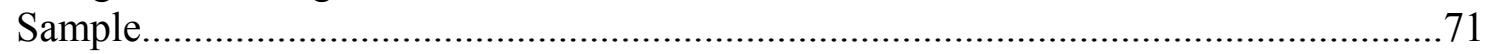

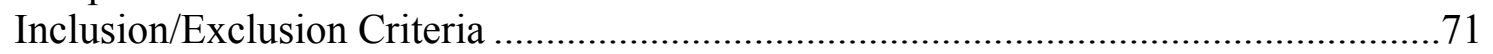

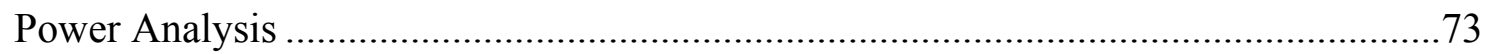

Protection of Human Subjects .............................................................................

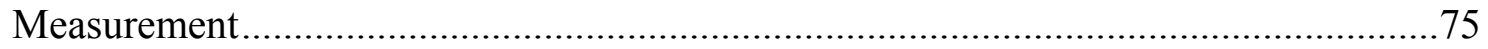

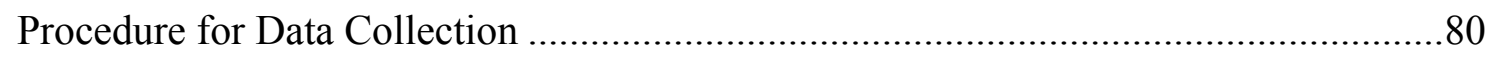

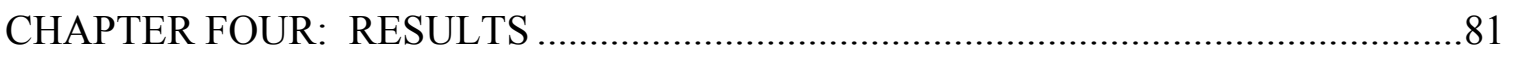

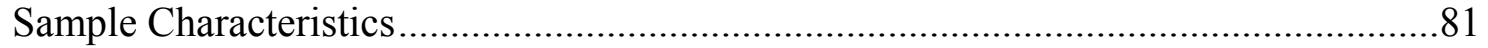

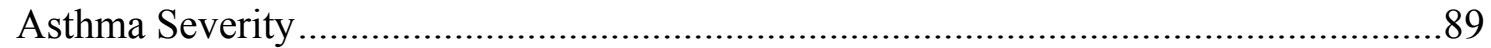

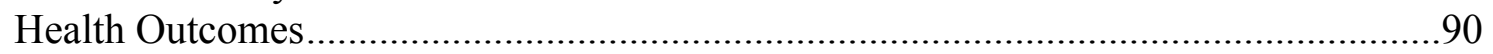

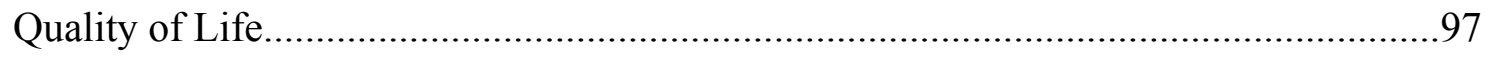

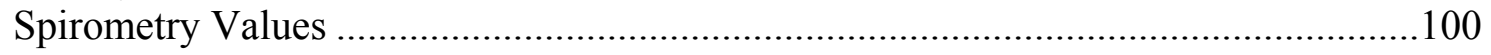

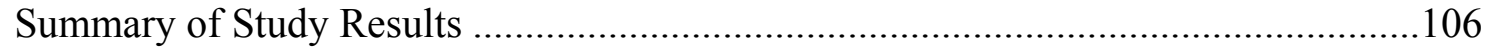




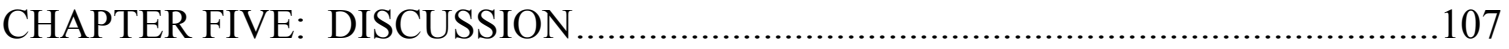

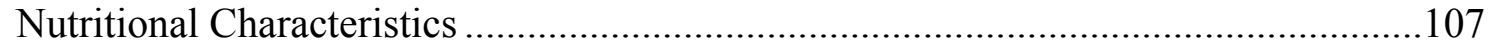

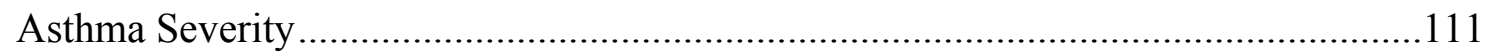

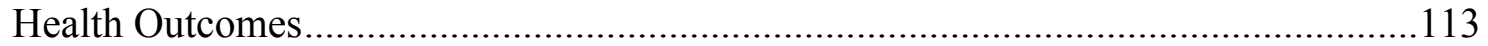

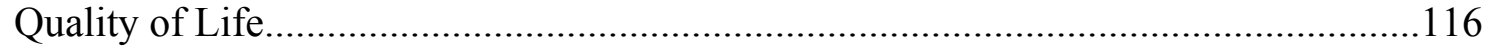

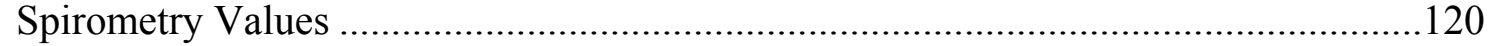

Theoretical Framework: Revised HRQOL Model................................................... 121

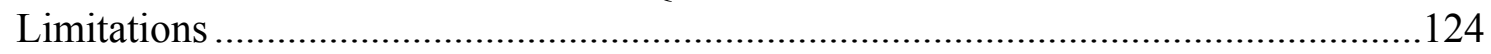

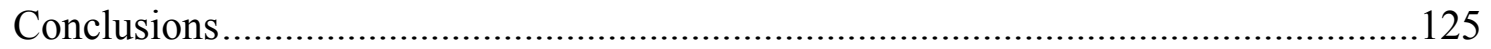

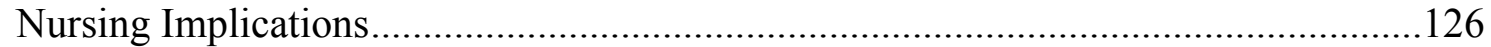

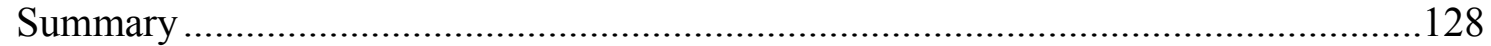

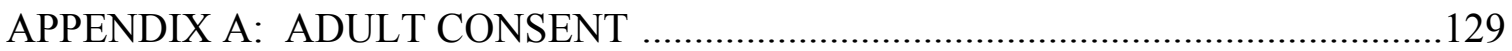

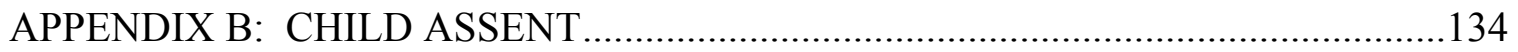

APPENDIX C: BODY MASS INDEX GROWTH CHARTS ....................................138

APPENDIX D: SOCIODEMOGRAPHIC QUESTIONNAIRE ................................141

APPENDIX E: PEDIATRIC ASTHMA QUALITY OF LIFE QUESTIONNAIRE.....145

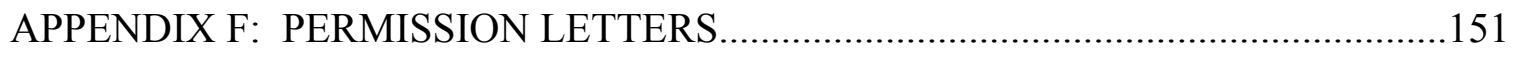

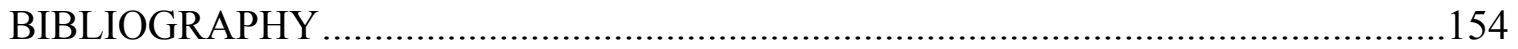

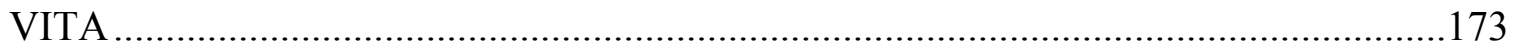




\section{LIST OF TABLES}

Table 1. Asthma Classifications ..........................................................................

Table 2. Genes Implicated in the Development of Asthma ..........................................12

Table 3. WHO Global Database on Body Mass Index 2006 .......................................18

Table 4. Prevalence of Obesity Among U.S. Children and Adolescents.......................21

Table 5. Disorders Related to Childhood Overweight, by Body System .......................24

Table 6. Description of Common Spirometric Test Values.......................................78

Table 7. Age, Gender, Ethnicity Characteristics for Subjects ...................................82

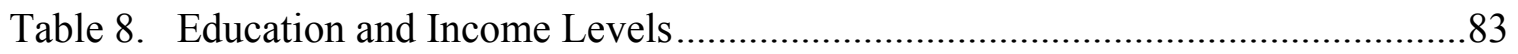

Table 9. Body Mass Index Characteristics for Children by Gender ............................84

Table 10. Body Mass Index Characteristics for Children and Parents ...........................85

Table 11. Parental BMI in Relation to Child BMI Values .............................................86

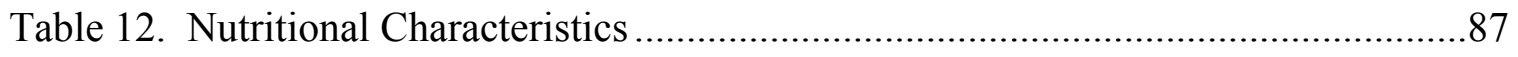

Table 13. Breakfast Characteristics for Normal/Overweight/Obese ............................87

Table 14. Family Meal Characteristics for Normal/Overweight/Obese ........................88

Table 15. Fast Food Characteristics for Normal/Overweight/Obese ............................89

Table 16. Asthma Classification Characteristics ....................................................90

Table 17. Health Outcomes and Asthma Severity Chi-Square Results ..........................91

Table 18. Missed School Characteristics .................................................................92

Table 19. Emergency Department Characteristics...................................................93 


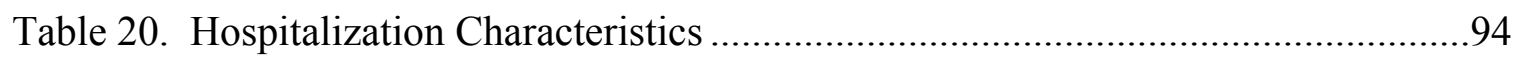

Table 21. Unscheduled Doctor/Clinic Visit Characteristics ........................................95

Table 22. Days Wheezing Characteristics ............................................................ 96

Table 23. Woke Up Coughing Characteristics ........................................................97

Table 24. Regression Analysis Results for Normal Weight and Obese Groups.............100 


\section{LIST OF FIGURES}

Figure 1. Revised Wilson and Cleary Model for Health-Related Quality of Life.......68

Figure 2. Revised HRQOL Model with Study Variables...........................124 


\section{LIST OF ABBREVIATIONS}

$\begin{array}{ll}\text { BMI } & \text { Body Mass Index } \\ \text { FEF } & \text { Forced Expiratory Flow } \\ \text { FEV1 } & \text { Forced Expiratory Volume in 1 Second } \\ \text { FVC } & \text { Forced Vital Capacity } \\ \text { HRQOL } & \text { Health Related Quality of Life } \\ \text { PAQLQ } & \text { Pediatric Asthma Quality of Life Questionnaire } \\ \text { PEFR } & \text { Peak Expiratory Flow Rate } \\ \text { QOL } & \text { Quality of Life }\end{array}$




\begin{abstract}
Over the last two decades the number of children and adolescents who are overweight has more than doubled. Currently, an estimated 18 percent of children and adolescents ages 6-19 years are overweight or obese. Following this trend in childhood overweight, there has been an alarming increase in the number of children with asthma who are overweight. The increasing trend in both asthma and overweight has led to the suggestion of a causal relationship between the two. Childhood overweight has been found to have a profound negative impact on quality of life (QOL), yet there is a dearth of research regarding the impact the co-morbidities of overweight and asthma have on the QOL of children.
\end{abstract}

The purpose of this study was to examine the differences in quality of life and health outcomes of overweight children with asthma compared to non-overweight children with asthma using a descriptive comparative survey design. The sample consisted of 9 to 14 year olds recruited from a large urban asthma clinic. The sample was divided into two groups, overweight and non-overweight. Along with quality of life, the health outcomes examined include asthma related missed number of school days, emergency department (ED) visits, hospitalizations, number of days wheezing, number of night wakings and spirometry values. QOL was measured using the Pediatric Asthma Quality of Life Questionnaire (PAQLQ). The obese group reported the highest 
percentage of ED visits, hospitalizations, and number of days wheezing compared to the normal weight group. Only the asthma related ED visit trend was found to be statistically significant $(\mathrm{p}=0.037)$. No statistical difference was found in QOL scores between the two groups. The conclusion and implication of these results point to the need for further research regarding the impact obesity plays in the lives of children and better management of asthma symptoms in overweight children which can influence hospitalization rates and use of the ED. 


\section{CHAPTER ONE}

\section{INTRODUCTION}

\section{$\underline{\text { Statement of the Problem }}$}

As the populations of the world have evolved from a mainly rural, mainly agrarian society to a more urban and industrial society, the challenges facing modern medicine have also evolved. What were once the mainstays of concern, infectious diseases such as polio, tuberculosis, and typhoid, have now been replaced with an equally fatal, if not more insidious problem. As the new millennium begins, the high mortality from infectious diseases has been replaced with chronic illnesses such as heart disease, diabetes, and asthma. In addition to this shift in treatment focus, modern medicine has moved away from its days of paternalism and has begun to include the patient's perspective in decision-making (Gerharz, Eiser, \& Woodhouse, 2003). With the encouragement of increased patient participation and decision making, there has been an accompanying interest in patient quality of life (QOL).

Childhood asthma is an example of a chronic illness that can impact a child's quality of life. Asthma is the most common chronic illness among children today (American Lung Association, 2005; Chipps, 2008), effecting an estimated 9.9 million children in the U.S. under the age of 18 (Bloom \& Cohen, 2007). Between 1980 and 1994, there was a $160 \%$ increase in the incidence of asthma among children 4 years of 
age and younger and a 74\% increase among children 5 to 14 years old (Mannino et al., 1998). This steady increase makes pediatric asthma the number one cause of hospitalization among children under the age of 15 and the third leading cause of preventable hospitalizations in the U.S. with approximately 444,000 hospitalizations annually (American Lung Association, 2009). The high prevalence of this disease and its continued drain on medical resources makes it a major cause for concern. Many children and adolescents are not only at risk due to asthma but also due to childhood obesity, another risk factor that has been rapidly increasing.

Within the past two decades, the health of children has been threatened by an increase in childhood overweight. The number of children who are overweight has more than doubled in the last 25 years (Dietz \& Robinson, 2005; US Preventive Services Task Force, 2005). Currently, nearly 9 million or 1 in 7 children and adolescents in the United States are considered overweight or obese (CDC, 2005; Swallen, Reither, Haas, \& Meier, 2005). This trend may be due, in part, to the fact that children's diets have changed to include high-calorie foods with little nutritional value and mandatory exercise has been removed from the educational curriculum. Unless this obesity trend is reversed, it has been predicted that today's children may be the first generation to live less healthy and even shorter lives than their parents (Olshansky et al., 2005).

Following this trend in obesity, studies have found an increased prevalence of asthma in children who are obese, which suggests the possibility that asthma and obesity may be causally related in some way (Castro-Rodriguez, Holberg, Morgan, Wright, \& Martinez, 2001; Chen, Kim, Houtrow, \& Newacheck, 2009). Furthermore, there is 
evidence to suggest that there is a negative relationship between obesity and asthma (Belamarich et al., 2000; Musaad et al., 2009). The increasing prevalence of both asthma and obesity are major public health concerns (Castro-Rodriguez et al., 2001). However, the root cause of both these increases remain unknown (Kimm \& Obarzanek, 2006; To, Vydykhan, Dell, Tassoudji, \& Harris, 2004). Recent studies suggest that the marked increases in obesity observed during the last twenty years may in part be causing the increase in asthma prevalence concomitantly observed (Castro-Rodriguez et al., 2001; Mannino et al., 2006).

Overall, childhood asthma has been found to have a minimal effect on QOL (Annett, Bender, Lapidus, Duhamel, \& Lincoln, 2001; Gibson, Henry, Vimpani, \& Halliday, 1995; Okelo et al., 2004). Conversely, childhood obesity has been found to have a profound negative impact on QOL (Friedlander, Larkin, Rosen, Palermo, \& Redline, 2003; Schwimmer, Burwinkle, \& Varni, 2003; Williams, Wake, Hesketh, Maher, \& Waters, 2005). However, it is unknown how the comorbidities of asthma and obesity affect the quality of life of children.

\section{$\underline{\text { Significance to Nursing }}$}

The increasing trend in the prevalence of both asthma and obesity requires that more research be conducted in assessing how these two health concerns together are affecting the quality of life of children. Quality of life is a reflection of overall wellbeing and therefore, an important concept for nursing to investigate. Nurses should not rely on just clinical outcomes to assess how well their patients are doing, but should include patient reported quality of life as part of their assessment process. To achieve 
this goal, optimal development of the patient's quality of life should be incorporated into the overall plan of care for every patient and be included in the outcome measurements. By developing a better understanding of quality of life this objective can be achieved.

Research has shown poor quality of life in obese children (Fontaine \& Barofsky, 2001; Schwimmer et al., 2003). However, this area of research needs to be expanded to include comorbidities such as asthma. In addition, new research is needed to provide a clearer understanding of the relationship between obesity and asthma. This expanded knowledge will be used by the discipline of nursing to guide future research directed at better management of resources and more effective interventions for treating and preventing obesity and asthma in children and in the process improve their overall wellbeing.

\section{Purpose of the Study}

The purpose of this study was to examine the differences in QOL and health outcomes in two different groups; overweight children with asthma and non-overweight children with asthma. Quality of life for each subject was measured using the Pediatric Asthma Quality of Life Questionnaire (PAQLQ). The health outcomes which were examined included asthma related school absences, number of ED visits, number of hospitalizations, and number of unscheduled doctor/clinic visits due over the last 6 months. Additional health outcomes examined included the number of days the child wheezed over the two weeks prior to their participation in this study and how many nights they woke up coughing, along with spirometric values. These health outcomes were chosen because they are strong indicators of a child's asthma severity (Belamarich 
et al., 2000; National Asthma Education and Prevention Program, 2003). A comparative analysis of the QOL scores and health outcome measurements was conducted to determine if differences existed among the two groups of subjects.

Hypotheses:

1. There is a difference in QOL in overweight children with asthma compared to non-overweight children with asthma.

2. There is a difference in health outcomes- missed number of school days, ED visits, hospitalizations, unscheduled doctor/clinic visit, number of days wheezing, and spirometry values- in overweight children with asthma compared to non-overweight children with asthma. 


\section{CHAPTER TWO}

\section{REVIEW OF THE LITERATURE}

In order to investigate the concept of quality of life and how QOL is impacted by the comorbidities of asthma and obesity, a review of the literature was conducted using the following computerized databases: Cumulative Index to Nursing and Allied Health Literature (CINAHL), MEDLINE, PSYCINFO, ERIC, Dissertation Abstracts, Library User Information Services (LUIS), and Pegasus Library Catalog. Keywords included quality of life, quality of life and children, childhood chronic illness, asthma, and obesity.

Using quality of life as the main keyword yielded over 77,000 results. When the keywords quality of life and children were combined, there were slightly over 6,000 results. Quality of life combined with asthma yielded 1494 results, and quality of life and obesity produced 668 results. However, when quality of life was combined with pediatric or childhood asthma, only 64 studies were reported and when QOL was combined with pediatric or childhood obesity only 9 studies were reported. Combining QOL and childhood chronic illness yielded only 3 studies. In addition, although 479 studies on asthma and obesity were reported, combining childhood asthma with obesity yielded only 12 reported studies. For purposes of this study, a total of 20 studies have been critiqued for this review of the literature. 
Furthermore, with the exception of a few influential works, the review was limited to only works published in English from 1995 forward. Reference lists and shelved books were also examined for this review.

In order to fully present the current knowledge available regarding QOL as it relates to asthma and obesity, this review will begin with a discussion on the background and significance of asthma and obesity in children. Then the focus will shift to QOL and the research literature regarding QOL in relation to asthma and obesity.

\section{Background and Significance of Asthma}

\section{Defining Asthma}

Asthma is a chronic inflammatory disease of the airways that affects people of all ages, in all parts of the world (Mullen, 2005). Asthma is characterized by variable and recurring symptoms, airway obstruction, bronchial hyper-responsiveness, and an ongoing inflammatory process (National Asthma Education and Prevention Program, 2007). An asthma exacerbation can be triggered by a variety of factors including viral respiratory infections, exposure to irritants, environmental/weather changes, exercise, cigarette/tobacco smoke, and allergens such as pollen, mold, animal dander, and dust (Burns, Dunn, Brady, Barber Star, \& Blosser, 2009). Asthma symptoms include wheezing, shortness of breath, chest tightness, and coughing, particularly at night and in the early morning (National Asthma Education and Prevention Program, 2007). As shown in Table 1, severity of asthma symptoms can be classified into four categories based on overall symptoms, short-acting beta 2 -agonist use for symptom control (i.e. albuterol), nighttime awakenings, interference with normal activity and lung function: 
intermittent, mild persistent, moderate persistent and severe persistent (National Asthma Education and Prevention Program, 2007).

Table 1. Asthma Classifications

\begin{tabular}{|l|l|l|l|l|}
\hline $\begin{array}{l}\text { Components of } \\
\text { Severity }\end{array}$ & Intermittent & $\begin{array}{l}\text { Mild } \\
\text { Persistent }\end{array}$ & $\begin{array}{l}\text { Moderate } \\
\text { Persistent }\end{array}$ & Severe Persistent \\
\hline Symptoms & $\leq 2$ days/wk & $>2$ days/wk & Daily & $\begin{array}{l}\text { Throughout the } \\
\text { day }\end{array}$ \\
\hline $\begin{array}{l}\text { Nighttime } \\
\text { Awakenings }\end{array}$ & $\leq 2 \mathrm{x} / \mathrm{month}$ & $3-4 \mathrm{x} / \mathrm{month}$ & $\begin{array}{l}>1 \mathrm{x} / \mathrm{wk} \text {, but not } \\
\text { nightly }\end{array}$ & Often 7x/wk \\
\hline $\begin{array}{l}\text { Short-acting beta } 2^{-} \\
\text {agonist use }\end{array}$ & $\leq 2$ days/wk & $\begin{array}{l}>2 \text { days/wk but not } \\
\text { daily }\end{array}$ & Daily & $\begin{array}{l}\text { Several times per } \\
\text { day }\end{array}$ \\
\hline $\begin{array}{l}\text { Interference with } \\
\text { normal activity }\end{array}$ & None & Minor limitation & Some limitation & Extremely limited \\
\hline $\begin{array}{l}\text { Lung Function } \\
\text { Normal FEV }\end{array}$ & $\begin{array}{l}\mathrm{FEV}_{1}=>80 \% \\
\text { predicted } \\
\text { extween }\end{array}$ & $\begin{array}{l}\mathrm{FEV}_{1}=60-80 \% \\
\text { predicted }\end{array}$ & $\begin{array}{l}\mathrm{FEV}_{1}<60 \% \\
\text { predicted }\end{array}$ \\
\hline
\end{tabular}

Primarily, there are two main types of childhood asthma: (1) recurrent wheezing in early childhood, mostly triggered by upper respiratory tract viral infections, and (2) chronic asthma associated with allergy and exercise that persists into later childhood and often adulthood (Liu, Spahn, \& Leung, 2004). In addition, a third type of childhood asthma has begun to emerge which typically occurs in females who develop obesity and early-onset puberty (prior to 11 years of age) (Liu et al., 2004).

\section{Asthma Prevalence}

Asthma poses a tremendous burden on society in terms of morbidity, mortality, quality of life, and healthcare costs (Mullen, 2005). Asthma is the number one common chronic condition in the U.S. (Tattersfield, Knox, Britton, \& Hall, 2002). Based on data from the 2007 National Health Interview Survey, 34 million Americans, or 114.5 per 
1,000 persons had been diagnosed with asthma by a health professional within their lifetime, 22.9 million currently had asthma, and 12.3 million had experienced an asthma exacerbation within the past year (American Lung Association, 2009).

Over the period 1980 through 1996, the prevalence of asthma in the United States increased dramatically for all age, sex, and racial groups (National Heart Lung and Blood Institute, 1999). Over the last decade, mortality and hospitalizations due to asthma have decreased and asthma prevalence rates have stabilized, possibly indicating an improved level of disease management (American Lung Association, 2009). Meanwhile, international asthma prevalence rates have continued to increase, with an estimated 300 million people affected worldwide (Masoli, Fabian, Holt, \& Beasley, 2004).

Asthma Prevalence in Children

Despite the stabilization of asthma prevalence rates, asthma remains the most common chronic childhood illness in the United States with an estimated 6.7 million children affected (American Lung Association, 2009; Chipps, 2008). Since 1999, children 5-17 years of age have shown the highest prevalence rates with 99.9 per 1,000 diagnosed with asthma, compared to 72.5 per 1,000 in those over 18 (American Lung Association, 2009). Asthma related emergency department (ED) visits and hospitalizations are also more common among children than adults (Mullen, 2005). In 2004, children accounted for over 754,000 ED visits, 198,000 hospitalizations, 7 million outpatient visits, and 12.8 million missed school days due to asthma (CDC, 2006). Although death due to asthma is rare in children, 195 children aged 0-17 years died from asthma in 2003 (CDC, 2006). 
Racial and Economic Disparities in Childhood Asthma

Although asthma affects children of all ages, races, ethnicities, and incomes, it afflicts minority and poor children disproportionately (McDaniel, Paxson, \& Waldfogel, 2006). In 2005, Puerto Ricans had asthma prevalence $125 \%$ higher than non-Hispanic whites, and non-Hispanic blacks and American Indians had asthma prevalence 25\% higher than non-Hispanic whites (CDC, 2006).

Data from the 2003 National Health Interview Survey found that children in poor families $(15 \%)$ were more likely to have been diagnosed with asthma than children in families that were not poor (12\%) (Dey \& Bloom, 2005). In addition, children in twoparent families (11\%) were less likely to have ever been diagnosed with asthma than children from single-mother families (16\%) (Dey \& Bloom, 2005).

A recent analysis using data from the National Health Interview Survey 1997 to 2003 compared differences in asthma prevalence and emergency department (ED) visits for asthma between non-Hispanic black and white children (McDaniel et al., 2006). The analysis found that asthma prevalence was consistently greater among black children (15.7\%) compared with white children (11.5\%), across all income levels (McDaniel et al., 2006). In addition, black children were twice as likely as white children to have had an ED visit for asthma in the past year (McDaniel et al., 2006).

Multiple asthma related ED visits and hospitalizations are risk factors for fatal asthma (Nair \& Cloutier, 2003). The rate of asthma deaths is highest among minorities, especially African-Americans. An analysis of trends in childhood asthma using five data sources from the National Center for Health Statistics found that racial disparities were 
largest for asthma hospitalizations and mortality: compared with white children, in 19981999, black children were three times more likely to be hospitalized and four times more likely to die from asthma (Akinbami \& Schoendorf, 2002).

Similar rates were reported by the CDC, which found that Puerto Ricans were the most likely to die from asthma, and had an asthma death rate $360 \%$ higher than nonHispanic whites (CDC, 2006). Non-Hispanic blacks had an asthma death rate over $200 \%$ higher than non-Hispanic whites (CDC, 2006). In addition, the ED visit rate for blacks was $350 \%$ higher than that for whites and the asthma hospitalization rate for blacks was 240\% higher than for whites (CDC, 2006).

\section{Asthma Etiology}

\section{Genetics}

The exact cause of childhood asthma is unclear. However, current research suggests an interplay between genetic and environmental factors (Liu et al., 2004). Family studies have shown that genetics plays a significant role in influencing an individual's risk of being diagnosed with asthma (Tattersfield et al., 2002). For example, the chance of a person developing asthma by age 50 is 10 times higher if they have a first degree relative with asthma (Rees, 2005). Furthermore, if both parents have asthma, their children have a one in three chance of developing asthma in their lifetime (Eggleston, 1993; Szeftel \& Schiffman, 2009).

The obvious role genetics play in the development of asthma and the ability to map the human genome has lead to numerous studies focusing on this relationship (Apter \& Szefler, 2004; Howard, Meyers, \& Bleecker, 2000; Kabesch et al., 2006). As shown in 
Table 2, recent studies using genome mapping suggest that susceptibility to asthma is determined by many genes (Kabesch et al., 2006; Tattersfield et al., 2002). Over 22 loci on 15 autosomal chromosomes have been linked to asthma (Liu et al., 2004). The hope for the future is that genetic markers can be used as a screening tool for development of childhood asthma and be used to predict an individual's response to different asthma medication options (Kabesch et al., 2006; Liu et al., 2004).

Table 2. Genes Implicated in the Development of Asthma

\begin{tabular}{|c|c|}
\hline Chromosome & Genes \\
\hline $5 \mathrm{q}$ & $\begin{array}{c}\text { Th2 cytokine cluster } \\
\text { (interleukin } 4,5,9,13)\end{array}$ \\
\hline $6 \mathrm{q}$ & Tumor necrosis factor $\alpha$ \\
\hline $11 \mathrm{q}$ & $\begin{array}{c}\text { Clara cell secretory protein, } \\
\text { high affinity IgE }\end{array}$ \\
\hline $12 \mathrm{q}$ & Interferon $\gamma$ \\
\hline $14 \mathrm{q}$ & T cell receptor $\alpha$ \\
\hline $16 \mathrm{q}$ & Interleukin-4R $\alpha$ \\
\hline $20 \mathrm{p}$ & ADAM33 \\
\hline
\end{tabular}

\section{Environment}

Although it appears that genetics predetermines an individual's risk of developing asthma, environment also plays a key role. The strong association of asthma with concomitant allergies suggests that environmental factors influence immune development toward the asthmatic phenotype in susceptible individuals (Liu et al., 2004). In fact, recurrent allergen exposure is a major contributor to disease severity (Liu et al., 2004). Consequently, removing the offending allergen(s) often results in a major reduction in 
asthma symptoms (Liu et al., 2004). For example, if a child is allergic to cat dander, removing the animal from the home will often decrease their asthma symptoms.

Besides animal dander, mold, and dust, other environmental factors such as tobacco smoke and air pollutants can aggravate airways causing inflammation and worsening asthma symptoms (Liu et al., 2004; National Institutes of Health, 2005). Furthermore, the incidence and prevalence of asthma has been shown to increase as communities adopt more urbanized or western lifestyles (Mullen, 2005). This is evident in the Far East where less affluent countries such as China and the Philippines have a lower prevalence of childhood asthma than more affluent countries such as Hong Kong, Singapore, and Taiwan (Lai et al., 1996; Lugogo, Kraft, \& Castro, 2008). In addition, a large international study involving 56 countries found the highest childhood asthma prevalence rates in the UK, New Zealand, Australia, North America, and parts of Central and South America (International Study of Asthma and Allergies in Childhood, 1998). Whereas the lowest rates were found in South Korea, Russia, Uzbekistan, Indonesia, and Albania (International Study of Asthma and Allergies in Childhood, 1998; Smyth, 2002). The increased prevalence of asthma in the developed world appears to be part of a generalized trend of increasing prevalence of allergic sensitization and allergic disease (Tattersfield et al., 2002). How these allergic trends along with genetic factors are contributing to the increased development of diseases like asthma still needs to be fully investigated (National Institutes of Health, 2005). 
Airway Remodeling

Until recently asthma was considered to be a condition of reversible airflow obstruction (Mullen, 2005). However, recent clinical data suggests that many patients with asthma, both children and adults, have evidence of residual airway obstruction and inflammation that exists even when asymptomatic (Mullen, 2005; Vignola et al., 2003). The irreversible changes resulting from chronic airway obstruction and inflammation can be seen on biopsy specimens, which reflect structural damage to the bronchi and subsequent remodeling of the bronchial architecture (Mullen, 2005; Vignola et al., 2003). This remodeling of the airway is thought to lead to permanent airway damage and functional impairment (Vignola et al., 2003).

\section{Asthma Treatment}

There is no cure for asthma. However, it can be controlled and managed with proper treatment. The general goals of asthma therapy consist of preventing chronic asthma symptoms and exacerbations (i.e. no sleep disruptions, no missed school days or work), maintaining normal activity levels (including exercise), having normal or nearnormal lung function, and having no or minimal side effects while receiving optimal medications (National Asthma Education and Prevention Program, 2003, 2007). Treatment for asthma consists of bronchodilators or short-acting beta 2 -agonists (i.e. albuterol) to relieve airway constriction, inhaled or oral corticosteroids (i.e. budesonide, fluticasone, prednisone) to control inflammation, and avoidance of asthma triggers such as smoke and other irritants (National Asthma Education and Prevention Program, 2003, 2007). 
Recently, combination therapy consisting of an inhaled long-acting beta 2 -agonists (i.e. salmeterol) along with an inhaled corticosteroid (i.e. fluticasone) have become the mainstay of therapy for patients with moderate or severe persistent asthma (Gilmartin, 2005). In addition, leukotriene modifiers (i.e. montelukast, zafirlukast), which can prevent bronchoconstriction at a cellular level, are being used as add-on therapy for patients on inhaled corticosteroids (Gilmartin, 2005).

\section{Economic Burden}

Despite the advances in therapeutic options, the economic burden of asthma in the U.S. has been increasing at an alarming rate over the past 15 years (Mullen, 2005). In 1990 , total costs due to asthma were estimated to be $\$ 6.2$ billion (K. B. Weiss \& Sullivan, 2001). By 1998 the cost of asthma had almost doubled to $\$ 11.3$ billion, with direct costs accounting for $\$ 7.5$ billion and indirect costs accounting for $\$ 3.8$ billion (National Heart Lung and Blood Institute, 1999). By 2007, it was estimated that the annual economic cost in the U.S. attributed to asthma totaled \$19.7 billion with $\$ 14.7$ billion in direct health care costs and $\$ 5$ billion in indirect costs (lost productivity) (American Lung Association, 2009).

The economic impact due to childhood asthma can be especially felt in hospital emergency departments where asthma represents $17 \%$ of all pediatric ED visits (Rachelefsky, Kennedy, \& Stone, 2006). One out of 3 children with asthma visit the emergency department because of an asthma-related event every year, and these visits cost 5 times as much as primary care visits for childhood asthma (Rachelefsky et al., 2006). In addition, pediatric ED visits for asthma are concentrated disproportionately 
among minority, disadvantaged, and urban children and the ED recidivism of this population is high (Teach et al., 2006). In response to this trend, one of the specific objectives included in Healthy People 2010 is the reduction in the rate of ED visits for childhood asthma (Teach et al., 2006; US Department of Health and Human Services, 2000).

In conclusion, asthma remains a major public health concern affecting approximately 22.9 million Americans (American Lung Association, 2009). Asthma is the most common chronic childhood illness in the U.S. affecting an estimated 6.7 million children and adolescents and accounting for up to 12.8 million lost school days (American Lung Association, 2009). The exact cause of asthma is unknown but is believed to be due to a complex interplay between genetics and the environment (Liu et al., 2004). There is no cure for asthma but it can be controlled and managed with proper treatment. With the advancement of disease management there has been an apparent stabilization of asthma prevalence rates over the last decade, however there remains enormous racial and economic disparities (Bernstein, 2008). Currently, the economic burden attributed to asthma is estimated at $\$ 19.7$ billion annually (American Lung Association, 2009). For these reasons, further research is needed into how the environment, including diet and nutrition, influences an individual's genetic predisposition towards developing asthma as well as the possibility of using gene therapy to treat asthma. In addition, new research is needed into how to decrease racial and economic disparities in children with asthma and effective methods to decrease the use of emergency departments as a main source of care. 
Background and Significance of Obesity

Obesity

A disturbing trend in American health has revealed itself in the past decade as millions of American waistlines have grown to uncomfortable and unhealthy sizes. The prevalence of obesity in the United States is increasing at an alarming rate. Body mass index (BMI), defined as the weight in kilograms divided by the square of the height in meters, is commonly used to classify overweight and obesity among adults (CDC, 2005). In adults, a BMI between 25 and 29.9 is defined as overweight, and a BMI of 30 or higher is considered obese (CDC, 2009a). According to data from the 2005-2006 National Health and Nutrition Examination Survey (NHANES), more than one-third of adults, or over 72 million people, are obese (Ogden, Carroll, McDowell, \& Flegal, 2007). An additional $34 \%$ of American adults meet the overweight criteria, for an estimated overall total of $66 \%$ of American adults either obese or overweight (Ogden et al., 2006). Obesity Prevalence

The incidence of obesity is increasing not only in the United States but globally as well. Worldwide there are more than 1.6 billion overweight adults, with at least 400 million of them clinically obese (World Health Organization, 2006b). In 2000, according to the World Health Organization (WHO), approximately $15 \%$ of the adult population in Europe was considered obese, compared to $21 \%$ in the United States (World Health Organization, 2000). Currently, the number of obese adults in the U.S. has risen even higher to $32 \%$ (Ogden et al., 2006). The rise in obesity rates is not restricted to industrialized societies alone, in fact, the rate of increase is often faster in developing 
countries than in the developed world (World Health Organization, 2006c). As detailed in Table 3, other areas of the world have reported increasing obesity rates including: Australia 15\%, Peru 16\%, South Africa 22\%, Finland 22\%, Israel 23\%, Saudi Arabia 36\%, New Zealand 53\%, and Tonga 56\% (World Health Organization, 2006c).

Table 3. WHO Global Database on Body Mass Index 2006

\begin{tabular}{|c|c|}
\hline Country & \% Obese Adults \\
\hline Tonga & 56.00 \\
\hline New Zealand & 53.40 \\
\hline Saudi Arabia & 35.60 \\
\hline Israel & 22.60 \\
\hline Finland & 22.51 \\
\hline South Africa & 21.56 \\
\hline Peru & 16.30 \\
\hline Canada & 16.20 \\
\hline Australia & 15.10 \\
\hline Great Britain & 11.00 \\
\hline France & 7.00 \\
\hline Ghana & 3.14 \\
\hline Japan & 2.37 \\
\hline
\end{tabular}

The World Health Organization has predicted that by 2015, approximately 2.3 billion adults will be overweight and over 700 million will be obese (World Health Organization, 2006c). These staggering statistics illustrate the growing need to address the issue of obesity as it moves from being a disease that affects a segment of the population to one that reaches epidemic and possible even pandemic proportions.

\section{Health Impact of Obesity}

The worldwide increase in the prevalence of obesity is especially concerning because of the multitude of heath problems associated with obesity. Obese and overweight adults are at greater risk for cardiovascular disease, hypertension, stroke, type 
2 diabetes and certain forms of cancer (World Health Organization, 2005). Non-fatal, but debilitating health problems associated with obesity include chronic musculoskeletal problems, respiratory difficulties, skin problems, and infertility (World Health Organization, 2006a). Approximately $85 \%$ of people with diabetes are type 2 , and of these, 90\% are overweight or obese (World Health Organization, 2006a). In addition, significant positive associations have been reported between obesity and higher death rates for the following cancers: esophagus, colon, liver, gallbladder, pancreas, kidney, stomach (in men), prostate, breast, uterus, cervix, and ovary (Li, Bowerman, \& Heber, 2005).

\section{Economic Impact of Obesity}

The true economic impact associated with the rise in obesity prevalence is difficult to determine due to the number of obesity-related conditions. However, it is believed that obesity accounts for $2-6 \%$ of total health care costs in several developed countries (World Health Organization, 2006a). The direct obesity related medical costs in the US have been estimated at $\$ 51.6$ billion, or $5.7 \%$ of overall health-care spending (Li et al., 2005; Wolf \& Colditz, 1998). Whereas the indirect costs attributable to obesity have been estimated at $\$ 47.6$ billion ( $\mathrm{Li}$ et al., 2005). Furthermore, it has been estimated that health care spending on obese Americans accounted for $27 \%$ of the growth in overall health care spending in the US between 1987 and 2001 (Thorpe, Florence, Howard, \& Joski, 2004). A recent study estimated medical spending due to overweight and obesity at $\$ 92.6$ billion annually, accounting for $9.1 \%$ of U.S. health expenditures (Finkelstein, Fiebelkorn, \& Wang, 2003; Weight-Control Information Network, 2007). 
The Obesity Cycle

One of the contributing factors for adult obesity is childhood obesity. The probability of childhood obesity persisting into adulthood is estimated to increase from approximately $20 \%$ at 4 years of age to approximately $80 \%$ by adolescence (Brownell \& Horgen, 2004; Guo \& Chumlea, 1999). Furthermore, the relationship between adult and childhood obesity appears to be cyclical. For example, parental obesity more than doubles the risk of adult obesity in both obese and nonobese children (Krebs \& Jacobson, 2003; Whitaker, Wright, Pepe, Seidel, \& Dietz, 1997). If both parents are lean, a healthy child has a $14 \%$ chance of becoming overweight, however, if one parent is obese, there is a $40 \%$ chance, and if both parents are obese the risk increases to $80 \%$ (Hagarty, Schmidt, Bernaix, \& Clement, 2004). The increased risk of obesity in children of obese parents is thought to be due to shared genes, environmental factors within families or a combination of both (Krebs \& Jacobson, 2003; Whitaker et al., 1997). Regardless of the cause, the increase in the prevalence of obesity in adults has been accompanied by a similar increase in the prevalence of obesity in children (Maffeis \& Tato, 2001).

\section{Childhood Obesity}

Body mass index is used to classify overweight and obesity among adults, and is also recommended to identify children who are overweight or obese (CDC, 2009a). For children, overweight is defined as a BMI between the $85^{\text {th }}$ and $94^{\text {th }}$ percentile for age and gender, and obese is defined as a BMI at or above the $95^{\text {th }}$ percentile for age and gender (CDC, 2009a). Because children are continuously growing, BMI percentile for age and 
gender is the preferred measure for detecting overweight instead of BMI value alone (US Preventive Services Task Force, 2005).

In the U.S., the number of overweight children has doubled and the number of overweight adolescents has tripled over the last two decades (US Preventive Services Task Force, 2005). Unfortunately, the number of overweight children and adolescents is still rising. As shown in Table 4, results from the 2003-2006 National Health and Nutrition Examination Survey (NHANES) showed an estimated 17 percent of children ages 6-11 years are overweight, which represents over a 60 percent increase from the overweight estimates of 11 percent obtained from NHANES III (CDC, 2009b).

Table 4. Prevalence of Obesity Among U.S. Children and Adolescents

\begin{tabular}{|c|c|c|c|c|}
\hline Age Group & $\begin{array}{c}\text { NHANES II } \\
1976-1980\end{array}$ & $\begin{array}{c}\text { NHANES III } \\
1988-1994\end{array}$ & $\begin{array}{c}\text { NHANES } \\
1999-2002\end{array}$ & $\begin{array}{c}\text { NHANES } \\
2003-2006\end{array}$ \\
\hline $\begin{array}{c}\text { Ages } \\
2 \text { through 5 }\end{array}$ & $5 \%$ & $7.2 \%$ & $10.3 \%$ & $12.4 \%$ \\
\hline $\begin{array}{c}\text { Ages } \\
6 \text { through 11 }\end{array}$ & $6.5 \%$ & $11.3 \%$ & $15.8 \%$ & $17.0 \%$ \\
\hline $\begin{array}{c}\text { Ages } \\
12 \text { through 19 }\end{array}$ & $5 \%$ & $10.5 \%$ & $16.1 \%$ & $17.6 \%$ \\
\hline
\end{tabular}

The increasing prevalence of childhood overweight is not restricted to the U.S. alone. An estimated 22 million children under five are considered overweight worldwide (World Health Organization, 2006c). Childhood overweight is prevalent even in the developing world; for example, in Thailand the prevalence of overweight in children 5 to 12 years old rose from $12.2 \%$ to $15.6 \%$ in just two years (World Health Organization, 2006a). 
This disturbing trend in childhood obesity lead the American Academy of Pediatrics (AAP) in 2003 to issue its first-ever policy statement dealing solely with identifying and preventing the problem of childhood obesity. The AAP Policy Statement on the prevention of pediatric overweight and obesity stresses the importance of early recognition of excessive weight gain and the promotion of dietary practices that encourage moderation and healthy food choices rather than restrictive eating patterns (Krebs \& Jacobson, 2003). In addition, the AAP obesity policy statement advocates that families should be educated about the impact they have on their children's development of lifelong habits of physical activity and nutritious eating (Krebs \& Jacobson, 2003).

More recently, the American Heart Association (AHA), in its 2005 Scientific Statement on Obesity, issued a warning that "childhood overweight is one of our most critical public health problems that threatens to ultimately reverse the favorable trends in cardiovascular morbidity and mortality that have occurred during the past half-century" (Daniels et al., 2005). In its statement the AHA recommended immediate action to prevent and treat childhood obesity.

\section{Effects of Childhood Overweight}

Childhood overweight is associated with a variety of adverse consequences, both physical and mental, which left unchecked can impact adult health as well (Dietz \& Robinson, 2005). Obese children are at higher risk for cardiovascular problems such as hypercholesterolemia and hypertension, as well as, endocrine disorders such as type 2 diabetes mellitus and menstrual irregularities (Dietz \& Robinson, 2005). In addition, the psychological stress of social stigmatization inflicted on obese children can lead to 
depression and low self-esteem, which can be just as damaging as the medical morbidities. Other health problems linked to obesity, as shown in Table 5 by body system, include pulmonary (asthma, obstructive sleep apnea syndrome), orthopedic (tibia vara, slipped capital femoral epiphysis), and gastrointestinal/hepatic (nonalcoholic fatty liver disease) (Daniels, 2006). The long-term effect of obesity is that it shortens an individual's life span through its co-morbidities, and the earlier the onset, the shorter the life span (Liu et al., 2004).

Current studies support the negative effects of childhood overweight especially in terms of future cardiovascular health. The Bogalusa (Louisiana) Heart Study examined over 9,000 children and adolescents for cardiovascular disease risk factors (Freedman, Dietz, Srinivasan, \& Berenson, 1999; Freedman, Khan, Dietz, Srinivasan, \& Berenson, 2001). The results showed that overweight schoolchildren were twice as likely as normal weight children to have elevated cholesterol levels and that $77 \%$ of the overweight children remained obese as adults (Freedman et al., 1999; Freedman et al., 2001). Furthermore, the Pathobiological Determinants of Atherosclerosis in Youth study examined over 3000 deceased individuals and found evidence of accelerated coronary atherosclerosis upon autopsy among obese adolescent boys and young men (McGill et al., 2002). 
Table 5. Disorders Related to Childhood Overweight, by Body System

\begin{tabular}{|c|c|}
\hline System and Disorder & Explanation \\
\hline \multicolumn{2}{|l|}{ Cardiovascular } \\
\hline Hypertension & High blood pressure \\
\hline Left ventricular hypertrophy & $\begin{array}{c}\text { Increased thickness of the heart's main pumping } \\
\text { chamber }\end{array}$ \\
\hline Atherosclerosis & Hardening of the arteries \\
\hline \multicolumn{2}{|l|}{ Metabolic } \\
\hline Insulin resistance & $\begin{array}{c}\text { The process in which the action of insulin is } \\
\text { hindered }\end{array}$ \\
\hline Dyslipidemia & $\begin{array}{l}\text { Abnormal changes in cholesterol and triglycerides } \\
\text { in the blood }\end{array}$ \\
\hline Metabolic syndrome & $\begin{array}{c}\text { Constellation of risk factors including elevated } \\
\text { blood pressure, increased triglyceride and decreased } \\
\text { HDL-cholesterol concentrations, and raised plasma } \\
\text { glucose }\end{array}$ \\
\hline Type 2 diabetes & $\begin{array}{l}\text { A condition in which the body either makes too } \\
\text { little insulin or cannot properly use the insulin it } \\
\text { makes, leading to elevated glucose levels }\end{array}$ \\
\hline \multicolumn{2}{|l|}{ Pulmonary } \\
\hline Asthma & $\begin{array}{l}\text { A chronic inflammatory pulmonary disorder } \\
\text { characterized by obstruction of the airways }\end{array}$ \\
\hline Obstructive sleep apnea & $\begin{array}{l}\text { A breathing disorder characterized by interruptions } \\
\text { of breathing during sleep }\end{array}$ \\
\hline \multicolumn{2}{|l|}{ Gastrointestinal } \\
\hline Nonalcoholic fatty liver disease & $\begin{array}{l}\text { Fatty inflammation of the liver not caused by } \\
\text { excessive alcohol use }\end{array}$ \\
\hline Gastroesophageal refux & $\begin{array}{c}\text { Backward flow of stomach contents into the } \\
\text { esophagus }\end{array}$ \\
\hline \multicolumn{2}{|l|}{ Skeletal } \\
\hline Tibia vara (Blount disease) & $\begin{array}{l}\text { Bowing of children's legs caused by a growth } \\
\text { disturbance in the proximal tibial epiphysis }\end{array}$ \\
\hline Slipped capital-femoral epiphysis & A disorder of the hip's growth plate \\
\hline \multicolumn{2}{|l|}{ Psychosocial } \\
\hline Depression & $\begin{array}{l}\text { A mood disorder characterized by sadness and loss } \\
\text { of interest in usually satisfying activities }\end{array}$ \\
\hline \multicolumn{2}{|l|}{ Other } \\
\hline Polycystic ovary syndrome & $\begin{array}{l}\text { A constellation of abnormalities including abnormal } \\
\text { menses, clinical manifestations of such androgen } \\
\text { excess as acne and excessive growth of hair, } \\
\text { elevated levels of circulatory androgens, and } \\
\text { polycystic ovaries on ultrasound evaluation }\end{array}$ \\
\hline
\end{tabular}


Further affecting the future health of children, metabolic syndrome, once only observed in adults, is now being seen in children. Metabolic syndrome is associated with an increased risk of cardiovascular disease and is characterized by a group of metabolic risk factors including insulin resistance, hypertension, dyslipidemia, and type 2 diabetes (American Heart Association, 2006). In a study examining 439 overweight children, the prevalence of metabolic syndrome increased with the severity of obesity and reached as high as 50\% in severely obese youngsters (R. Weiss et al., 2004).

Coinciding with the increased incidence of metabolic syndrome has been the increase in type 2 diabetes among children. Type 2 diabetes, which is characterized primarily by insulin resistance and a relative decrease in insulin secretion, has typically been considered a disease of adults (Fagot-Campagna et al., 2000). However, over the last two decades an alarming number of newly diagnosed diabetes cases in children and adolescents are now the type 2 form (Goran, Ball, \& Cruz, 2003; Roy, 2005). Currently, type 2 diabetes accounts for up to $45 \%$ of all newly diagnosed diabetes in pediatric patients, and is especially common in certain minority populations, such as African Americans and Mexican Americans (Dietz \& Robinson, 2005; Fagot-Campagna et al., 2000). A recent study found $25 \%$ of 55 overweight children and $21 \%$ of 112 overweight adolescents had impaired glucose tolerance as well as $4 \%$ of the overweight adolescents had undiagnosed type 2 diabetes (Sinha et al., 2002).

Obesity-related diseases, especially type 2 diabetes and cardiovascular risk, are emerging problems in the pediatric population (Goran et al., 2003). How these new pediatric health problems will ultimately impact future adult health is unknown. 
However, it has been predicted that if a solution to the rising incidence of childhood overweight is not found soon, today's children will be the first generation to live shorter lives than their parents (Olshansky et al., 2005).

\section{Causes of Childhood Overweight}

Somewhat similar to asthma, the exact cause of obesity is unclear. Several factors are considered to contribute to obesity in children. These factors tend to fit into one of two categories: genetic or environmental. While the factors related to genetic endowment cannot be easily modified, those factors related to the environment are more or less amenable to change (Ritchie et al., 2001). These factors include meal patterns and dietary intake, lack of physical activity, and economic factors. An examination of these aspects and their relationship to childhood obesity follows.

\section{Meal Patterns and Dietary Intake}

It appears that many factors can influence an individual's weight. However, dietary factors such as the increase in childhood consumption of high-fructose corn syrup, mainly in the form of sweetened soft drinks, has often been sited as a major contributing factor in childhood obesity. In the book "Fat Land" (Crister, 2003), the use of sweeteners as a contributing factor for obesity was examined. The author found that between 1980 and 1998 the total use of sweeteners rose from 123 to $155.1 \mathrm{lb}$ per person per year, a $26 \%$ increase. In addition, the use of high-fructose corn syrup rose from 19.0 to $63.8 \mathrm{lb}$ per person per year, a $236 \%$ increase overall.

High-fructose corn syrup is the main ingredient in sweetened soft drinks. In a study by Ludwig (Ludwig, Peterson, \& Gortmaker, 2001) and associates, the use of 
sugar-sweetened soft drinks among 548 middle-school children ages 11 to 12 was examined. The study found that for each additional daily soft drink consumed there was a 60 percent increased risk for the development of obesity, even after controlling for demographics, lifestyle, and diet.

Of additional concern, children today consume twice as much soda as milk, the reverse of twenty years ago (Toriano, Briefel, Carroll, \& Bialostosky, 2000). According to the 1989-91 Continuing Survey of Food Intakes by Individuals (CSFII), soft drinks were the sixth leading food source of energy and the second leading food source of carbohydrate among U.S. children age 2 to 18 years (Munoz, Krebs-Smith, BallardBarbash, \& Cleveland, 1997). From 1977 to 1998 the prevalence of soft drink consumption among children ages 6 to 17 years has increased $48 \%$ from $37 \%$ in 1977 to 56\% in 1998 (French, Lin, \& Guthrie, 2003). This trend is unfortunate for three main reasons: 1 milk may protect against the development of obesity in children (Pereira et al., 2002); 2. increasing calcium intake is associated with lower weight in adults and children and less weight gain over time (Zemel, 2002); and 3. weight loss is higher in overweight people who follow a dairy rich diet (Brownell \& Horgen, 2004; Zemel, 2003).

Not only are children consuming more sweeteners and less milk, but they are also consuming more calories, especially away from the home. Serving sizes have increased, and the fast-food industry has capitalized on this by "super-sizing" its products. The AAP found that the absence of "family meals" is associated with lower fruit and vegetable consumption as well as the consumption of more fried food and carbonated 
beverages (Krebs \& Jacobson, 2003). This trend is especially disturbing because family meals provide the structure and predictability children need throughout their childhood, which leads to less overeating and weight issues (Satter, 2005). In a study of over 17,000 adults and children, those who reported eating fast-food had higher intake of energy, fat, saturated fat, sodium, carbonated soft drink, and lower intake of vitamins A and C, milk, fruits and vegetables than those who did not report eating fast food $(\mathrm{P}<.001)$ (Paeratakul, Ferdinand, Champagne, Ryan, \& Bray, 2003).

In a study by Krebs-Smith (Krebs-Smith et al., 1996) and associates, the fruit and vegetable intake of over 3,000 children aged 2 to 18 years was examined. The researchers found that one quarter of all vegetables consumed by children were frenchfries and that only one in five children consumed the recommended five or more servings of fruits and vegetables per day. Similar results were reported by the 2005 Youth Risk Behavior Survey, which found only $20 \%$ of high school students reported eating the recommended 5 or more servings of fruits and vegetables per day (Eaton et al., 2006).

Along with the decline in milk, fruit, and vegetable intake by children, a decline in breakfast consumption has also been observed. An analysis of national food consumption surveys from 1965-1991, found a decline in breakfast consumption over the 25 years especially among adolescents, $74.9 \%$ to $64.7 \%$ (Siega-Riz, Popkin, \& Carson, 1998). This decline is worrisome because studies have found a possible positive role for breakfast consumption in maintaining normal weight in children and adolescents (Rampersaud, Pereira, Girard, Adams, \& Metzel, 2005). A 2001 study by Dwyer and 
colleagues of $1,4938^{\text {th }}$ graders found significantly fewer overweight subjects consumed breakfast $(70 \%)$ compared with non-overweight subjects $(80 \%)(\mathrm{p}=.0004)$.

Concern about the increase in overweight among children has started to influence some school districts to reexamine the types of snacks and beverages, especially soft drinks, being sold in school vending machines. Results from a national Gallup Youth Survey of 785 students age 13 to 17 found that $67 \%$ of the students stated they bought junk food or soft drinks from vending machines at school and $23 \%$ stated that they ate a “a great deal” of junk food in a typical week (Hellmich, 2004).

Locally, in 2004 the Chicago Public Schools revamped its vending machine programs, allowing school vending machines to sell only the following types of beverages and snacks: juices containing 100\% fruit juice in elementary schools and in high schools juices containing no less than $50 \%$ fruit juice, water, non-carbonated sports drinks, snacks with no more than $30 \%$ calories from fat and $40 \%$ sugar by weight, and no candy or chewing gum (Chicago Public Schools, 2004). Nationally, states such as New York, Nebraska, and West Virginia have already banned the sale of junk food in elementary schools until after lunch (Heller, 2006). The Child Nutrition Promotion and School Lunch Protection Act of 2009 (H.R.1324), is an amendment to the Child Nutrition Act of 1966, seeking to improve the national school nutrition standards for foods and beverages sold outside of school meals, and is currently being deliberated on by the House Subcommittee on Healthy Families and Communities (GovTrack.us, 2009). 
Lack of Physical Activity

Another possible contributing cause to the increase prevalence of obesity is lack of physical activity. As modern society has become more industrialized, leisure activities have become more sedentary. Individuals spend more of their leisure activity watching television, videos, and playing computer games. In addition, with increasing urbanization, there has been a decrease in frequency and duration of physical activities of daily living for children, such as walking or riding bikes to school and doing household chores (Krebs \& Jacobson, 2003).

Media Use

The 2005 Youth Risk Behavior Survey found that of the high school students surveyed, $21 \%$ played video or computer games or used a computer for something other than school work for 3 or more hours per day on an average school day (Eaton et al., 2006). In addition, $37 \%$ of students reported watching television for 3 or more hours per day (Eaton et al., 2006). Overall, the prevalence of watching television 3 or more hours a day was higher among black (64\%) than white (29\%) and Hispanic (46\%) (Eaton et al., 2006).

In a study by Anderson (1998) and associates, the relationship between physical activity and television viewing with BMI was examined using the data from the National Health and Nutrition Examination Survey III. The results showed 26\% of U.S. children watched 4 or more hours of television per day and $67 \%$ watched at least 2 hours per day. Children who watched more than 4 hours of television a day had greater body fat $(\mathrm{P}<.001)$ and had a greater body mass index $(\mathrm{P}<.001)$ than those who watched less than 2 
hours per day (Andersen, Crespo, Bartlett, Cheskin, \& Pratt, 1998). A similar study by Robinson (1999), examined the effects of reducing media use on changes in adiposity, physical activity, and dietary intake in school age children and found that the intervention group had a statistically significant decrease in BMI compared to the control group even though the intake of high-fat foods and the amount of moderate-to-vigorous physical activity remained the same for both groups. These findings suggest that decreasing media use alone could help reduce childhood obesity.

Vigorous Physical Activity

Lack of vigorous physical activity is very common among American youth (Gordon-Larsen, McMurray, \& Popkin, 2000; National Association for Sport and Physical Education \& American Heart Association, 2006). In a study of 2,000 third and fourth grade children, the researchers found the most common leisure time activities reported by boys were playing video games (33\%), playing football (32\%), bicycling (31\%), watching television (28\%), and playing basketball (26\%) (Harrell, Gansky, Bradley, \& McMurray, 1997). The most common activities reported by the girls were doing homework (39\%), bicycling (31\%), watching television (30\%), dancing (27\%), and reading $(23 \%)$. These findings indicate that elementary school children, especially girls, have basically sedentary recreational activities (Harrell et al., 1997).

The lack of physical activity is worse among high school students. More than a third of adolescents in grades 9 to 12 do not regularly participate in vigorous physical activity (Grunbaum et al., 2004; National Association for Sport and Physical Education \& American Heart Association, 2006). Whereas, over 11\% of the more than 15,000 high 
school students surveyed for the 2003 National Youth Risk Behavior Survey, reported no moderate to vigorous physical activity (Grunbaum et al., 2004). Overall, among high school students, males are more physically active than females (Grunbaum et al., 2004; National Association for Sport and Physical Education \& American Heart Association, 2006).

Gender Differences

Other studies have found similar results regarding differences in activity level between genders. Of additional concern is the age-related decline in physical activity from childhood to adolescence, especially among females (Bradley, McMurray, Harrell, \& Deng, 2000; Eaton et al., 2006; Gordon-Larsen et al., 2000; Grunbaum et al., 2004; Harrell et al., 1997; Kimm et al., 2000). Results from the 2005 national Youth Risk Behavior Survey, which consisted of over 13,000 students from grades 9-12, found that overall, $74 \%$ of ninth graders participated in vigorous physical activity on a regular basis, while only $62 \%$ of $12^{\text {th }}$ graders participated in the same level of activity (Eaton et al., 2006). Among female students, $68 \%$ of the $9^{\text {th }}$ graders surveyed reported participating in regular (20 minutes, at least three times a week) physical activity, compared to only $52 \%$ of $12^{\text {th }}$ graders (Eaton et al., 2006).

In a longitudinal study of 656 third through tenth grade children, the change in both the activities done and the intensity of those activities from childhood to adolescence was examined (Bradley et al., 2000). The researchers found that even though both genders reported a significant decrease in vigorous activities over time $(\mathrm{P}<0.0001)$, boys were more likely than girls to maintain their participation in vigorous 
activities $(\mathrm{P}<0.0008)$. In addition the results showed that beginning in grades seven and eight, more than half of girls (55.7\%) reported mostly sedentary activities, and the number of female subjects reporting more sedentary activities increased with each increase in grade.

In a similar study involving only girls, changes in physical activity of 2379 subjects starting from ages 9-10 were studied over a 10 year period (Kimm et al., 2000). Daily activities, both physical (e.g., bike riding, dancing, and running) and sedentary (e.g., watching TV, reading, and talking), as well as habitual activities (e.g., seasonal sports, classes/lessons) were examined. Overall, the data showed a dramatic decrease in the level of physical activity during the transition from childhood to adolescence (Kimm et al., 2000). The results showed that the level of girls' daily activity declined by $35 \%$ from ages 9-10 to 18-19 years, whereas the level of habitual activity declined by $83 \%$ (Kimm et al., 2000). Racial and Ethnic Disparities

Along with gender differences, racial and ethnic disparities in physical activity patterns exist as well. Recent studies have found that African-American and Hispanic children and adolescents participate in fewer vigorous activities and/or more sedentary activities than Whites, with differences noted as early as elementary school (Bradley et al., 2000; Eaton et al., 2006; Gordon-Larsen et al., 2000; Grunbaum et al., 2004; Kimm et al., 2000). Results from the 1996 National Longitudinal Study of Adolescent Health consisting of a study population of over 17,000 adolescents enrolled in US middle and high schools found that moderate to vigorous physical activity was lower and inactivity 
higher for non-Hispanic black and Hispanic adolescents (Gordon-Larsen et al., 2000). In addition, the 2005 national Youth Risk Behavior Survey, found that among high school students, white students (39\%) are more physically active than black (30\%) and Hispanic (33\%) (Eaton et al., 2006).

In a longitudinal study examing both race and gender, changes in common activities ranging from video games to running were examined in 656 subjects in $3^{\text {rd }}$ through $10^{\text {th }}$ grade over a six year period (Bradley et al., 2000). African-American girls reported fewer vigorous activities than Caucasian or other race girls $(\mathrm{P}=0.027)$ (Bradley et al., 2000). In addition, African-American and Caucasian boys reported similar activity patterns until sixth and seventh grades when African-American boys began reporting more sedentary activities than Caucasians or other races $(\mathrm{P}=0.004)$.

Physical Education Requirements

Further contributing to the decrease seen in vigorous physical activity among children is the lack of physical education requirements in schools. Even though the majority of states mandate physical education, most do not require a specific amount of instructional time and half allow exemptions or waivers (National Association for Sport and Physical Education \& American Heart Association, 2006). Nationwide the percentage of high school students who attended a physical education class has dropped from 42\% in 1991 to 28\% in 2003 (Centers for Disease Control and Prevention, 2004). It is recommended that school-age children should participated in at least 150 minutes per week of physical education and all middle and high school students should participate in 
at least 225 minutes of physical education per week (National Association for Sport and Physical Education \& American Heart Association, 2006).

Currently, two states in the country, Illinois and Massachusetts, require physical education in every grade K-12 (National Association for Sport and Physical Education \& American Heart Association, 2006). However, Illinois grants exemptions and waivers for school districts regarding physical education time or credit requirements. In addition, both Illinois and Massachusetts, permit schools to allow students to substitute other activities for their required physical education credit (National Association for Sport and Physical Education \& American Heart Association, 2006).

\section{Economic Factors}

The economic factors contributing to the obesity epidemic are complex. Modern technical advances have made it easier than ever to provide more calories to people at a lower cost than ever possible while simultaneously shrinking the need for physical work (Brownell \& Horgen, 2004). In other words, individuals can easily find inexpensive food to eat without much physical effort. Fast food restaurants, such as McDonalds, Taco Bell, and Burger King are classic examples of the easy availability of inexpensive high calorie food contributing to the current obesity epidemic.

Compounding the issue, many schools have turned to the soft drink and fast food industries to help balance and fund their education budgets. Vending machines mostly dispensing soft drinks, candy, and salty snacks have become a seductive source of revenue for many school districts and can be found in the majority of U.S. schools- $58 \%$ of elementary schools, $84 \%$ of middle schools, and $94 \%$ of high schools (Okie, 2005). In 
contrast, many schools have cut physical education as part of their curriculum in order to have more time for academics (Crister, 2003).

The role economic factors play in the prevalence of the obesity epidemic is especially evident among the poor. The poor are more likely to experience interruptions in income, which leads to food insecurity. Therefore, the impulse is to eat for today because the future or the availability of food for tomorrow is unclear, which leads to unintended overeating and obesity (Dietz, 1995; Townsend, Peerson, Love, Achterberg, \& Murphy, 2001). In addition, access to healthy foods is often limited in impoverished areas whereas fast food is widely available (Brownell \& Horgen, 2004). A study examining food-buying opportunities in Mississippi, North Carolina, Maryland, and Minnesota found that there were 4 times more supermarkets located in white neighborhoods compared to black neighborhoods (Morland, Wing, Diez Roux, \& Poole, 2002). The study also showed that fewer households in poor and black neighborhoods have access to private transportation, which suggests that residents of these neighborhoods would have greater difficulty obtaining healthy food.

\section{Genetic Factors}

Over 200 specific genetic factors related to obesity in humans have been identified, however, a single genetic test for risk does not exist (Chagnon, Perusse, Weisnagel, Rankinen, \& Bouchard, 2000). Genes may be associated with metabolic rates, dietary induced thermogenesis, appetite and food preferences, satiety, fat storage, and physical activity expression (Ritchie et al., 2001). A study comparing 37 normal weight 3 to 4 year old children with either obese or non-obese parents found that children 
of obese parents had lower intakes of calories, lower non-resting energy expenditure, and lower resting energy expenditure (REE) (Griffiths, Rivers, \& Payne, 1987). In a study involving 101 multiethnic prepubertal girls, basal metabolic rate, sleeping metabolic rate, and total energy expenditure were lower in African American girls than in white girls $(\mathrm{P}<0.05)$ (Treuth, Butte, \& Wong, 2000). These variations in energy expenditure could help to explain some of the variation in obesity rates among certain ethnic and racial groups as well as children of obese parents.

The most convincing argument for the association between genetics and obesity can be found when examining the connection between parental obesity and risk of overweight. In a retrospective cohort study of 854 subjects, the researchers found that parental obesity more than doubled the risk of adult obesity among both obese and nonobese children under 10 years of age (Whitaker et al., 1997). In addition, a longitudinal British study of over 12,000 subjects showed that children with overweight or obese parents had higher risks of adult obesity, were more likely overweight in childhood, and also showed a stronger pattern of overweight tracking from childhood to adulthood (Lake, Power, \& Cole, 1997).

Other studies support these earlier findings that the best predictor of overweight in a child is obesity in family members (Wardle, 2005). In a large study of 3636 four year old twins, the researchers found that genetic factors contributed substantially to individual differences in weight (Koeppen-Schomerus, Wardle, \& Plomin, 2001). In addition, a study of 106 overweight children age 3 to 18 years found that obesity in one or both parents correlated with a higher percentage of ideal body weight $(\mathrm{p}=0.01)$ 
(Anavian, Brenner, Fort, \& Speiser, 2001). As well as, 58\% of the overweight children had a first- or second-degree relative with a history of type 2 diabetes (Anavian et al., 2001).

In conclusion, the exact cause of the increasing prevalence of obesity is multifactorial. The contributing factors of childhood obesity include meal patterns and dietary intake, declining rates of physical activity, and increasing time spent in sedentary behaviors such as TV viewing, video games, and computer use. Economic factors contributing to obesity include easy availability of inexpensive high calorie food, limited access to healthy foods in impoverished neighborhoods, increased reliance on vending machines for school revenue, and food insecurity. In addition, genetic factors are a major contributor to childhood obesity especially when both parents are overweight or obese.

Further research is needed to understand the interplay of these many factors contributing to the increasing prevalence of overweight in children. More research designs are needed that investigate biological and behavioral responses in children who are not yet overweight, but are at risk of becoming overweight in order to shed light on the etiological factors (Wardle, 2005). In addition, more research is needed on the environmental aspects, especially in the home, that contribute to obesity so parents and clinicians can teach children how to resist those elements in their environment that put them at risk for overweight (Wardle, 2005). 
$\underline{\text { Asthma and Obesity }}$

The increase in prevalence of both asthma and obesity has lead to a number of studies examining the possible relationship between these two variables. However, much of the research in this area has focused on adults (Akerman, Calacanis, \& Madsen, 2004; Ford \& Mannino, 2005; Luder, Ehrlich, Lou, Melnik, \& Kattan, 2004; Spivak, Hewitt, Onn, \& Half, 2005). A study examing the trends in obesity among adults, used data from the NHANES I, II, and III which showed that people with asthma are far more likely to be obese than people who do not have asthma (Ford \& Mannino, 2005). In a retrospective study of 143 individuals aged 18-88, the researchers found that the prevalence of obesity increased along with increasing asthma severity in adults (Akerman et al., 2004). Furthermore, the results showed that females with asthma were significantly more overweight than males, mean BMI 35.9 vs. $32.14(\mathrm{p}=0.01)$ (Akerman et al., 2004). These findings suggest that obesity may be a potentially modifiable risk factor for asthma (Akerman et al., 2004).

This idea is supported by the results from research conducted with patients who have lost weight following gastric bypass surgery. In a study of 500 morbidly obese patients who underwent laparoscopic adjustable gastric banding surgery, 163 patients had comorbidities such as diabetes, gastroesophageal reflux disease, and asthma (Spivak et al., 2005). At 36 months post successful weight loss surgery, over $80 \%$ of the patients, who had asthma symptoms prior to surgery, reported resolution or improvement in their symptoms (Spivak et al., 2005). 
Much of the limited research examining obesity and asthma among children has focused on inner-city and minority populations due to the higher prevalence of asthma and obesity in these groups. A cross-sectional study using data from the Third National Health and Nutrition Examination Survey 1988-1994, showed that two of the highest risk groups for developing asthma were children over age 10 with a BMI greater than or equal to the $85^{\text {th }}$ percentile and children with a parental history of asthma who were 10 years or younger and of African American ethnicity (Rodriguez, Winkleby, Ahn, Sundquist, \& Kraemer, 2002).

In another study examining ethnicity, Figueroa-Munoz, Chinn, \& Rona (2001), examined 4-11 year old children in the United Kingdom and found that obesity, measured using BMI values, was associated with asthma regardless of ethnicity. They found this association to be strongest among inner-city girls. However, in another study done in the U.K., which examined the relationship between BMI and asthma, the researchers found that the trend in overweight and obesity could not explain the increase in asthma (Chinn \& Rona, 2001). The researchers concluded that obesity might be a "marker" of lifestyle differences associated with both asthma and overweight in children and not directly cause asthma.

A more recent study examining the relationship between body mass index and the development of asthma in children, followed 4393 asthma-free children for up to 14 years (Mannino et al., 2006). Asthma developed in 218 (5\%) of the children. An analysis of the data showed that a BMI at or greater than the $85^{\text {th }}$ percentile at age 2-3 years was a risk factor for subsequent asthma development in boys but not girls (Mannino et al., 
2006). In addition, boys with a BMI always at or above the $85^{\text {th }}$ percentile were also found to be at risk for subsequent asthma development, but not girls (Mannino et al., 2006). The researchers concluded from these results that boys with high body masses may be at an increased risk of developing asthma (Mannino et al., 2006).

In inner-city children, asthma is the most frequent cause of hospitalization (Mannino et al., 2002; K. B. Weiss \& Wagener, 1990). In a study examining inner-city black and Hispanic children age 2 to 18 years with asthma $(n=209)$, researchers found that the prevalence of overweight was higher in children with moderate to severe asthma compared to the non-asthma control group $(n=1017)$ (Luder, Melnik, \& DiMaio, 1998). In addition, the results showed that being overweight was associated with greater asthma symptoms (Luder et al., 1998). In a similar study using mostly Hispanic inner-city study subjects $(78 \%)$, the researchers found a higher incidence of obesity in the children with asthma than those without asthma (45.9\% vs 30.2\%; $\mathrm{p}=.04)$ (Gennuso, Epstein, Paluch, \& Cerny, 1998). However, this study found no relationship between asthma severity and obesity, with $48 \%$ of subjects with mild-moderate asthma being obese, and $37 \%$ of subjects with moderate-severe asthma being obese.

In a more recent study, Belamarich (2000) and associates examined inner-city children with asthma and determined that there was a higher incidence of obesity in Latino study subjects. The study also pointed out that obese children with asthma used more asthma medications, wheezed more, and had a greater proportion of unscheduled emergency department visits (Belamarich et al., 2000). However, the obese children did not have more hospitalizations. 
Finally, an international study conducted in Taiwan, examined the relationship between asthma, lung function, and BMI in over 15,000 school-aged children (Chu et al., 2009). The researchers found the prevalence of asthma increased as BMI elevated in both male and females. In addition, high BMI coincided with low FEV1/FCV scores on lung function testing which is associated with lung impairment. (Chu et al., 2009). A similar result was found in a study conducted in Nova Scotia, Canada, which examined 3,804 students 10 to 11 years of age (Sithole, Douwes, Burstyn, \& Veugelers, 2008). Controlling for socioeconomic factors, the researchers found a linear association between BMI and asthma with a $6 \%$ increase in prevalence per unit increase of BMI (Sithole et al., 2008).

From the review of the literature there appears to be a relationship, between asthma and obesity. However, whether this relationship is a direct or indirect one has yet to be fully determined. One theory proposed, which supports the view that asthma causes obesity, is that parents of asthmatic children may restrict their child's activity level for fear of inducing an asthma exacerbation, which would put them at increased risk for obesity due to a more sedentary lifestyle (Figueroa-Munoz et al., 2001). While a number of individuals with asthma might avoid vigorous activity and thus put on weight, this would seem, at best, an incomplete explanation for asthma causing obesity (Shaheen, 1999).

The reverse association, that obesity causes asthma, has also been examined. Support for this theory can be found in the longitudinal data from the Nurses' Health Study II, which is an ongoing prospective cohort study of over 100,000 registered nurses, 
age 24 to 44 years examining the relationships between lifestyle, diet, and health. Researchers examined the results from 1991 to 1995 and found that BMI had a strong, independent, and positive association with the risk of adult-onset asthma (Camargo, Weiss, Zhang, Willett, \& Speizer, 1999).

Still other researchers have suggested that obese children with asthma may just be having obesity-related chest symptoms that mimic asthma. In a large study of 5,984 Israeli children, researchers found that asthma, wheezing, and inhaler use were more common in obese children than in non-obese children (Bibi et al., 2004). However, bronchial hyperreactivity was greater among non-obese asthmatic children compared to their obese counterparts (Bibi et al., 2004).

Regardless of the direction of the relationship, there appears to be a link between asthma and obesity. Because of this connection and the increase in prevalence of asthma and obesity, researchers have begun to examine how asthma and obesity affects, not only each other, but quality of life as well.

\section{Quality of Life}

Because of the overall effect it has on an individual's health, quality of life is an important concept to study. Policy-makers, researchers, clinicians, and the public at large consider quality of life to be an important dimension of the health of a population or an individual (Harrison, Juniper, \& Mitchell-DiCenso, 1996). With this view in mind, this review of QOL will begin with the evolution of the concept, a brief review of the QOL literature by discipline, followed by a review of the literature regarding children and 
QOL, QOL in children with asthma, QOL in children with obesity, and QOL in children with asthma and obesity.

\section{Evolution of the Concept of $Q O L$}

Historically, the concept of quality of life was first pondered and conceptualized by the great philosophers of ancient Greece: Socrates, Plato, and Aristotle. While the essence of quality of life can be found in their conceptualization of happiness and the good life, in more recent times, this conceptualization is defined by the field of study in which it is applied. As such, a profile of the concept of quality of life can be seen in a review of the literature related to the various fields of study that have attempted to define and explore the concept.

From a philosophical perspective, the concept of quality of life implies an evaluation or the quality or goodness of a person's life. There are several terms, which are considered related to the quality or good life, including happiness, well-being, contentment, satisfaction, pleasure, flourishing, and excellence (Musschenga, 1997). In the disciplines of psychology and sociology, the discourse on the concept of quality of life has centered on whether quality of life is a subjective or objective concept (Draper, 1997). In these fields, quality of life can be defined using the objective approach by examining human needs or the subjective approach by examining fulfillment of human wants and desires.

An overlapping of subjective and objective views can be seen in the disciplines of medicine and nursing. Since 1948, when the World Health Organization defined health as being not only the absence of disease and infirmity, but also as a state of physical, 
mental, and social well-being, quality of life issues have become steadily more important in health care practice and research (Testa \& Simonson, 1996).

\section{Holistic and Pragmatic Views}

The meaning of quality of life and how it should be quantified has divided the medical discourse into two camps: those who support a broad concept of quality of life or a holistic view (Bergner, 1985; C. Ferrans \& Powers, 1985; Gill \& Feinstein, 1994) and those who take a more biomedical or pragmatic view, believing the parts can be reduced for health-outcome measurement purposes (Aaronson, 1988; G.H. Guyatt \& Cook, 1994; G. H. Guyatt, Veldhuyzen Van Zanten, Feeny, \& Patrick, 1989).

Guyatt and Cook (1994) found their research results supported the objective view of quality of life. They contended that although patient's personal values are important, it should not override the clinician's assessment of the patient's quality of life. Guyatt and Cook (1994) recommended that the clinician conduct the inquiry needed to ascertain the patient's values and take those values into account when making treatment recommendations.

Research supporting the holistic or subjective view conducted by Gill and Feinstein (1994) critically analyzed twenty-five randomly selected articles from the medical literature and systematically evaluated how well quality of life was defined and measured. They identified three ways in which quality of life is defined in the health context; objective measures, functional performance, and patient's own evaluation. However, they felt that the patient's own evaluation was the most important in determining quality of life. Supporting this view, Eiser and Morse (2001) found the 
subjective rating of health status to be the defining characteristic of quality of life, in contrast to the concepts such as functional or health status. In addition, the World Health Organization (1993) defines quality of life subjectively, as the individual's perception of their position in life in the context of the culture and value systems in which they live and in relation to their goals, standards, and concerns (King \& Hinds, 2003).

Furthermore, quality of life (QOL) and health related quality of life (HRQOL) are often used interchangeably in the literature. Testa and Simonson (1996) define health related quality of life as "the physical, psychological, and social domains of health, seen as distinct areas that are influenced by a person's experiences, beliefs, expectations, and perceptions" (p. 835). However, the concept of health related quality of life implies that one can analyze quality of life into its health and non-health related components, which is improbable because of the interconnectedness of health status with other aspects of life, such as personal relationships and coping strategies (Leplege \& Hunt, 1997). For the purpose of this review, the term quality of life will be used and will include the concept of health related quality of life.

\section{Review of the Quality of Life Literature}

\section{Quality of Life and Children}

Although the concept of quality of life has been widely researched in the adult population, interest in children's quality of life did not gain momentum until the 1980s (Eiser \& Morse, 2001). Only a limited number of QOL studies have been conducted with children, with much of the research focusing on the areas of pediatric oncology (Eiser, 
Eiser, \& Stride, 2005; Odame et al., 2006; Russell, Hudson, Long, \& Phipps, 2006) and debilitating chronic illnesses, such as rheumatoid arthritis (Brunner et al., 2006; Riddle et al., 2006; Sawyer et al., 2005) and cystic fibrosis (Janse, Sinnema, Uiterwaal, Kimpen, \& Gemke, 2004; Koscik et al., 2005; Thomas, Mitchell, O'Rourke, \& Wainwright, 2006). In addition, quality of life research with children is especially complicated because children are constantly developing both physically and mentally throughout childhood. The physical and mental changes that take place during childhood make it difficult to determine whether changes in quality of life are caused by improvement or deterioration in physical condition or whether such changes are masked by development or adaptation (Vincent \& Higginson, 2003). Furthermore, a child's perception of and interaction with the world is different than adults.

Early efforts to describe and measure quality of life in children focused on functional problems and relied on assessments made by clinicians (Ditesheim \& Templeton, 1987; Eiser \& Morse, 2001; Herndon et al., 1986). Herndon (1986) and associates examined quality of life in 12 children who survived major burn injuries, ranging in age from 9 months to 12 years. They evaluated quality of life based on degree of scarring, performance of activities of daily living, and psychological adjustment. The researchers found that one third of the children had excessive fear, regression, and neurotic and somatic complaints, but all showed remarkable energy in adjusting and adapting to their disabilities despite major physical and psychological traumas (Herndon et al., 1986). 
Another early study of quality of life in children, which focused on functional problems, was conducted by Ditesheim \& Templeton (1987), who examined short and long-term quality of life in 120 children following repair of high imperforate anus. The researchers evaluated quality of life based on school attendance, social relations, and physical capabilities centered on their fecal incontinence. Interestingly, one of the researchers, Ditesheim, had undergone surgical repair of a high imperforate anus as a newborn, which the researchers felt greatly added to the ability to get parents to open up about their child's problems. The results showed that after 10 years of age, a child's fecal continence ability became a major determinant of their quality of life.

The main criticism of these early examples of quality of life studies conducted with children by Herndon et al. (1986) and Ditesheim \& Templeton (1987) is that they do not attempt to define quality of life and often quality of life was used interchangeably with "social and psychological problems" or was restricted to demographic or clinical indicators (Eiser \& Morse, 2001). However, the findings from these early studies did help to lead the way for modern quality of life work involving children by emphasizing that children have the ability to adapt even after a major injury or surgery and that children's views about their disability are important (Eiser \& Morse, 2001).

One group of researchers, Lansky and associates (L. L. Lansky, List, Lansky, Cohen, \& Sinks, 1985), made one of the first attempts to measure quality of life in children by involving a parent-rated instrument measuring play in children (Eiser \& Morse, 2001). Lansky et al. (1985) believed that play is "the work of children," and therefore, an instrument measuring play would be a reflection of a child's performance 
status. In addition, a child's ability to engage in age-appropriate play influences not only peer contacts, skill acquisition, and more general feelings of self-esteem but in essence is a major part of overall quality of life (L. L. Lansky et al., 1985). The play-performance scale was tested on 98 pediatric oncology patients, 29 of their siblings, and 40 healthy children of hospital employees ranging ages 1 to 16 years (S. B. Lansky, List, Lansky, Ritter-Sterr, \& Miller, 1987). The researchers found the tool to be feasible, effective, and able to be administered repeatedly to even extremely ill children. In addition, the parents were reliable reporters of their child's daily functioning, which was reflected by the fact that the parent ratings on the play scale were similar to the global ratings of the oncology nurses and other clinicians (S. B. Lansky et al., 1987).

From these early studies an increasingly larger and more sophisticated literature concerning quality of life in children has emerged (Eiser \& Morse, 2001). Much of the current research involving QOL of children with chronic illness has focused on either comparing children with chronic illness to "healthy" children using generic QOL instruments or using disease-specific QOL instruments to measure the effect of the disease on lifestyle (Eiser \& Morse, 2001).

An extensive review of 137 articles measuring QOL in children was done by Eiser \& Morse (2001). Their review found that 43 of the articles were primarily concerned with the development of new QOL measures, 79 reported subsequent development of these same measures, and 15 used a battery approach to measure QOL (Eiser \& Morse, 2001). The reviewers found that despite the growth in development of measures of QOL in children, many of the QOL tools had limitations such as limited 
psychometric data, lack of parallel forms for children and proxy raters, and lack of understanding of a child's ability to complete a paper-and-pencil questionnaire (Eiser \& Morse, 2001). Because QOL in children is a newly emerging field with a limited body of empirical work, the authors recommended that more research be conducted using QOL measures in children in order to gain experience that would guide development of a second generation of more sophisticated measures (Eiser \& Morse, 2001).

As stated earlier, the majority of the QOL research literature that has been conducted with children has focused on potentially fatal and debilitating illness such as cancer, cystic fibrosis, and arthritis. For example, a study involving 57 children with juvenile idiopathic arthritis, compared the impact of different treatment options on QOL (Riddle et al., 2006). The researchers found that the children receiving steroid treatments experienced the most improved QOL compared to the other groups, despite greater incidence of adverse side effects (Riddle et al., 2006). Another study, involving 25 children who survived brain tumors (astrocytoma or medullablastoma) compared QOL between those treat with and without radiation (Odame et al., 2006). The results showed that the survivors treated with radiation therapy had lower QOL scores and diminished physical activity (Odame et al., 2006). However, only one recent study attempted to compare QOL among children with various different chronic illnesses, including asthma.

For this study, the researchers examined differences in perception of quality of life between 181 parents of children with cystic fibrosis, acute lymphatic leukemia, juvenile idiopathic arthritis, or asthma and 37 pediatricians (Janse et al., 2004). The results showed that in all patient groups the pediatrician assessed the child to have less 
pain/discomfort in comparison to the parents (Janse et al., 2004). In addition, clear differences in perception of QOL between the parents of children with chronic illnesses and physicians were found, however, the asthma group showed the least amount of variance (Janse et al., 2004). One of the limitations of this study is the lack of direct QOL assessment of the children involved. Although the perception of QOL of the parents of children with chronic illnesses and their health care providers is important, more important is the actual perception of QOL of the child who has the disease.

It appears from the review of the child QOL literature that the concept of QOL as it relates to children remains nebulous. Therefore, for the purpose of this paper, the remainder of this review will focus on the limited number of QOL research studies relating to children with asthma and/or obesity. Due to the limited number of studies examined for this review, methodology and gaps in the literature will be discussed at the end of the section.

Quality of Life in Children with Asthma

The majority of studies regarding QOL and asthma have focused on adults. The majority of the adult studies found asthma had mild impact on QOL except in those subjects who had recently been hospitalized for an acute exacerbation (Gibson, Talbot, Toneguzzi, \& Population Medicine Group 91C, 1995). Due to the increasing prevalence of asthma among children, research has now begun to emerge regarding childhood asthma and quality of life. However, the number of studies conducted on child QOL and asthma remains limited. The majority of studies have focused on development and validation of disease-specific QOL instruments such as the Pediatric Asthma Quality of 
Life Questionnaire (PAQLQ) (Raat et al., 2005; Tauler et al., 2001), or the impact of various treatments such as inhaled corticosteroids on QOL (Lemanske et al., 2002; Murphy, Fitzpatrick, Cruz-Rivera, Miller, \& Parasuraman, 2003). Few studies have focused specifically on the impact of childhood asthma on QOL. For this review, only three studies were found that specifically examined QOL in children with asthma.

Similar to the results found with adults, the limited number of QOL and childhood asthma research studies have found minimal to moderate QOL impairment. In a study, by Annett, Bender, Lapidus, DuHamel, \& Lincoln (2001), the researchers examined the relationship between quality of life and asthma using 339 subjects from a larger clinical trial, the Childhood Asthma Management Program (CAMP), which examined children with mild to moderate asthma (mean age, 9.3 years). The children in the study had mild asthma symptoms during the 2 weeks before their 12-month follow-up clinic visits. Scores from the Pediatric Asthma Quality of Life Questionnaire (PAQLQ) showed most of the children were bothered "a bit" or "hardly at all" by their asthma. Children with moderate asthma did report more activity limitations (5.71 v 5.44; $\mathrm{P}=.04)$. However, this is a modest difference. The main limitations of this study can be found in the choice of study population. The researchers did not include severe asthmatics in their sample and only $29(8.5 \%)$ of the sample were African-American. Including a larger minority sampling and including more severe asthmatics would have strengthened the study and made it more generalizable.

Another study examing quality of life among high school students found similar results. Gibson, Henry, Vimpani, \& Halliday (1995) examined asthma knowledge, 
attitudes, and QOL among 4161 high school students and 1104 of their teachers in New South Wales, Australia. QOL was measured using the PAQLQ. It was reported that 23\% of the study subjects had asthma and this caused mild to moderate quality of life impairment, especially with strenuous activity. Surprisingly, $22 \%$ of the asthmatic high school students reported that they were current smokers, which was similar to that reported by non-asthmatic adolescents (Gibson, Henry et al., 1995). One of the limitations of this study is that the study sample was from Australia, which makes it harder to generalize the results to the U.S. population. In addition, the researchers did not report correlation results between the smoking asthmatics and those who reported QOL impairment with strenuous activity. It would have been interesting to see if the current smoker asthmatic subjects were the same ones reporting higher QOL impairment levels. Furthermore, the researchers only examined adolescents with asthma; therefore, the results are less generalizable to children with asthma.

In a similar study, Okelo and associates (2004) also focused on QOL and adolescents with asthma. Their study included 185 adolescents with asthma and used only the emotional measurement components of the PAQLQ as well as the Child Health and Illness Profile-Adolescent Edition (CHIP-AE) to examine emotional QOL. In addition, the researchers looked at health outcomes including emergency department visits, hospitalizations, and missed school. The results showed that poorer emotional QOL was associated with poorer control of asthma symptoms $(\mathrm{P}<.0001)$, missed school $(\mathrm{P}<.05)$, and doctor visits for worsened asthma $(\mathrm{P}<.05)$ (Okelo et al., 2004). The main limitation of this study was the use of self-reported data about asthma symptoms and only 
a modest response rate from the adolescent subjects. The researchers conclude from their results that because of the association shown between emotional symptoms and asthma severity, the evaluation of asthma-specific emotional QOL, should be included in the assessment of all adolescents with asthma (Okelo et al., 2004).

\section{Quality of Life in Children with Obesity}

Whereas asthma research has found minimal to moderate impact on QOL, obesity research has shown a significant affect on quality of life. Although relatively few empirical studies have evaluated the effects of obesity on QOL, a review by Fontaine \& Barofsky (2001) found that the majority of studies published on obesity have indicated that obesity impairs quality of life, and higher degrees of obesity are associated with greater impairment. In addition, the majority of obesity QOL-related studies have focused on the effects of weight reduction after gastric surgery (Fontaine \& Barofsky, 2001). The majority of surgical intervention studies have found dramatic improvements in QOL indices such as overall physical functioning, work capacity, mental health, selfesteem, social interaction, and general satisfaction with life (Fontaine \& Barofsky, 2001). However, the effect of obesity on the QOL of children and adolescents has received only a limited amount of investigation. From an extensive review of the literature only five studies were found examining QOL in obese children.

One of the few studies to examine QOL in obese children was a recent crosssectional study comparing quality of life scores in 106 obese children, 106 children with cancer, and 401 healthy children ages 5 to 18 years using a pediatric QOL inventory generic core scale, PedsQL 4.0 (Schwimmer et al., 2003). The results showed that the 
obese children were five times more likely to have an "impaired" quality of life compared to healthy children- score of 67 , compared to 83 (out of 100 total) (Schwimmer et al., 2003). Overall the obese children reported significantly lower QOL $(p<.001)$ in all domains compared with the healthy controls. In addition, the analysis of the data showed the likelihood of an obese child having impaired QOL was similar to a child or adolescent diagnosed as having cancer. The researchers found this result unexpected and important because previous studies have found that children diagnosed as having cancer and who were receiving chemotherapy have the lowest QOL scores when compared with healthy children and children with juvenile rheumatoid arthritis, type 1 diabetes mellitus, and congenital heart disease. Furthermore, the researchers commented that although obese children may also experience physical limitations and teasing from peers, they are not exposed to the intense medical interventions and severe adverse effects that are common in pediatric cancer (Schwimmer et al., 2003). The main limitation of this study was that only children and adolescents with severe obesity were examined, whether similar findings would be seen in children with lesser degrees of obesity is still unknown (Schwimmer et al., 2003).

A second study, Friedlander, Larkin, Rosen, Palermo, \& Redline (2003), also examined QOL in obese children. A cross-sectional analysis of 371 children ages 8 to 11 years old examined QOL in overweight and at risk for overweight school-aged children compared to normal weight peers (Friedlander et al., 2003). 17.5\% of the children sampled were overweight $\left(\mathrm{BMI}>95^{\text {th }}\right.$ percentile $)$ and $12.4 \%$ were considered at risk for overweight (BMI $85^{\text {th }}-95^{\text {th }}$ percentile). QOL of was measured using the Child Health 
Questionnaire-Parent Form 50 (CHQ-PF50), which was completed by the child's parent. The results showed that the overweight children scored significantly lower on the psychosocial health summary $(\mathrm{p}<.001)$ and on subscales measuring self-esteem $(\mathrm{p}<.001)$, physical functioning $(\mathrm{p}=.01)$, behavior $(\mathrm{p}=.001)$, and global general health $(\mathrm{p}<.001)$. In addition, the parents, of the children who were overweight, reported higher levels of emotional distress because of their child's health. Children at risk for overweight only scored significantly lower for physical functioning. The main limitation of this study was the use of parental reports to measure QOL as opposed to children's self-reports, which may have been more accurate. Furthermore, although asthma was specifically included as a covariate because of its association with obesity in the literature, the analysis of this relationship was not reported.

Additionally, a third study, Swallen, Reither, Haas, \& Meier (2005), conducted a cross-sectional analysis using data from the 1996 National Longitudinal Study of Adolescent Health, a nationally representative sample of adolescents in grades 7 to 12 during the 1994-1995 school year. The subjects totaled 4743 with 59\% non-Hispanic white, $21 \%$ non-Hispanic black, $12 \%$ Hispanic, $3 \%$ Asian, and 5\% other. The researchers measured health-related quality of life by using a tool they created based on the four dimensions of the Pediatric Quality of Life Inventory (PedsQL), physical health, emotional functioning, social functioning, and school functioning. The results found that adolescents who were overweight (OR: 2.17; 95\% CI) or obese (OR: 4.49; 95\% CI) were significantly more likely to report poor general health than adolescents with normal BMI. However, only the obese 12-14 year olds reported lower self-esteem (OR: $3.47,95 \% \mathrm{CI}$ ) 
and poorer school/social functioning (OR: 2.33; 95\% CI). The researchers speculated that the possible reason for why in most adolescents they studied, there appears not to be a relationship between BMI and psychosocial QOL, is that because overweight is now more common among adolescents maybe the new cohort of young Americans is more tolerant of weight differences (Swallen et al., 2005). One of the limitations of this study was the use of self-reported physical health measurements. The adolescents studied may have under-reported their health problems, thus improving their QOL score. Another limitation of this study was the use of a researcher created HRQL tool. Although the tool was based on the PedsQL, which has strong reliability and validity, the new version created by the researchers of this study had not been previously tested. Therefore, the validity of the results are questionable.

The fourth study reviewed which examined QOL in overweight children was a cross-sectional analysis of 1456 school children age 9 to 12 years conducted in Victoria, Australia (Williams et al., 2005). QOL was measured using the parent-proxy and child self-reported PedsQL 4.0 questionnaires. Of the 1456 participants, 1099 (75.5\%) were classified as not overweight, 294 (20.2\%) overweight, and 63 (4.3\%) obese (Williams et al., 2005). The results showed at the subscale level, decreases in physical and social functioning for obese children compared with children who were not overweight $(\mathrm{P}<$ .001) (Williams et al., 2005). Differences in total and physical PedsQL scores between not overweight and overweight were not significant. Of the three groups, obese children had the lowest overall QOL scores $(\mathrm{P}<.001)($ Williams et al., 2005). One of the strengths of this study was the use of trained field workers to measure children's heights and 
weights. However, one of the limitations of this study was the use of parent-proxy questionnaires to measure QOL.

The fifth and final study reviewed regarding QOL and obesity in children, compared 182 obese and non-obese children and adolescents recruited from community pediatric clinics and a hospital-based obesity clinic in Israel using the Pediatric Quality of Life Inventory (PedsQL) questionnaire (Pinhas-Hamiel et al., 2006). The emotional and school domains scores of the moderately obese children were similar to the normal weight children. However, moderately obese children did demonstrate significantly lower scores on the physical domain component of the PedsQL when compared to the normal weight children. $(\mathrm{P}<0.01)$ Children with severe obesity scored significantly lower in all domains compared to normal weight children $(\mathrm{P}<0.01)$ (Pinhas-Hamiel et al., 2006). Although, this study was conducted in Israel, one of it's strengths is that the obesity rates among adults in Israel are similar to the U.S. and therefore the results could theoretically be generalized to the U.S.

\section{Obesity, Asthma, and QOL in Children}

While a small number of studies related to childhood obesity and QOL have been reported, there is a significant lack of studies examing both asthma and obesity together with quality of life. Only three studies were found that examined all three areas. The first study was conducted by a group of German researchers. Ravens-Sieberer, Redegeld, \& Bullinger (2001) compared quality of life in 1019 children with obesity $(n=584)$, asthma/atopic dermatitis $(n=330)$, or both $(n=105)$. QOL was measured using the German KINDL quality of life questionnaire, a 24 item instrument with six dimensions 
and a total score as well as a chronic generic and an obesity module. Among the three groups, the results showed higher impairment in QOL in children with obesity, which improved following obesity treatment. In addition, QOL was found to be dependent on age and gender with increased age over 13 years and female gender having the lowest QOL scores (Ravens-Sieberer, Redegeld, \& Bullinger, 2001). The main limitation of this study is the use of the German KINDL QOL questionnaire, which has been used only minimally in QOL research studies. The questionnaire's limited use and the fact that it was originally written in German make it difficult to generalize the results to the U.S. population. In addition, a 3-way-variance analysis was conducted to identify differences in KINDL scores between groups, however, only the details of the low QOL results for the obesity group were reported and discussed.

The second study to examine all three variables, QOL, asthma, and obesity, was a pilot study conducted by researchers, Blandon Vijil, Del Rio Navarro, Berber Eslava, \& Sienra Monge (2004), in Mexico. The study subjects consisted of a total of 100 obese, overweight, and normal weight children with intermittent or mild persistent asthma ranging in age 7 to 17 (Blandon Vijil, Del Rio Navarro, Berber Eslava, \& Sienra Monge, 2004). Of the 100 subjects, 29 were categorized as normal weight, 18 overweight, and 53 obese. In addition, out of the 100 subjects in the study $66 \%$ were male and $34 \%$ female (Blandon Vijil et al., 2004). The subjects were administered the Spanish version of the PAQLQ. The results showed significant differences in quality of life in the obese asthmatic group only $(\mathrm{p}<0.000)$. No differences were found between the normal weight and overweight asthmatics $(\mathrm{p}=1)$. As well as, no significant differences were found 
between genders. One of the limitations of this study is the fact that it was only a pilot study and therefore only a small sample group was used. However, the preliminary results are promising and open to further investigation.

The third and final study reviewed was conducted in the Netherlands using a cross-sectional study design of 1758 school children age 7 to 10 years (van Gent et al., 2007). Quality of life was evaluated using the Pediatric Asthma Quality of Life Questionnaire (PAQLQ). For all three domains of quality of life; symptoms, emotions, and activity, children with both asthma and excessive body weight had lower scores than children with either asthma alone or excessive body weight alone $(\mathrm{P}<.01)$ (van Gent et al., 2007). One of the limitations of this study was the use of the PAQLQ to measure QOL in children, who did not have asthma, and then use that data to measure QOL. The PAQLQ tool developed by Dr. Juniper (Juniper, Guyatt, Feeny, Griffith, \& Ferrie, 1997), was specifically created to measure QOL in children with asthma and has only been validated in children with asthma. Therefore, the study results regarding lower QOL scores for overweight children with asthma compared to children with asthma are valid. However, the significance of those scores compared to normal weight children and overweight children are debatable.

In conclusion, the reviewed studies by Ravens-Sieberer (2001), Blandon Vijil (2004), and van Gent (2007) are similar in that they all examined quality of life, obesity, and asthma in children and all were conducted outside the United States. In addition, all three studies found that children with obesity have the highest rate of impairment in quality of life. Taking this concept further, the studies by Blandon Vijil (2004) and van 
Gent (2007), using the PAQLQ, found that obesity combined with asthma significantly lowered QOL scores. It is important for these findings to be replicated and expanded on by researchers here in the U.S. in order to determine ways to improve the quality of life of obese children with asthma.

Review of Methodology

As stated earlier, quality of life is difficult to study in children because children and adolescents are constantly developing both physically and mentally. Of the studies examined for this review, all used a comparative study design (Annett et al., 2001; Blandon Vijil et al., 2004; Friedlander et al., 2003; Gibson, Henry et al., 1995; Okelo et al., 2004; Pinhas-Hamiel et al., 2006; Ravens-Sieberer et al., 2001; Schwimmer et al., 2003; Swallen et al., 2005; van Gent et al., 2007; Williams et al., 2005). Comparative designs are hypothesis-testing approaches designed to build support for theory (Brink \& Wood, 1998). One of the weaknesses of this type of design is the lack of manipulation of the independent variable. In the above studies, the independent variables included weight/height (BMI) and/or asthma severity, both of which can only be observed and not directly manipulated. This lack of control of the independent variable is a threat to the internal validity. However, the strength of this design is that it provides external validity and allows generalizations to be made because of the less rigid control of the variables and the use of a field setting (Brink \& Wood, 1998).

Another strength of the studies examined is the extent of sample sizing. In the studies reviewed, the sample size ranged from 100 to over 1,000 subjects (Annett et al., 2001; Blandon Vijil et al., 2004; Friedlander et al., 2003; Gibson, Henry et al., 1995; 
Okelo et al., 2004; Pinhas-Hamiel et al., 2006; Ravens-Sieberer et al., 2001; Schwimmer et al., 2003; Swallen et al., 2005; van Gent et al., 2007; Williams et al., 2005). The relatively large sample sizes used in these studies make the results obtained from them more generalizable to the rest of the population.

None of the studies reviewed used an experimental design. An experimental study design requires manipulation of an independent variable, randomization, and a control group. The independent variables, weight/height (BMI) and asthma severity cannot be deliberately manipulated. Only three of the studies (Annett et al., 2001; Friedlander et al., 2003; Swallen et al., 2005) reviewed used random sampling for selection of subjects. However, over half of the studies reviewed used a control group for comparison (Friedlander et al., 2003; Gibson, Henry et al., 1995; Pinhas-Hamiel et al., 2006; Schwimmer et al., 2003; Swallen et al., 2005; van Gent et al., 2007; Williams et al., 2005).

In a quasi-experimental design, one of the three properties of an experimental design is missing (Trochim, 2001). Randomization or a control group can be missing and still qualify as a quasi-experimental design, however, manipulation of the independent variable is still required. None of the studies reviewed contained manipulation of the independent variable therefore neither the experimental nor quasi-experimental designs apply.

Due to the inability to manipulate the independent variables, weight/height (BMI) and/or severity of asthma, the comparative research design used unanimously by the 
studies examined for this review is the most applicable design to explore quality of life in children with asthma and obesity.

\section{Gaps in the Literature}

\section{Asthma and QOL}

Quality of life in children with cancer and chronic illnesses, such as rheumatoid arthritis and cystic fibrosis, has been extensively researched. However, quality of life research involving asthma in children has received little attention even though asthma is the number one chronic illness among children and the number one cause of hospitalization (Mannino et al., 2002). The majority of the limited number of studies examing quality of life in asthmatic children have used the PAQLQ to measure QOL and have found only minimal to moderate impairment (Annett et al., 2001; Gibson, Henry et al., 1995). These studies have shown that QOL is a good indicator of health behaviors. For example, if a child's quality of life is improving, it is a good sign that their asthma is being properly controlled. However, additional studies need to be conducted using disease-specific QOL tools such as the PAQLQ in order to enhance development of more sophisticated measures of QOL in children (Eiser \& Morse, 2001). Furthermore, parents often can have a poor perception of the problems and emotions their children with asthma suffer, and therefore, more studies need to be conducted using QOL tools, such as the PAQLQ, which have a child as well as parent-version of the tool (Roger, 1999).

In addition, there is a lack of studies examining QOL using multiple measures. For example, using both a generic QOL tool, such as the PedsQL, and a disease-specific tool, such as the PAQLQ, to measure QOL. The use of a single child-completed 
questionnaire may not capture the complexity of the objective (activities and symptom frequency) and subjective aspects (feelings about activities and symptoms) of QOL (Annett et al., 2001). Therefore, more studies need to be conducted using multiple measures to assess QOL, including one or more child-completed QOL questionnaires as well as assessment of specific health status domains including psychosocial factors such as child-coping strategies and child behavioral/emotional characteristics (Annett et al., 2001).

Studies need to be conducted using accurate height and weight measurements as well as asthma symptoms confirmed by a medical professional in order to strengthen and clarify findings from previous studies. Studies examining both obesity and asthma together have relied on self-reported asthma symptoms and/or self-reported height and weight (Chinn \& Rona, 2001; Figueroa-Munoz et al., 2001). Self-report is unreliable. Self-reported data about recent asthma symptoms is subject to limitations of recall, recall bias, and selection bias (Okelo et al., 2004).

There is a lack of studies examining all levels of asthma severity and QOL. In addition, there is a lack of studies examining specifically QOL of children with asthma. The two studies reviewed, which included mild to severe asthma, were conducted only with adolescents (Gibson, Henry et al., 1995; Okelo et al., 2004). The one study reviewed that examined QOL in children with asthma (Annett et al., 2001) included only mild to moderate asthmatics in the sample. Asthma severity in adults has been shown to contribute to QOL impairment (Juniper, Svensson, Mork, \& Stahl, 2004). This important 
finding needs to be correlated with QOL findings in children as well as adolescents by examing all degrees of asthma severity.

Higher prevalence and severity of asthma symptoms have been found in minorities, especially African-Americans (CDC, 2002). However, there is a paucity of studies which examine QOL in minority children with asthma. The one study reviewed by Gibson, Henry, Vimpani, \& Halliday (1995) was conducted in Australia and obviously did not include African-Americans. The two other studies reviewed (Annett et al., 2001; Okelo et al., 2004) included only a small sampling of minority children and adolescents ranging from $8.5 \%$ to $16.3 \%$. More studies need to be conducted with a larger sampling of minority populations.

\section{Childhood Obesity and $Q O L$}

Despite the alarming increase in childhood obesity over the last two decades, there is a disturbing lack of studies examining childhood obesity and quality of life. It is obvious from the lack of studies found examining childhood obesity and QOL that more studies need to be conducted in this area of research. The results of the five studies reviewed are confusing because four different approaches to measuring QOL were utilized. Schwimmer et al. (2003) used the PedsQL questionnaire, Friedlander et al. (2003) used parental report using the CHQ-PF50, Swallen et al. (2005) used their own self-created version of the PedsQL, and Williams et al. (2005) and Pinhas-Hamiel et al. (2006) used both the parent-proxy and the child self-report version of the PedsQL. The results on the impact of childhood obesity on QOL varied from severe QOL impairment to only poor general health. 
Additional studies need to be conducted examing overweight and obese children and adolescents before conclusions can be drawn about the impact of childhood obesity on QOL. In addition, more studies need to be conducted looking at the long-term effects of childhood obesity on QOL. Furthermore, future research into childhood obesity needs to include minority children because of the higher risk of obesity among minority children.

Obesity, Asthma, and QOL in Children

Only three studies were found for this review that examined all three variables in children; obesity, asthma, and quality of life. All three studies by Ravens-Sieberer et al. (2001), Blandon Vijil et al. (2004), and van Gent et al. (2007) were conducted outside the United States. Although the incidence of childhood obesity and asthma has been increasing worldwide, the US has seen the highest increases in both conditions. Therefore, further studies need to be conducted here in the US in order to understand the significance of childhood obesity and asthma on QOL.

In conclusion, there is a significant dearth of studies examing asthma and childhood obesity and the impact these conditions have on QOL. In addition, even though there is a higher incidence of obesity and asthma in African-Americans, there is a lack of inclusion of minority populations in examing how asthma and obesity are impacting QOL in children. Additional research needs to done to assess how two increasingly common health conditions, asthma and obesity, are together affecting the quality of life of children. 


\section{Theoretical Framework}

The framework that will guide this dissertation is the revised health-related quality of life model developed by C. E. Ferrans and associates (2005). The original health-related quality of life (HRQOL) model was developed by Wilson \& Cleary in 1995. Their model was one of the first conceptual models of HRQOL that incorporated the viewpoint of the patient. They accomplished this by including in their model the patient's perception of symptoms and overall quality of life, as well as values (C. E. Ferrans, 2005). Their model contained conceptually distinct measures of HRQOL which included five levels: biological and physiological factors, symptoms, functioning, general health perceptions, and overall quality of life (Wilson \& Cleary, 1995). In addition, the patient's values and preferences were shown as contributing to the last two levels, general health perceptions and overall quality of life.

The original model was revised in 2005 by Ferrans and associates in three substantive ways: arrows were added to show that biological function is influenced by characteristics of both individuals and environments; non-medical factors were deleted and are understood to be part of the characteristics of the individual and environment; and labels were omitted on the arrows to enhance clarity (C. E. Ferrans, Zerwic, Wilbur, \& Larson, 2005). The final revised Wilson and Cleary model for health-related quality of life is seen in Figure 1. 
Figure 1. Revised Wilson and Cleary Model for Health-Related Quality of Life

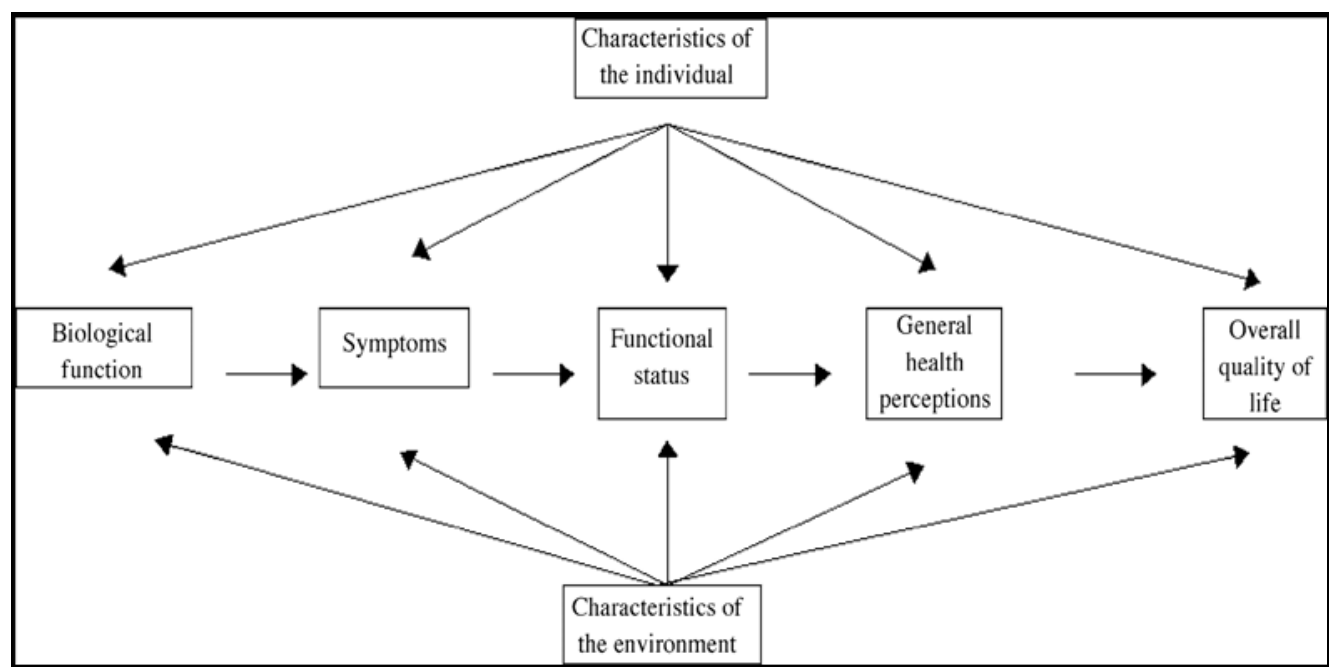

In the revised model of HRQOL by Ferrans (2005), both individual and environmental characteristics are shown influencing the five distinct types of measures of patient outcomes, which make up HRQOL. Characteristics of the individual are categorized as demographic, developmental, psychological, and biological factors that influence health outcomes. BMI is an example of a biological factor. Characteristics of the environment are categorized as either social or physical. Social environmental characteristics are the interpersonal or social influences that affect health outcomes, including the influence of family, friends, and healthcare providers (C. E. Ferrans et al., 2005). Physical environmental characteristics include settings such as the home, neighborhood, and workplace that influence health outcomes either positively or 
negatively (C. E. Ferrans et al., 2005). For example, neighborhoods with walking paths and bicycle trails encourage physical activity.

The five types of measures of patient outcomes, which are influenced by the characteristics of the individual and the environment, include biological function, symptoms, functional status, general health perceptions, and overall quality of life. First, biological function is defined as the function of cells, organs and organ systems, which can be assessed through such indicators as laboratory tests, physical assessment, and medical diagnoses (C. E. Ferrans et al., 2005). Second, symptoms refers to the physical, emotional, and cognitive symptoms perceived by the patient. Symptoms can be measured by frequency, intensity, and distress. The third component, functional status includes physical, psychological, social and role function with the focus being on the optimization of the function that remains (C. E. Ferrans et al., 2005). A way to assess functional status would be to measure aerobic capacity by using a symptom-limited exercise test, which measures maximal oxygen uptake (C. E. Ferrans et al., 2005). The fourth component is general health perceptions, which is a synthesis of all the various aspects of health in an overall subjective assessment. Ferrans (2005) states that this component of the model is best measured using a single global question asking people to rate their health on a Likert scale ranging from poor to excellent. The fifth and final component is overall quality of life. Overall quality of life is defined as subjective wellbeing, which reflects how happy or satisfied someone is with life as a whole. Overall quality of life includes the domains of health and functioning, psychological and spiritual, family, social, and economic (C. E. Ferrans, 1996). Ferrans (2005) recommends this 
final component be measured through a single global question, asking how satisfied the individual is with life in general, or through a series of questions about satisfaction with various aspects of life.

Although there is a lack of published literature on the relatively new, revised model of HRQOL by Ferrans (2005), the description of QOL presented is sound, making a distinction between health-related quality of life and overall quality of life. This distinction will only enhance the understanding of the concept of QOL and was wellsuited for this study. 


\section{CHAPTER THREE}

\section{METHODOLOGY}

\section{Purpose of the Study}

The purpose of this study was to examine the differences in QOL and health outcomes in two different groups; overweight children with asthma and non-overweight children with asthma.

\section{Design and Setting}

A descriptive, comparative survey design was used for this study. The setting was a pediatric asthma clinic affiliated with a large free-standing Midwestern pediatric hospital. In addition, the geographic area where this study took place, has one of the highest asthma mortality rates in the United States (Galatzer-Levy, 2003).

\section{$\underline{\text { Sample }}$}

The sampling method for this study was a convenience sample. The sampling took place over a 13 month period from July 2008 to August 2009. The sample was separated into two groups, overweight and non-overweight children with asthma. The sample consisted of 90 children age 9 to 14 years of age; 54 normal weight and 36 overweight.

\section{Inclusion/Exclusion Criteria}

The inclusion criteria was children ages 9 to 14 years of age. In addition, only children with mild persistent, moderate persistent, and severe persistent asthma were 
included in the study. Mild persistent asthma is defined as having day symptoms less than two days a week requiring the use of a beta 2 -agonist and night symptoms, such as cough or wheezing less than 3-4 times a month (National Asthma Education and Prevention Program, 2007). Moderate persistent asthma is defined as having day symptoms requiring daily use of a beta 2 -agonist and night symptoms once a week or more but not nightly (National Asthma Education and Prevention Program, 2007). Severe persistent asthma is defined as having continual symptoms of cough, wheeze, chest tightness or difficulty breathing requiring frequent us of a beta $a_{2}$-agonist as well as frequent night symptoms (National Asthma Education and Prevention Program, 2007). For each subject, asthma severity classification was determined by a physician prior to the child's visit to the asthma clinic.

For the purpose of this study, only the English version of the Pediatric Asthma Quality of Life Questionnaire was used. Therefore, subjects were required to read and write in English in order to be included in the study group.

Further exclusion criteria included children who were severely developmental or motor delayed due to the potential difficulty in administering the QOL questionnaire to these types of children and to eliminate the possibility of confounding variables. Also, in order to reduce additional confounding variables, children with chronic illnesses other than asthma (i.e. diabetes, rheumatoid arthritis, cystic fibrosis) were excluded from the study as well.

The overweight inclusion criteria used for this study followed the current recommended definition of overweight in children (CDC, 2009a). Childhood overweight 
was defined as a BMI between the $85^{\text {th }}$ and $94^{\text {th }}$ percentile for age and gender and obese was defined as having a BMI at or above the $95^{\text {th }}$ percentile for age and gender (CDC, 2009a). Both overweight and obese children were included in the study.

\section{$\underline{\text { Power Analysis }}$}

In a review of the literature using quality of life questionnaires, the tools reviewed had more than adequate power with the sample sizes used in the studies. In a research study by Schwimmer, Burwinkle, \& Varni (2003) examining obesity and quality of life, a total of 106 overweight children were compared to 106 children with cancer and 401 healthy children. The results of the study showed a significant difference between groups with reported effect sizes ranging from $0.78-2.01$ on the different quality of life subscales. In a study by Guyatt, Juniper, Griffith, Feeny, \& Ferrie (1997) using the Pediatric Asthma Quality of Life Questionnaire (PAQLQ), the same tool which will be used for this study, significant results were found at an alpha of .001 to .05 for withinsubject change. The power analysis reported for this study resulted in an effect size of 1.00 using a total of 54 subjects (G. H. Guyatt, Juniper, Griffith, Feeny, \& Ferrie, 1997).

Based on the above review of the literature and statistical consultation (K. Hyung, personal communication, June 1,2007 ) a power analysis was done in order to calculate the appropriate sample size needed for this study. A total sample size of 100 subjects (50 per group) was determined to provide $80 \%$ power to detect a difference of 0.57 in effect size (effect size $=$ mean difference divided by the standard deviation $)$ with a two-sided ttest and alpha $=0.05$. 
The final number of total subjects achieved for this study was 90; 54 normal weight and 36 overweight and obese. A posterior power analysis found a total of 66 subjects would detect a difference of 0.80 in effect size with a two-sided t-test and alpha $=0.05$, and 159 subjects would detect a difference of 0.50 in effect size (B. Jegier, personal communication, September 8, 2009). A power analysis using “G Power" computer software (Faul \& Erdfelder, 1992) was calculated for a two-sided t-test and alpha $=0.05$ based on the achieved study sample $\left(\mathrm{N}_{1}=54, \mathrm{~N}_{2}=36\right)$. The results showed the study sample had a power of $63 \%$ with the ability to detect a difference of 0.50 in effect size and a power of $95 \%$ to detect a difference of 0.80 in effect size.

\section{Protection of Human Subjects}

IRB approval was obtained from the participating children's hospital as well as Loyola University, prior to the start of the study. Informed consent was obtained from the child's legal guardian, as shown in Appendix A. If the child's parent or legal guardian were not present at the clinic visit then they were not allowed to participate in the study.

Children 12 years of age and older were given a written assent form to sign. The assent form contained the same elements of the parental consent form but the language was modified in order to be more understandable to children, as shown in Appendix B. For children under 12 years of age, verbal assent was obtained and certified by the individual explaining the study to the subject. For their participation in the study the children were allowed to pick an item from an assortment of stickers and pencils, as compensation for their participation in the study. 
Confidentiality was maintained throughout the study. In addition, all Health Insurance Portability and Accountability Act (HIPAA) regulations were followed as required by the federal government. Unfortunately, full anonymity was not possible for this study since the subjects were not randomly chosen. However, identifying information was not made available to anyone who was not directly involved in the study. All the data was coded. In addition, all data collected was stored in a locked file cabinet in the principal investigator's office when not in use for analysis.

\section{$\underline{\text { Measurement }}$}

The key variables for this study were asthma, overweight, quality of life, and health outcomes. Asthma and overweight were the main independent variables along with age, gender, socioeconomic status, and race/ethnicity. Quality of life and health outcomes were the main dependent variables. Asthma related health outcomes included missed number of school days, ER visits, hospitalizations, number of days wheezing, and spirometry values.

\section{Anthropometric Measurement}

Children were weighed and measured with their clothes on and shoes off as per the standard asthma clinic procedure. Weights were measured in kilograms using a calibrated, hospital-grade, Detecto mechanical scale (Detectoscale.com). The validity of the scale was established by the manufacture of the equipment and the certification of its use by the American Academy of Pediatrics.

The subject's height was measured to the nearest centimeter using a calibrated wall-mounted Accustat stadiometer (Genentech; San Francisco, CA). Subjects were 
measured without shoes and were asked to stand as erect as possible with their heels together, looking straight ahead as per standard asthma clinic procedure. The height measurements were converted to meters squared and used with the weight in kilograms to calculate the body mass index for each subject. Both the Detecto mechanical scale and the Accustat stadiometer were checked for accuracy and calibrated annually by the bioengineering department of the hospital.

\section{Definition of Overweight}

Body mass index (BMI) was calculated by weight in kilograms divided by the square of the height in meters. BMI percentiles for age and gender, which have been established by the Centers for Disease Control and Prevention using data from the National Health and Nutrition Examination Survey III (NHANES III) were used to identify overweight children for this study (Kuczmarski et al., 2000; Ogden, Flegal, Carroll, \& Johnson, 2002). The CDC Body Mass Index-For-Age Percentile growth charts can be found in Appendix C. BMI at or above the $85^{\text {th }}$ percentile for age and gender was defined as overweight. The subject's BMI was calculated from the height and weight measurements obtained the day of their clinic visit.

\section{Definition of Asthma}

Children with asthma were recruited from the asthma clinic. As per clinic protocol, all children were prescreened and given as asthma severity classification by a physician prior to their first asthma clinic appointment. For this study, only children with mild to severe persistent asthma classifications were used as subjects. As stated previously, mild persistent asthma was defined as having day symptoms less than two 
days a week requiring the use of a beta 2 -agonist and night symptoms, such as cough or wheezing less than 3-4 times a month (National Asthma Education and Prevention Program, 2007). Moderate persistent asthma was defined as having day symptoms requiring daily use of a beta 2 -agonist and night symptoms once a week or more but not nightly (National Asthma Education and Prevention Program, 2007). Severe persistent asthma was defined as having continual symptoms of cough, wheeze, chest tightness or difficulty breathing requiring frequent us of a beta 2 -agonist as well as frequent night symptoms (National Asthma Education and Prevention Program, 2007). In addition, spirometry measurements were conducted as per clinic protocol prior to the subject's clinic visit, which further established the diagnosis of asthma.

\section{Spirometry}

Measurement of pulmonary function was obtained through spirometry testing performed at the asthma clinic. Spirometry is a physiological test that measures how an individual inhales or exhales volumes of air and is used as a screening test of general respiratory health (Miller et al., 2005). Spirometry was performed at the time of the subject's clinic appointment using a KoKo spirometer (Pulmonary Data Service; Louisville, CO). Spirometry was performed as per standard clinic procedure by a spirometry certified registered nurse with children standing and with nose clips. All spirometric assessments were performed according to American Thoracic Society/European Respiratory Society (ATS/ERS) standards (Miller et al., 2005). All spirometric values examined for this study are listed and described in Table 6 (Arnall, 1999; Spahn, Stewart, \& Chipps, 2008). 
Table 6. Description of Common Spirometric Test Values

\begin{tabular}{|l|l|l|}
\hline Abbreviation & \multicolumn{1}{|c|}{ Name } & \multicolumn{1}{c|}{ Description } \\
\hline FVC & $\begin{array}{l}\text { Forced Vital } \\
\text { Capacity }\end{array}$ & $\begin{array}{l}\text { The volume of air that can forcibly be blown out after a full } \\
\text { inspiration, until no more can be expired. }\end{array}$ \\
\hline FEV1 & $\begin{array}{l}\text { Forced Expiratory } \\
\text { Volume in 1 Second }\end{array}$ & $\begin{array}{l}\text { The maximum volume of air which can be forcibly exhaled in the } \\
\text { first second during the FVC maneuver. }\end{array}$ \\
\hline FEV1/FVC & FEV1\% & $\begin{array}{l}\text { This is the ratio of FEV1 to FVC. The amount of air exhaled in the } \\
\text { first second (FEV1) divided by the total amount of air exhaled } \\
\text { during a maximal forced exhalation (FVC). }\end{array}$ \\
\hline FEF 25-75\% & $\begin{array}{l}\text { Forced Expiratory } \\
\text { Flow 25-75\% }\end{array}$ & $\begin{array}{l}\text { The average flow of air coming out of the lungs during the middle } \\
\text { half of the forced viral capacity (FVC). }\end{array}$ \\
\hline PEFR & $\begin{array}{l}\text { Peak Expiratory } \\
\text { Flow Rate }\end{array}$ & $\begin{array}{l}\text { The maximum flow rate achieved during the forced vital capacity } \\
\text { (FVC) maneuver beginning after full inspiration and starting and } \\
\text { ending with maximal expiration. }\end{array}$ \\
\hline
\end{tabular}

\section{Health Outcomes}

For each subject, the parent/guardian was asked to complete a sociodemographic questionnaire which included asthma related health questions that were used to measure health outcomes, as shown in Appendix D. The health outcomes measured included asthma related school absences, number of emergency department (ED) visits, number of unscheduled doctor or clinic visits for asthma, and number of hospitalizations over the last 6 months. In addition, the questionnaire assessed for the number of days the child wheezed and the number of nights the child was awakened by asthma over the two weeks prior to their clinic appointment. These particular health outcomes were chosen because they are good indicators of asthma management and severity (National Asthma Education and Prevention Program, 2007). In addition, in a similar study, which examined asthma symptoms in overweight and non-overweight children with asthma, the researchers found that overweight children had a higher incidence of ED use and increased days reported wheezing (Belamarich et al., 2000). 
Quality of Life

Quality of life was measured using the Pediatric Asthma Quality of Life Questionnaire (PAQLQ) developed by Dr. Elizabeth Juniper. The PAQLQ was designed to measure asthma-specific quality of life in children age 7 to 17 years and includes problems identified by children with asthma as being most important and troublesome to them in their everyday lives (Juniper, 1997). The PAQLQ has been translated into more than 30 languages, however, only the English version of the questionnaire was utilized for this study.

The PAQLQ is a 23-item, 7-point Likert scale covering three domains. The three domains are symptoms (consisting of 10 items, including shortness of breath, wheeze, cough, tightness of chest, and tiredness), emotional function (consisting of 8 items, including frustration, fear, anxiety, anger, and feeling different and left out), and activity limitation (consisting of 5 items, including physical, social, school, and sleeping) (Juniper, 1997). The 7-point response scale ranges from $1=$ extremely bothered/all of the time to $7=$ not bothered/none of the time, the lower the score the greater the level of impairment. Each item is equally weighted therefore analysis of the results can be done directly from the recorded score for each item. The results are calculated as the mean score for each of the domains as well as the overall quality of life, which is the mean score of all the items. A Cronbach alpha reliability coefficient of .84 has been reported for this tool (Juniper, 2005). The PAQLQ takes approximately 10 to 15 minutes to complete. 
The PAQLQ is available in both an interviewer and self-administered format. For the purpose of this study, the self-administered version was used as shown in Appendix E. The reading level for the self-administered PAQLQ was calculated at a 9 year old reading level using Fry’s Readability Graph (Fry, 1977; Schrock, 1995). The reading level for the PAQLQ concedes well with the age range of 9 to 14 year olds selected for this study.

\section{Procedure for Data Collection}

Prior to their clinic appointment, potential study subjects were identified from the list of scheduled appointments by the asthma clinic nurses. Subjects were asked to participate in the study when they arrived for their scheduled asthma clinic appointment. If the subjects agreed to participate, consent/assent was obtained, and the parent or legal guardian was given the demographic questionnaire to complete. The child was given the Pediatric Asthma Quality of Life questionnaire to complete. After completing the questionnaires, the child's age, gender, height, weight, and the spirometry readings were attached to the questionnaire with all identifiers removed. An identifying code number was written in the top right hand corner. 


\section{CHAPTER FOUR}

\section{RESULTS}

Statistical analysis was completed using Statistical Package for the Social Sciences (SPSS) version 16.0 statistical software. Descriptive statistics were used to describe and summarize overall data. For continuous dependent outcomes, a one-way analysis of variance (ANOVA) was used to assess for differences between groups. For nominal dependent outcomes a nonparametric Pearson two-way chi squared analysis was conducted. For ordinal and non-normally distributed dependent outcomes, a KruskalWallis one-way analysis of variance was used. In addition, a multiple regression analysis was conducted to identify factors which were most predictive of quality of life.

\section{$\underline{\text { Sample Characteristics }}$}

\section{General Sample Characteristics}

A total of ninety children were recruited for the study. Data was analyzed only if the child and their parent/legal guardian completed both the PAQLQ and demographic questionnaire. All 90 children and their parent/legal guardian completed both questionnaires; therefore all 90 subjects and the data obtained were used for analysis.

As shown in Table 7, the majority, $68.9 \%$, of the children were male $(\mathrm{N}=62)$. $31.1 \%(\mathrm{~N}=28)$ of the children were female. The age range of the children were 9 to 14 
years of age, with a mean of $11.37(\underline{\mathrm{SD}}=1.83)$. In addition, the majority of the children were white, $43.3 \%(\mathrm{~N}=39) .26 .7 \%(\mathrm{~N}=24)$ of the children were identified as black or African American, 23.3\% $(\mathrm{N}=21)$ Hispanic or Latino, 5.6\% $(\mathrm{N}=5)$ Asian, and $1.1 \%(\mathrm{~N}$ =1) other.

Table 7. Age, Gender, Ethnicity Characteristics for Subjects

\begin{tabular}{|c|c|c|c|}
\hline Characteristic & Group & N & Percent \\
\hline Age & 9 & 22 & 24.4 \\
& 10 & 12 & 13.3 \\
& 11 & 12 & 13.3 \\
& 12 & 14 & 15.6 \\
& 13 & 15 & 16.7 \\
\hline Gender & 14 & 15 & 16.7 \\
\hline Ethnicity & Male & 62 & 68.9 \\
& Female & 28 & 31.1 \\
\hline & White & 39 & 43.3 \\
& Black & 24 & 26.7 \\
& Hispanic or Latino & 21 & 23.3 \\
& Asian & 5 & 5.6 \\
& Other & 1 & 1.1 \\
\hline
\end{tabular}

Of the parent/legal guardians completing the sociodemographic questionnaire, the majority $(55.6 \%, \mathrm{~N}=50)$ reported having completed 2 years of college or more. Income level was more varied with $23.3 \%(\mathrm{~N}=21)$ reporting a yearly income level of less than $\$ 25,000$ and $27.8 \%(\mathrm{~N}=25)$ reporting a yearly income level of $\$ 100,000$ or more. Only one parent/legal guardian refrained from reporting education level and a total of 6 participants did not report income level. Reported education and income levels are shown in Table 8. 
Table 8. Education and Income Levels

\begin{tabular}{|l|c|c|}
\hline \multicolumn{1}{|c|}{ Education } & Frequency & Percent \\
\hline Completed less than $8^{\text {th }}$ grade & 9 & 10.0 \\
High school diploma or GED & 29 & 32.2 \\
Trade School & 1 & 1.1 \\
2 or 4 year college degree & 32 & 35.6 \\
Graduate degree & 18 & 20.0 \\
Total & 89 & 98.9 \\
Missing & 1 & 1.1 \\
\hline \multicolumn{1}{|c|}{ Income } & Frequency & Percent \\
\hline Less than $\$ 25,000 / \mathrm{yr}$ & 21 & 23.3 \\
$\$ 25,000-49,999 / \mathrm{yr}$ & 14 & 15.6 \\
$\$ 50,000-74,999 / \mathrm{yr}$ & 13 & 14.4 \\
$\$ 75,000-99,999 / \mathrm{yr}$ & 11 & 12.2 \\
$\$ 100,000$ a year or more & 25 & 27.8 \\
Total & 84 & 93.3 \\
Missing & 6 & 6.7 \\
\hline
\end{tabular}

\section{BMI Characteristics}

Body mass index (BMI) percentile scores for age and gender were calculated for each child from the height and weight measurements obtained the day of their clinic visit. This calculation was then used to determine whether the child was normal weight, overweight, or obese. The majority of the children were normal weight $(60.0 \%, \mathrm{~N}=54)$, with $68.5 \%$ male $(\mathrm{N}=37)$ and $31.5 \%(\mathrm{~N}=17)$. The total percentage of overweight children for the sample was $21.1 \%(\mathrm{~N}=19)$, with the majority, $78.9 \%$ male $(\mathrm{N}=15)$ and only $21.1 \%$ female $(\mathrm{N}=4)$. The total percentage of obese children for the sample was $18.9 \%(\mathrm{~N}=17)$, with $58.8 \%$ male $(\mathrm{N}=10)$ and $41.2 \%$ female $(\mathrm{N}=7)$. Combined, a total of $36(40 \%)$ of the children were overweight or obese, with the majority male, $69.4 \%(\mathrm{~N}$ $=25)$ and $30.6 \%$ female $(\mathrm{N}=11)$. Gender and BMI characteristics are shown in Table 9. 
Table 9. Body Mass Index Characteristics for Children by Gender

\begin{tabular}{|c|c|c|}
\hline Child BMI & Frequency & Percent \\
\hline Normal Weight & 37 & \\
Male & 17 & 31.5 \\
Female & 54 & 60.0 \\
Total Sample & & \\
Overweight & 15 & 78.9 \\
Male & 4 & 21.1 \\
Female & 19 & 21.1 \\
Total Sample & & \\
Obese & 10 & 58.8 \\
Male & 7 & 41.2 \\
Female & 17 & 18.9 \\
Total Sample & & \\
Male & 25 & 69.4 \\
Female & 11 & 30.6 \\
Total Sample & 36 & 40.0 \\
\hline
\end{tabular}

From the sociodemographic questionnaire, BMI was calculated for each parent from the self-reported height and weight measurements. Eighty-one (90\%) height and weight measurements were reported for mothers and $58(64.4 \%)$ for fathers. Thirty-six (44.4\%) of the mothers were normal weight, 22 (27.2\%) were overweight, and 23 (28.4\%) were obese. Combined, the overweight and obese mothers represented $55.6 \%$ $(\mathrm{N}=45)$ of the reporting sample. The obese children had the highest percentage of obese mothers, $46.6 \%$ [7/15] compared to the overweight (29.4\%, [5/17]) and normal weight children $(22.4 \%$, [11/49]). Only $20.7 \%(\mathrm{~N}=12)$ of the fathers were normal weight. Thirty-one (53.4\%) of the fathers were overweight and $15(25.9 \%)$ were obese. Therefore, combined, the overweight and obese fathers represented the majority $(79.3 \%$, $\mathrm{N}=46$ ) of the reported sample. The obese children had the highest percentage of obese fathers $(55.6 \%,[5 / 9])$ compared to the overweight $(35.7 \%,[5 / 14])$ and normal weight children $(14.3 \%,[5 / 35])$. Overall, the obese children had the highest percentage of obese 
parents $(50 \%,[12 / 24])$ compared to the overweight $(32.3 \%,[10 / 31])$ and normal weight $(19.1 \%,[16 / 84])$ children. Table 10 shows the body mass index (BMI) characteristics for the children as well as parents and Table 11 shows the parental BMI values in relation to the child BMI values.

Table 10. Body Mass Index Characteristics for Children and Parents

\begin{tabular}{|l|c|c|}
\hline \multicolumn{1}{|c|}{ Child BMI } & Frequency & Percent \\
\hline Normal & 54 & 60.0 \\
Overweight & 19 & 21.1 \\
Obese & 17 & 18.9 \\
Overweight/Obese & 36 & 40.0 \\
Total & 90 & --- \\
\hline Mother BMI & & \\
\hline Normal & 36 & 44.4 \\
Overweight & 22 & 27.2 \\
Obese & 23 & 28.4 \\
Overweight/Obese & 45 & 55.6 \\
Missing & 9 & 10.0 \\
Total & 81 & --- \\
\hline Father BMI & & \\
\hline Normal & 12 & 20.7 \\
Overweight & 31 & 53.4 \\
Obese & 15 & 25.9 \\
Overweight/Obese & 46 & 79.3 \\
Missing & 32 & 35.6 \\
Total & 58 & --- \\
\hline
\end{tabular}


Table 11. Parental BMI in Relation to Child BMI Values

\begin{tabular}{|l|c|c|c|c|}
\hline \multirow{2}{*}{ Parental BMI Groups } & \multicolumn{4}{|c|}{ Child BMI Groups } \\
\cline { 2 - 5 } & Normal Weight & Overweight & Obese & Total \\
\hline \% BMI Mother & & & & \\
Normal & $24(49.0 \%)$ & $8(47.1 \%)$ & $4(26.7 \%)$ & $36(44.4 \%)$ \\
Overweight & $14(28.6 \%)$ & $4(23.5 \%)$ & $4(26.7 \%)$ & $22(27.2 \%)$ \\
Obese & $11(22.4 \%)$ & $5(29.4 \%)$ & $7(46.6 \%)$ & $23(28.4 \%)$ \\
Total & $49(100 \%)$ & $17(100 \%)$ & $15(100 \%)$ & $81(100 \%)$ \\
\hline \% BMI Father & & & & \\
Normal & $8(22.9 \%)$ & $3(21.4 \%)$ & $1(11.1 \%)$ & $12(20.7 \%)$ \\
Overweight & $22(62.8 \%)$ & $6(42.9 \%)$ & $3(33.3 \%)$ & $31(53.4 \%)$ \\
Obese & $5(14.3 \%)$ & $5(35.7 \%)$ & $5(55.6 \%)$ & $15(25.9 \%)$ \\
Total & $35(100 \%)$ & $14(100 \%)$ & $9(100 \%)$ & $58(100 \%)$ \\
\hline \% BMI Mother/Father & & & & \\
Normal & $32(38.0 \%)$ & $11(35.4 \%)$ & $5(20.8 \%)$ & $48(34.5 \%)$ \\
Overweight & $36(42.9 \%)$ & $10(32.3 \%)$ & $7(29.2 \%)$ & $53(38.2 \%)$ \\
Obese & $16(19.1 \%)$ & $10(32.3 \%)$ & $12(50.0 \%)$ & $38(27.3 \%)$ \\
Total & $84(100 \%)$ & $31(100 \%)$ & $24(100 \%)$ & $139(100 \%)$ \\
\hline
\end{tabular}

\section{Nutritional Characteristics}

Nutritional characteristics are shown in Table 12. The majority of the respondents reported that their child ate breakfast every morning $(87.8 \%, \mathrm{~N}=79)$. The obese children reported the highest percentage of consistent breakfast consumption $(94.1 \%,[16 / 17])$. Over half of the respondents reported eating together as a family at least 5 or more times a week $(67.8 \%, \mathrm{~N}=61)$. When divided into normal weight, overweight, and obese groups, children in the obese group had the highest percentage of family meals with $88.3 \%$ [15/17] reporting they ate together as a family at least 5 or more times a week compared to the overweight $(58 \%,[11 / 19])$ and normal weight $(64.8 \%$, [35/54]). In addition, $79.9 \%$ of the respondents reported eating fast food at least once a week or more $(\mathrm{N}=72)$. The obese group reported the lowest percentage of fast food 
consumption, with only $5.9 \%$ [1/17] reporting eating fast food 3 or more times a week.

Nutritional characteristics divided into normal weight, overweight, and obese groups are shown in Table 13 (Breakfast), Table 14 (Family Meals), and Table 15 (Fast Food).

Table 12. Nutritional Characteristics

\begin{tabular}{|c|c|c|}
\hline Breakfast & Frequency & Percent \\
\hline Yes, eats breakfast & 79 & 87.8 \\
No, skips breakfast & 11 & 12.2 \\
\hline Family Meals & & \\
\hline Once per week & 1 & 1.1 \\
Twice per week & 7 & 7.8 \\
Three times per week & 9 & 10.0 \\
Four times per week & 12 & 13.3 \\
Five times per week & 25 & 27.8 \\
Six times per week & 7 & 7.8 \\
Every day/ seven times & 29 & 32.2 \\
\hline Fast Food & & \\
\hline None & 18 & 20.0 \\
Once per week & 48 & 53.3 \\
Twice per week & 13 & 14.4 \\
Three times per week & 9 & 10.0 \\
Four times per week & 1 & 1.1 \\
Five times per week & 1 & 1.1 \\
Six times per week & 0 & 0.0 \\
Everyday/seven times & 0 & 0.0 \\
\hline
\end{tabular}

Table 13. Breakfast Characteristics for Normal/Overweight/Obese

\begin{tabular}{|l|c|c|c|}
\hline Breakfast & Frequency & Percent & Cumulative Percent \\
\hline Normal weight & & & \\
Yes, eats breakfast & 47 & 87.0 & 87.0 \\
No, skips breakfast & 7 & 13.0 & 100.0 \\
Total & 54 & 100.0 & --- \\
\hline Overweight & & & \\
Yes, eats breakfast & 16 & 84.2 & 84.2 \\
No, skips breakfast & 3 & 15.8 & 100.0 \\
Total & 19 & 100.0 & --- \\
\hline Obese & & & \\
Yes, eats breakfast & 16 & 94.1 & 94.1 \\
No, skips breakfast & 1 & 5.9 & 100.0 \\
Total & 17 & 100.0 & --- \\
\hline
\end{tabular}


Table 14. Family Meal Characteristics for Normal/Overweight/Obese

\begin{tabular}{|l|c|c|c|}
\hline Family Meals & Frequency & Percent & Cumulative Percent \\
\hline Normal weight & & & \\
Once per week & 0 & 0.0 & 0.0 \\
Twice per week & 3 & 5.6 & 5.6 \\
Three times per week & 7 & 13.0 & 18.5 \\
Four times per week & 9 & 16.7 & 35.2 \\
Five times per week & 12 & 22.2 & 57.4 \\
Six times per week & 5 & 9.3 & 66.7 \\
Every day/ seven times & 18 & 33.3 & 100.0 \\
Total & 54 & 100.0 & --- \\
& & & \\
\hline Overweight & & & \\
Once per week & 0 & 0.0 & 0.0 \\
Twice per week & 3 & 15.8 & 15.8 \\
Three times per week & 2 & 10.5 & 26.3 \\
Four times per week & 3 & 15.8 & 42.1 \\
Five times per week & 6 & 31.6 & 73.7 \\
Six times per week & 1 & 5.3 & 78.9 \\
Every day/ seven times & 4 & 21.1 & 100.0 \\
Total & 19 & 100.0 & --- \\
\hline Obese & & & \\
Once per week & 1 & 5.9 & 5.9 \\
Twice per week & 1 & 5.9 & 11.8 \\
Three times per week & 0 & 0.0 & 11.8 \\
Four times per week & 0 & 0.0 & 11.8 \\
Five times per week & 7 & 41.2 & 52.9 \\
Six times per week & 1 & 5.9 & 58.8 \\
Every day/ seven times & 7 & 41.2 & 100.0 \\
Total & 17 & 100.0 & --- \\
& & & \\
\hline
\end{tabular}


Table 15. Fast Food Characteristics for Normal/Overweight/Obese

\begin{tabular}{|l|c|c|c|}
\hline \multicolumn{1}{|c|}{ Fast Food } & Frequency & Percent & Cumulative Percent \\
\hline Normal weight & 11 & 20.4 & \\
Never/Zero & 29 & 53.7 & 20.4 \\
Once per week & 6 & 11.1 & 74.1 \\
Twice per week & 6 & 11.1 & 85.2 \\
Three times per week & 1 & 1.9 & 96.3 \\
Four times per week & 1 & 1.9 & 98.1 \\
Five times per week & 0 & 0.0 & 100.0 \\
Six times per week & 0 & 0.0 & --- \\
Every day/ seven times & 54 & 100.0 & --- \\
Total & & & --- \\
\hline Overweight & 2 & 10.5 & \\
Never/Zero & 10 & 52.6 & 10.5 \\
Once per week & 5 & 26.3 & 63.2 \\
Twice per week & 2 & 10.5 & 89.5 \\
Three times per week & 0 & 0.0 & 100.0 \\
Four times per week & 0 & 0.0 & --- \\
Five times per week & 0 & 0.0 & --- \\
Six times per week & 0 & 0.0 & --- \\
Every day/ seven times & 19 & 100.0 & --- \\
Total & & & --- \\
\hline Obese & 5 & 29.4 & \\
Never/Zero & 9 & 52.9 & 29.4 \\
Once per week & 2 & 11.8 & 82.4 \\
Twice per week & 1 & 5.9 & 94.1 \\
Three times per week & 0 & 0.0 & 100.0 \\
Four times per week & 0 & 0.0 & --- \\
Five times per week & 0 & 0.0 & --- \\
Six times per week & 0 & 0.0 & --- \\
Every day/ seven times & 0.0 & --- \\
Total & 17 & 100.0 & \\
\hline
\end{tabular}

\section{Asthma Severity}

Asthma severity can be classified into four levels; intermittent, mild persistent, moderate persistent and severe persistent. For this study only three classifications were examined; mild persistent, moderate persistent, and severe persistent. Among the children, $55.5 \%(\mathrm{~N}=50)$ were classified as having moderate or severe asthma. The obese group had the largest percentage of moderate and severe asthma $(76.4 \%,[13 / 17])$ 
compared to the overweight $(42.1 \%,[8 / 19])$ and normal weight groups $(53.7 \%,[29 / 54])$.

The obese children also demonstrated the highest percentage of the maximum level of asthma severity, severe persistent $(23.5 \%,[4 / 17])$ compared to the overweight $(5.3 \%$, [1/19]) and normal weight groups $(9.3 \%,[5 / 54])$. Further analysis was not statistically significant $\left(\chi^{2}=6.122, \mathrm{df}=4, \mathrm{p}=.190\right)$. Asthma classification characteristics are shown in Table 16 and asthma severity chi-square results in Table 17.

Table 16. Asthma Classification Characteristics

\begin{tabular}{|l|c|c|c|c|}
\hline Asthma Classification & Normal Weight & Overweight & Obese & Total \\
\hline $\begin{array}{l}\text { Mild Persistent } \\
\text { Count } \\
\text { Percentage }\end{array}$ & 25 & 11 & 4 & 40 \\
\hline $\begin{array}{l}\text { Moderate Persistent } \\
\text { Count } \\
\text { Percentage }\end{array}$ & $46.3 \%$ & $57.9 \%$ & $23.5 \%$ & $44.4 \%$ \\
\hline $\begin{array}{l}\text { Severe Persistent } \\
\text { Count } \\
\text { Percentage }\end{array}$ & 24 & 7 & 9 & 40 \\
\hline $\begin{array}{l}\text { Total } \\
\text { Count } \\
\text { Percentage }\end{array}$ & $54.4 \%$ & $36.8 \%$ & $52.9 \%$ & $44.4 \%$ \\
\hline
\end{tabular}

\section{$\underline{\text { Health Outcomes }}$}

\section{School Absences}

In the last 6 months prior to the time they were surveyed, the majority of the children did not miss school because of their asthma $(52.2 \%, \mathrm{~N}=47)$. However, $47.8 \%$ $(\mathrm{N}=43)$ did miss at least one day of school due to their asthma with $22.2 \%$ missing four days or more in the last 6 months. $53.7 \%(\mathrm{~N}=29)$ out of 54 normal weight children, $52.6 \%(\mathrm{~N}=10)$ out of the 19 overweight children, and $47.1 \%(\mathrm{~N}=8)$ out of the 17 obese children sampled missed no school due to their asthma. 
For all six of the health outcomes, an initial Pearson chi-square analysis was run to determine if there was a difference among the three weight categories; normal weight, overweight and obese. However, in performing the analysis the sample size was insufficient to meet the assumption of chi-square for three groups, as greater than $20 \%$ of cells had expected counts less than 5. Therefore, chi-square analysis was rerun using two groups; normal weight and a newly created combined category of overweight and obese. A chi-square analysis using these two groups; normal weight and overweight/obese, did not demonstrate significance on the variable of missed school days, $\chi^{2}(1)=.119, p=$ $.730, \mathrm{~N}=90$. Health outcomes and asthma severity chi-square analysis results are shown in Table 17 and descriptive characteristics for missed school days can be found in Table 18.

Table 17. Health Outcomes and Asthma Severity Chi-Square Results

\begin{tabular}{|l|c|c|c|}
\hline Pearson Chi-Square & Value & df & $\begin{array}{c}\text { Significance } \\
(2-\text {-sided })\end{array}$ \\
\hline Missed School Days & .119 & 1 & .730 \\
\hline ED Visits & 2.269 & 1 & .132 \\
\hline Hospitalizations & .082 & 1 & .774 \\
\hline Unscheduled Clinic Visits & .208 & 1 & .648 \\
\hline Days Wheezing & 1.302 & 2 & .522 \\
\hline Night Time Coughing & .342 & 2 & .843 \\
\hline Asthma Severity & 6.122 & 4 & .190 \\
\hline
\end{tabular}


Table 18. Missed School Characteristics

\begin{tabular}{|l|c|c|c|}
\hline & Frequency & Percent & Cumulative Percent \\
\hline Overall & & & \\
No school missed & 47 & 52.2 & 52.2 \\
1 to 3 days & 23 & 25.6 & 77.8 \\
4 to 6 days & 12 & 13.3 & 91.1 \\
7 days or more & 8 & 8.9 & 100.0 \\
Total & 90 & 100.0 & -- \\
\hline Normal Weight & & & \\
No school missed & 29 & 53.7 & 53.7 \\
1 to 3 days & 13 & 24.1 & 77.8 \\
4 to 6 days & 6 & 11.1 & 88.9 \\
7 days or more & 6 & 11.1 & 100.0 \\
Total & 54 & 100.0 & --- \\
\hline Overweight & & & \\
No school missed & 10 & 52.6 & 52.6 \\
1 to 3 days & 6 & 31.6 & 84.2 \\
4 to 6 days & 2 & 10.5 & 94.7 \\
7 days or more & 1 & 5.3 & 100.0 \\
Total & 19 & 100.0 & --- \\
\hline Obese & & & \\
No school missed & 8 & 47.1 & 47.1 \\
1 to 3 days & 4 & 23.5 & 70.6 \\
4 to 6 days & 4 & 23.5 & 94.1 \\
7 days or more & 1 & 5.9 & 100.0 \\
Total & 17 & 100.0 & --- \\
\hline
\end{tabular}

\section{Emergency Department Visits}

In the last 6 months prior to the time they were surveyed, the vast majority of the children, $80 \%(\mathrm{~N}=72)$ did not visit an emergency department (ED) for asthma symptoms. Only $15.6 \%(\mathrm{~N}=14)$ went to the $\mathrm{ED}$, once or twice for their asthma, and $4.4 \%(\mathrm{~N}=4)$ went three times or more to the ED due to their asthma symptoms.

However, when the number of ED visits are separated into normal weight, overweight, and obese groups, the obese group accounts for the highest percentage of ED visits, $41.2 \%$ [7/17], compared to the overweight $15.8 \%$ [3/19] and normal weight $14.9 \%$ 
[8/54]. Emergency department characteristics are shown in Table 19. A Pearson chisquare analysis of the normal weight and overweight/obese groups did not show significance, $\chi^{2}(1)=2.269, p=.132, \mathrm{~N}=90$. Using a Fisher's Exact test, there is a significant difference in ED visits between the normal weight and obese children, $p=$ .037 .

Table 19. Emergency Department Characteristics

\begin{tabular}{|l|c|c|c|}
\hline & Frequency & Percent & Cumulative Percent \\
\hline Overall & & & \\
None & 72 & 80.0 & 80.0 \\
1 to 2 times & 14 & 15.6 & 95.6 \\
3 or more times & 4 & 4.4 & 100.0 \\
Total & 90 & 100.0 & --- \\
\hline Normal Weight & & & \\
$\quad$ None & 46 & 85.2 & 85.2 \\
1 to 2 times & 5 & 9.3 & 94.4 \\
3 or more times & 3 & 5.6 & 100.0 \\
Total & 54 & 100.0 & --- \\
\hline Overweight & & & \\
None & 16 & 84.2 & 84.2 \\
1 to 2 times & 3 & 15.8 & 100.0 \\
3 or more times & 0 & 0.0 & --- \\
Total & 19 & 100.0 & --- \\
\hline Obese & & & \\
None & 10 & 58.8 & 58.8 \\
1 to 2 times & 6 & 35.3 & 94.1 \\
3 or more times & 1 & 5.9 & 100.0 \\
Total & 17 & 100.0 & --- \\
\hline
\end{tabular}

\section{Hospitalizations}

For the 6 months prior, the majority $(90 \%, \mathrm{~N}=81)$ of the children were not hospitalized due to their asthma symptoms. When divided into three groups, the obese children reported the highest percentage, $17.7 \%$ [3/17] of hospitalization rate compared to the overweight $(5.3 \%,[1 / 19])$, and normal weight $(9.3 \%,[5 / 54])$ groups.

Hospitalization characteristics are shown in Table 20. A Pearson chi-square analysis showed no significance among normal weight and overweight/obese on the variable of 
hospitalization, $\chi^{2}(1)=.082, p=.774, \mathrm{~N}=90$. A Fisher's Exact test also showed no significance, $p=.387$.

Table 20. Hospitalization Characteristics

\begin{tabular}{|l|c|c|c|}
\hline & Frequency & Percent & Cumulative Percent \\
\hline Overall & & & \\
None & 81 & 90.0 & 90.0 \\
1 to 2 times & 7 & 7.8 & 97.8 \\
3 or more times & 2 & 2.2 & 100.0 \\
Total & 90 & 100.0 & --- \\
\hline Normal Weight & & & \\
$\quad$ None & 49 & 90.7 & 90.7 \\
1 to 2 times & 4 & 7.4 & 98.1 \\
3 or more times & 1 & 1.9 & 100.0 \\
Total & 54 & 100.0 & --- \\
\hline Overweight & & & \\
None & 18 & 94.7 & 94.7 \\
1 to 2 times & 1 & 5.3 & 100.0 \\
3 or more times & 0 & 0.0 & --- \\
Total & 19 & 100.0 & --- \\
\hline Obese & & & \\
None & 14 & 82.4 & 82.4 \\
1 to 2 times & 2 & 11.8 & 94.1 \\
3 or more times & 1 & 5.9 & 100.0 \\
Total & 17 & 100.0 & --- \\
\hline
\end{tabular}

\section{Unscheduled Doctor/Clinic Visits}

For the 6 months prior to their scheduled clinic visit, $66.7 \%(\mathrm{~N}=60)$ of the children surveyed did not have an unscheduled doctor or clinic visit due to their asthma symptoms. The number of children, who had at least one or more unscheduled visits for asthma symptoms, were evenly distributed between the three groups; normal weight $35.2 \%$ [19/54], overweight 26.4\% [5/19], and obese 35.3\% [6/17]. Unscheduled doctor/clinic visit characteristics are shown in Table 21. A Pearson chi-square analysis 
demonstrated no statistically significant difference on the unscheduled doctor/clinic visits between groups, $\chi^{2}(1)=.208, p=.648, \mathrm{~N}=90$.

Table 21. Unscheduled Doctor/Clinic Visit Characteristics

\begin{tabular}{|l|c|c|c|}
\hline & Frequency & Percent & Cumulative Percent \\
\hline Overall & & & \\
None & 60 & 66.7 & 66.7 \\
1 to 2 times & 22 & 24.4 & 91.1 \\
3 or more times & 8 & 8.9 & 100.0 \\
Total & 90 & 100.0 & --- \\
\hline Normal Weight & & & \\
$\quad$ None & 35 & 64.8 & 64.8 \\
1 to 2 times & 14 & 25.9 & 90.7 \\
3 or more times & 5 & 9.3 & 100.0 \\
Total & 54 & 100.0 & --- \\
\hline Overweight & & & \\
None & 14 & 73.7 & 73.7 \\
1 to 2 times & 4 & 21.1 & 94.7 \\
3 or more times & 1 & 5.3 & 100.0 \\
Total & 19 & 100.0 & --- \\
\hline Obese & & & \\
None & 11 & 64.7 & 64.7 \\
1 to 2 times & 4 & 23.5 & 88.2 \\
3 or more times & 2 & 11.8 & 100.0 \\
Total & 17 & 100.0 & --- \\
\hline
\end{tabular}

\section{Days Wheezing}

In the two weeks prior to their clinic visit, $36.6 \%(\mathrm{~N}=33)$ of the children reported wheezing at least one day or more. The obese children reported a higher percentage of days wheezing, 47.1\% [8/17], compared to the overweight $(21 \%,[4 / 19])$ and normal weight $(38.9 \%,[21 / 54])$. However, this difference in frequency of days wheezing was not statistically significant, $\chi^{2}(2)=1.302, p=.522, \mathrm{~N}=90$. Days wheezing characteristics are shown in Table 22. 
Table 22. Days Wheezing Characteristics

\begin{tabular}{|l|c|c|c|}
\hline & Frequency & Percent & Cumulative Percent \\
\hline Overall & & & \\
None & 57 & 63.3 & 63.3 \\
1 to 2 days & 21 & 23.3 & 86.7 \\
3 to 5 days & 10 & 11.1 & 97.8 \\
6 days or more & 2 & 2.2 & 100.0 \\
Total & 90 & 100.0 & --- \\
\hline Normal Weight & & & \\
None & 33 & 61.1 & 61.1 \\
1 to 2 days & 12 & 22.2 & 83.3 \\
3 to 5 days & 7 & 13.0 & 96.3 \\
6 days or more & 2 & 3.7 & 100.0 \\
Total & 54 & 100.0 & --- \\
\hline Overweight & & & \\
None & 15 & 78.9 & 78.9 \\
1 to 2 days & 2 & 10.5 & 89.5 \\
3 to 5 days & 2 & 10.5 & 100.0 \\
6 days or more & 0 & 0.0 & --- \\
Total & 19 & 100.0 & --- \\
\hline Obese & & & \\
None & 9 & 52.9 & 52.9 \\
1 to 2 days & 7 & 41.2 & 94.1 \\
3 to 5 days & 1 & 5.9 & 100.0 \\
6 days or more & 0 & 0.0 & --- \\
Total & 17 & 100.0 & --- \\
\hline
\end{tabular}

\section{Woke Up Coughing at Night}

In the two weeks prior to their clinic visit, the majority $(68.9 \%, \mathrm{~N}=62)$ of the children reported no episodes of night waking from coughing due to their asthma.

Among the normal weight $(33.4 \%,[18 / 54])$, overweight $(26.4 \%,[5 / 19])$, and obese $(29.4 \%,[5 / 17])$ groups the number of children reporting at least one nighttime episode of coughing over the last two weeks was evenly distributed. Woke up coughing characteristics are shown in Table 23. Chi-square analysis showed no statistical significant association between weight and episodes of night waking, $\chi^{2}(2)=.342, p=$ $.843, \mathrm{~N}=90$. 
Table 23. Woke Up Coughing Characteristics

\begin{tabular}{|l|c|c|c|}
\hline & Frequency & Percent & Cumulative Percent \\
\hline Overall & & & \\
None & 62 & 68.9 & 68.9 \\
1 to 2 nights & 19 & 21.1 & 90.0 \\
3 to 5 nights & 5 & 5.6 & 95.6 \\
6 nights or more & 4 & 4.4 & 100.0 \\
Total & 90 & 100.0 & --- \\
\hline Normal Weight & & & \\
None & 36 & 66.7 & 66.7 \\
1 to 2 nights & 12 & 22.2 & 88.9 \\
3 to 5 nights & 3 & 5.6 & 94.4 \\
6 nights or more & 3 & 5.6 & 100.0 \\
Total & 54 & 100.0 & --- \\
\hline Overweight & & & \\
None & 14 & 73.7 & 73.7 \\
1 to 2 nights & 4 & 21.1 & 94.7 \\
3 to 5 nights & 1 & 5.3 & 100.0 \\
6 nights or more & 0 & 0.0 & --- \\
Total & 19 & 100.0 & --- \\
\hline Obese & & & \\
None & 12 & 70.6 & 70.6 \\
1 to 2 nights & 3 & 17.6 & 88.2 \\
3 to 5 nights & 1 & 5.9 & 94.1 \\
6 nights or more & 1 & 5.9 & 100.0 \\
Total & 17 & 100.0 & --- \\
\hline
\end{tabular}

\section{Quality of Life}

Quality of life was measured using the Pediatric Asthma Quality of Life

Questionnaire (PAQLQ). The PAQLQ is a 23-item, 7-point Likert scale covering three domains; symptoms, emotional function, and activity limitation. The 7-point response scale ranges from $1=$ extremely bothered/all of the time to $7=$ not bothered/none of the time, the lower the score the greater the level of impairment. Each item is equally weighted. The results were calculated as the mean score for each domain as well as the overall quality of life, which was calculated as the mean score for all the items.

The PAQLQ symptom domain consists of 10 items which include shortness of breath, wheeze, cough, tightness of chest, and tiredness. Possible total scores on the 
symptom domain range from 10 (lowest) to 70 (highest). Actual symptom domain total scores reported for this study ranged from 17 to $70(\mathrm{M}=57.59, \mathrm{SD}=12.90, \mathrm{~N}=90)$. The symptom domain mean scores ranged from 1.7 to $7.0(\mathrm{M}=5.76, \mathrm{SD}=1.29, \mathrm{~N}=90)$. For the normal weight group the symptom domain mean score was $5.774(\mathrm{SD}=1.30, \mathrm{~N}=$ $54)$, for the overweight group 5.621 ( $\mathrm{SD}=1.46, \mathrm{~N}=19)$, and for the obese group 5.865 $(\mathrm{SD}=1.10, \mathrm{~N}=17)$. A one-way analysis of variance (ANOVA) was calculated on the children's symptom mean scores on the PAQLQ. The analysis was not significant, F (2, $87)=.166, p=.847$

The PAQLQ emotional function domain consists of 8 items which include frustration, fear, anxiety, anger and feeling different and left out. Possible total scores on the emotional function domain range from 8 (lowest) to 56 (highest). The emotional function domain total scores reported for this study ranged from 12 to $56(\mathrm{M}=48.26$, SD $=10.99, \mathrm{~N}=90)$. The emotional function domain mean scores ranged from 1.5 to $7(\mathrm{M}=$ $6.03, \mathrm{SD}=1.37, \mathrm{~N}=90$ ). For the normal weight group the emotional function domain mean score was $6.04(\mathrm{SD}=1.39, \mathrm{~N}=54)$, for the overweight group $5.96(\mathrm{SD}=1.43, \mathrm{~N}=$ $19)$, and for the obese group $6.05(\mathrm{SD}=1.30, \mathrm{~N}=17)$. A one-way analysis of variance (ANOVA) was calculated on the children's emotional function mean scores on the PAQLQ. The analysis was not significant, $F(2,87)=.026, \mathrm{p}=.974$.

The PAQLQ activity limitation domain consists of 5 items which include physical, social, school, and sleeping. Possible total scores on the activity limitation domain range from 5 (lowest) to 35 (highest). The activity limitation domain total scores reported for this study ranged from 5 to $35(\mathrm{M}=28.91, \mathrm{SD}=6.38, \mathrm{~N}=90)$. The activity 
limitation domain mean scores ranged from 1 to $7(\mathrm{M}=5.78, \mathrm{SD}=1.28, \mathrm{~N}=90)$. For the normal weight group the activity limitation domain mean score was $5.793(\mathrm{SD}=1.35$, $\mathrm{N}=54)$, for the overweight group the mean score was $5.85(\mathrm{SD}=1.16, \mathrm{~N}=19)$, and for the obese group the mean score was $5.67(\mathrm{SD}=1.18, \mathrm{~N}=17)$. A one-way analysis of variance (ANOVA) was calculated on the children's activity limitation mean scores on the PAQLQ. The analysis was not significant, $\mathrm{F}(2,87)=.094, \mathrm{p}=.911$.

The scores from the three domains were added together in order to calculate an overall quality of life (QOL) score for the PAQLQ. Possible overall QOL scores range from 23 (lowest) to 161 (highest). The overall QOL scores for this study ranged from 34 to $161(\mathrm{M}=134.76, \mathrm{SD}=28.89, \mathrm{~N}=90)$. The overall QOL mean scores ranged from 1.47 to $7.0(\mathrm{M}=5.86, \mathrm{SD}=1.26, \mathrm{~N}=90)$. For the normal weight group the reported overall QOL mean score was $5.87(\mathrm{SD}=1.27, \mathrm{~N}=54)$, for the overweight group the overall QOL mean score was $5.79(\mathrm{SD}=1.34, \mathrm{~N}=19)$ and for the obese group the overall QOL mean score was $5.88(\mathrm{SD}=1.14, \mathrm{~N}=17)$. A one-way analysis of variance (ANOVA) was calculated on the children's overall response mean scores to the QOL questions. The analysis was not significant, $\mathrm{F}(2,87)=.034, \mathrm{p}=.966$.

Individual questions for the PAQLQ were also examined using a non-parametric Kruskal-Wallis test. Only one question, question number 3, approached statistically significant individual analysis results. Question 3 is part of the activity limitation domain, and asks the child how bothered they have been over the last week doing "activities with friends and family". On question number 3, the mean score for the normal weight group was $6.11(\mathrm{SD}=1.525, \mathrm{~N}=54)$, while this score increased slightly 
for the overweight group $6.16(\mathrm{SD}=1.068, \mathrm{~N}=19)$ and decreased in the obese group $5.47(\mathrm{SD}=1.463, \mathrm{~N}=17)$. Although the Kruskal-Wallis test was not statistically significant for the activity limitation domain, the analysis for question 3 approached statistical significance $(\mathrm{H}=5.857, \mathrm{df}=2, \mathrm{p}=.053)$.

A regression analysis comparing the normal weight and obese groups was performed to examine whether child size (BMI) and child asthma severity classification could be used to predict overall QOL using the QOL scores from the PAQLQ. The results indicated that asthma severity was a significant predictor of overall QOL ( $\beta=$ 23.737, $\mathrm{p}=.002)$. Neither child size $(\beta=7.160, \mathrm{p}=.619)$ nor the interaction between child size and asthma severity $(\beta=-1.879, \mathrm{p}=.912)$ were significant predictors of overall QOL. Regression analysis results are shown in Table 24.

Table 24. Regression Analysis Results for Normal Weight and Obese Groups

\begin{tabular}{|l|c|c|c|c|c|}
\hline & \multicolumn{2}{|l|}{ Unstandardized Coefficients } & $\begin{array}{c}\text { Standardized } \\
\text { Coefficients }\end{array}$ & \multicolumn{2}{|l|}{} \\
\hline Model & B & Std. Error & Beta & $\mathrm{t}$ & Sig. \\
& & & & & .108 \\
\%BMI child Normal or Obese & 7.160 & 14.319 & .500 & .619 \\
Asthma Severity & -23.737 & 7.257 & -.412 & -3.271 & .002 \\
Size and Asthma Severity & -1.879 & 16.847 & -.026 & -.112 & .912 \\
\hline
\end{tabular}

\section{$\underline{\text { Spirometry Values }}$}

Spirometry is one of the most important tests of lung function in asthma (Spahn et al., 2008). Measurement of pulmonary function was obtained using a KoKo spirometer (Pulmonary Data Service; Louisville, CO). The KoKo spirometry values were calculated 
based on height, weight, race/ethnicity, age and gender (R. Story, personal communication, September 17, 2009). Six elements of the spirometry testing results were examined: FVC, FEV1, FEV1/FVC, FEF 25-75\%, PEFR. All values were measured in liters and reported as the best or highest value obtained after three measurement attempts as per clinic procedure.

\section{FVC Values}

The first element examined was forced vital capacity (FVC). The FVC is the volume of air, after a full inspiration, which can be forcibly and maximally exhaled out of the lungs until no more can be expired (Arnall, 1999). The overall mean FVC value was $\mathrm{M}=2.79(\mathrm{SD}=0.82, \mathrm{~N}=90) . \quad \mathrm{FVC}$ means among the three groups demonstrated similar values; normal weight $\mathrm{M}=2.70(\mathrm{SD}=.786, \mathrm{~N}=54)$, overweight $\mathrm{M}=2.80(\mathrm{SD}=.927, \mathrm{~N}$ $=19)$, and obese $\mathrm{M}=3.03(\mathrm{SD}=.773, \mathrm{~N}=17)$. Nonparametric testing using a KruskalWallis one-way anlysis of variance was not statistically significant $(\mathrm{H}=2.912, \mathrm{df}=2, \mathrm{p}=$ $.233)$.

The FVC percent (FVC\%) of predicted value was also examined. The percentage of predicted FVC is calculated from the predicted FVC value and the FVC value obtained during testing. A $\mathrm{FVC} \%$ value less than $80 \%$ of the predicted volume is a sign of restriction. The $\mathrm{FVC} \%$ predicted values ranged from $78 \%$ to $140 \%(\mathrm{M}=101.12 \%, \mathrm{SD}=$ $12.48, \mathrm{~N}=90$ ). The mean values of the $\mathrm{FVC} \%$ predicted values were all greater than $80 \%$ for all three groups; normal weight $\mathrm{M}=99.80 \%(\mathrm{SD}=12.439, \mathrm{~N}=54)$, overweight $M=99.89 \%(S D=11.180, N=19)$, and obese $M=106.71 \%(S D=13.109, N=17) . A$ Kruskal-Wallis analysis was not statistically significant $(\mathrm{H}=3.652, \mathrm{df}=2, \mathrm{p}=.161)$. 
FEV1 Values

The forced expiratory volume in 1 second (FEV1) is the maximum volume of air which can be forcibly exhaled in the first second during the FVC maneuver (Arnall, 1999). The FEV1 is the gold standard measure for diseases characterized by airflow restriction such as asthma (Spahn et al., 2008). FEV1 primarily measures airflow through the mid- to large sized airways (Spahn et al., 2008). The overall mean value for FEV1 was $\mathrm{M}=2.32(\mathrm{SD}=0.71, \mathrm{~N}=90)$. Among the three groups the mean FEV1 values were similar; normal weight $\mathrm{M}=2.25(\mathrm{SD}=.6746, \mathrm{~N}=54)$, overweight $\mathrm{M}=2.30(\mathrm{SD}=.837$, $\mathrm{N}=19)$, and obese $\mathrm{M}=2.56(\mathrm{SD}=.654, \mathrm{~N}=17)$. A Kruskal-Wallis analysis was not statistically significant $(\mathrm{H}=3.576, \mathrm{df}=2, \mathrm{p}=.167)$.

The FEV1 percentage (FEV1\%) of predicted is calculated from the FEV1 predicted value and the actual FEV1 value obtained during the FVC maneuver. According to the National Heart Lung and Blood Institute asthma guidelines, children with FEV1 values of more than $80 \%$ of predicted have mild asthma, those with FEV1 values between $60 \%$ to $80 \%$ have moderate persistent asthma, and those with values less than $60 \%$ of predicted have severe persistent asthma (National Asthma Education and Prevention Program, 2007; Spahn et al., 2008). However, children with asthma often have normal FEV1 values when they are well, therefore a normal FEV1 value does not rule out asthma (Spahn et al., 2008). The overall FEV1\% of predicted mean results for the study sample was $91.02 \%(\mathrm{SD}=13.15, \mathrm{~N}=90)$. The mean $\mathrm{FEV} 1 \%$ predicted value was highest for the obese group, $96.53 \%(\mathrm{SD}=12.860, \mathrm{~N}=17)$ compared to the overweight $(\mathrm{M}=88.58 \%, \mathrm{SD}=13.773, \mathrm{~N}=19)$ and normal weight $(\mathrm{M}=90.15 \%, \mathrm{SD}=$ 
$12.779, \mathrm{~N}=19$ ) groups. However, Kruskal-Wallis analysis was not statistically significant $(\mathrm{H}=3.049, \mathrm{df}=2, \mathrm{p}=1.67)$.

FEV1/FVC Values

The FEV1/FVC ratio is the amount of air exhaled in the first second (FEV1) divided by the total amount of air exhaled during a maximal forced exhalation (FVC) (Spahn et al., 2008). Studies have shown the FEV1/FVC ratio to be a more sensitive measure of asthma severity and lung function than the FEV1 (Bacharier et al., 2004; Spahn et al., 2008). The overall mean FEV1/FVC ratio value was $\mathrm{M}=0.83(\mathrm{SD}=.08, \mathrm{~N}$ =90). The FEV1/FVC ratios for all three groups showed similar mean values; normal weight $\mathrm{M}=.837(\mathrm{SD}=.081, \mathrm{~N}=54)$, overweight $\mathrm{M}=.817(\mathrm{SD}=.083, \mathrm{~N}=19)$, and obese $\mathrm{M}=.844(\mathrm{SD}=.053, \mathrm{~N}=17)$. Kruskal-Wallis analysis was not statistically significant $(\mathrm{H}=1.621, \mathrm{df}=2, \mathrm{p}=.445)$.

The FEV1/FVC percent of predicted value is calculated from the FEV1/FVC predicted value and the actual FEV1/FVC value obtained and indicates what percentage of the total FVC was expelled from the lungs during the first second of forced exhalation (Arnall, 1999). A normal FEV1/FVC ratio percentage in children is $86 \%$, with values below $80 \%$ indicative of airflow restriction (Spahn et al., 2008). The overall mean value for FEV1/FVC percent of predicted was $94.89 \%(\mathrm{SD}=10.04, \mathrm{~N}=90)$. All three groups had similar FEV1/FVC percent of predicted mean values; normal weight $95.81 \%$ (SD = $10.161, \mathrm{~N}=54)$, overweight $92.89 \%(\mathrm{SD}=11.396, \mathrm{~N}=19)$, and obese $94.18 \%(\mathrm{SD}=$ 8.041, $\mathrm{N}=17)$. Kruskal-Wallis analysis was not statistically significant $(\mathrm{H}=1.015, \mathrm{df}=$ $2, p=.602)$ 
FEF $25-75 \%$ Values

The Forced Expiratory Flow (FEF) is the measure of how much air can be expired from the lungs and is divided into quartiles expressed as FEF $25 \%$, FEF 50\%, and FEF75\% of forced vital capacity (FVC) (Arnall, 1999). The forced expiratory flow between $25 \%$ and $75 \%$ (FEF $25-75 \%$ ) measures airflow in the middle half of the forced vital capacity (Arnall, 1999; Spahn et al., 2008). FEF25-75\% is effort independent and considered to be an accurate indicator of peripheral airway obstruction (Spahn et al., 2008). In pediatric asthma, the FEF $25-75 \%$ is one of the first parameters to be abnormal and is often the most significantly impaired of all the spirometric measures (Spahn et al., 2008).

The overall FEF $25-75 \%$ mean value for the study sample was $\mathrm{M}=2.41$ (SD = $.094, \mathrm{~N}=90$ ). The FEF $25-75 \%$ mean values calculated for the normal weight group were $\mathrm{M}=2.324(\mathrm{SD}=.859, \mathrm{~N}=54)$, for the overweight group $\mathrm{M}=2.320(\mathrm{SD}=1.177$, $\mathrm{N}=19)$, and for the obese group $\mathrm{M}=2.796(\mathrm{SD}=.877, \mathrm{~N}=17)$. Further analysis using a Kruskal-Wallis test showed no significant results $(\mathrm{H}=4.083$, $\mathrm{df}=2, \mathrm{p}=.130)$.

The FEF $25-75 \%$ percentage of predicted values were generated from the FEF 25$75 \%$ predicted values compared to the actual FEF $25-75 \%$ values obtained. The overall mean FEF $25-75 \%$ percentage of predicted value for the study sample was $77.50 \%$ (SD = $23.96, \mathrm{~N}=90$ ). For the three groups, the overweight children had the lowest percentage of predicted FEF $25-75 \%$ value at $72.68 \%(\mathrm{SD}=27.635, \mathrm{~N}=19)$ compared to the normal weight $(76.56 \%, \mathrm{SD}=22.673, \mathrm{~N}=54)$ and obese $(85.88 \%, \mathrm{SD}=22.913, \mathrm{~N}=17)$ groups. However, a Kruskal-Wallis test was not significant $(\mathrm{H}=2.687, \mathrm{df}=2, \mathrm{p}=.261)$. 
PEFR

The peak expiratory flow rate (PEFR) is the maximum flow rate achieved during the forced vital capacity (FVC) maneuver, beginning after full inspiration and starting and ending with maximal forced expiration (Arnall, 1999). PEFR measures the peak or maximum flow of expired air therefore it is a sensitive test for the presence of obstructive diseases like bronchoconstriction due to asthma (Arnall, 1999).

The overall PEFR mean value for the study sample was $\mathrm{M}=5.22(\mathrm{SD}=1.35, \mathrm{~N}=$ 89). One PEFR value was missing from the study sample. All three groups had similar PEFR values. The PEFR mean value calculated for the normal weight group was $\mathrm{M}=$ $5.052(\mathrm{SD}=1.22, \mathrm{~N}=53)$, for the overweight group $\mathrm{M}=5.402(\mathrm{SD}=1.77, \mathrm{~N}=19)$, and for the obese group $\mathrm{M}=5.527(\mathrm{SD}=1.14, \mathrm{~N}=17)$. Kruskal-Wallis analysis was not statistically significant $(\mathrm{H}=2.107, \mathrm{df}=2, \mathrm{p}=.349)$.

The PEFR percent of predicted value is calculated from the PEFR predicted value and the actual PEFR value achieved by the subject. The overall PEFR percent of predicted value was $86.99 \%(\mathrm{SD}=14.57, \mathrm{~N}=89)$. All three groups demonstrated similar PEFR percent of predicted values; normal weight $86.36 \%(\mathrm{SD}=12.724, \mathrm{~N}=53)$, overweight $88.26 \%(\mathrm{SD}=18.627, \mathrm{~N}=19)$, and obese $87.53 \%(\mathrm{SD}=15.717, \mathrm{~N}=17)$. Kruskal-Wallis analysis was not statistically significant $(\mathrm{H}=.254, \mathrm{df}=2, \mathrm{p}=.881)$. 
$\underline{\text { Summary of Study Results }}$

1. The children in the obese group had the highest percentage of obese mothers (46.6\%) and obese fathers (55.6\%) compared to the overweight and normal weight children.

2. The children in the obese group had the highest percentage of family meals per week $(88.3 \%)$, lowest percentage of fast food consumption $(5.9 \%)$ per week, and highest percentage of not skipping breakfast (94.1\%).

3. The children in the obese group had the highest percentage of ED visits $(41.2 \%)$. Using a Fisher's Exact test a statistically significant difference in ED visits between the normal weight and obese children was found $(p=.037)$.

4. The children in the obese group had the highest percentage of hospitalizations in the last 6 months (17.7\%) and highest percentage of days wheezing in the last two weeks $(47.1 \%)$ compared to the overweight and normal weight children $(\mathrm{p}=$ $.774)$.

5. There was no statistical significant difference in overall and domain score values for the PAQLQ among the normal weight, overweight, and obese groups.

6. The children in the obese group had the lowest mean value for question number 3 on the activity limitation domain of the PAQLQ $(p=.053)$.

7. Asthma severity was the best predictor of QOL based on the PAQLQ.

8. FEV1\% of predicated percentage was highest for the children in the obese group (96.53\%) compared to the normal and overweight children. 


\section{CHAPTER V \\ DISCUSSION}

The increasing trend in childhood obesity has made children with chronic illnesses, such as asthma, more vulnerable to additional health problems. The primary purpose of this study was to examine the differences in quality of life (QOL) and health outcomes in normal weight and overweight children with asthma. QOL was measured using the pediatric asthma quality of life questionnaire (PAQLQ). A sociodemographic questionnaire was used to determine nutritional characteristics of the sample and included questions regarding specific health outcomes: missed number of school days, emergency department visits, hospitalizations, unscheduled doctor/clinic visits, number of days wheezing, and night waking due to coughing. Additionally, lung function was assessed using spirometric measurement.

\section{Nutritional Characteristics}

The obese children in this study had the highest percentage of obese parents (50\%) compared to the overweight (32.3\%) and normal weight (19.1\%) children. These findings support the idea of a cyclical relationship between adult obesity and childhood obesity. If one parent is obese, a child has a $40 \%$ chance of being overweight and if both parents are obese this risk jumps to $80 \%$ (Hagarty et al., 2004). This cyclical relationship is thought to be due to a complex interplay between shared genes and environmental factors within families. 
These environmental factors are reflected in the sociodemographic questionnaire used for this study. The questionnaire contained items regarding eating practices which included breakfast frequency, family meals, and fast food consumption. An overwhelming majority of the children ate breakfast every day $(87.8 \%)$, with the obese children reporting the highest percentage of consistent breakfast consumption $(94.1 \%)$ compared to the overweight $(84.2 \%)$ and normal weight groups $(87.0 \%)$. Breakfast is considered the most important meal of the day, and can directly influence caloric consumption throughout the day (Farshchi, Taylor, \& Macdonald, 2005). Children who skip breakfast have been shown to have higher overall daily caloric intakes, higher BMI values, and lower levels of physical activity (Keski-Rahkonen, Kaprio, Rissanen, Virkkunen, \& Rose, 2003; Rampersaud et al., 2005). Although other studies have shown that overweight and obese children are more likely to skip breakfast (Dwyer et al., 2001; Keski-Rahkonen et al., 2003), that finding was not supported by this study.

Over half of the study sample reported having family meals together at least 5 or more times per week (67.8\%). Once again, the obese group of children recorded the highest percentage of family meals $(88.3 \%)$. This finding, along with the higher percentage of breakfast consumption in the obese group, is consistent with a study by Woodruff \& Hanning (2009) of 3223 school-age children, which found higher family dinner frequency was significantly associated with less soft drink consumption and eating breakfast.

The majority of the children reported consuming fast food at least once a week or more $(79.9 \%)$. However, the obese children had the lowest percentage of overall fast 
food consumption with only one obese child reporting eating fast food 3 or more times per week. The consumption of fast food has repeatedly been shown to adversely affect weight, leading to obesity and other health issues such as high cholesterol and hypertension (Paeratakul et al., 2003; Pereira et al., 2005). Conspicuously, in this study sample, fast food consumption was shown not to be as pronounced of a nutritional concern in the obese group.

Although further analysis found the differences in nutritional characteristics between the normal weight, overweight, and obese groups not statistically significant, the results do demonstrate a positive trend between breakfast consumption, higher family dinner frequency and lower fast food consumption. However, these positive nutritional trends were seen in the obese group.

A number of possibilities exist that could produce this combination of healthy habits with the negative outcome of obesity. One reason for this unpredicted relationship could be the quality and quantity of the foods the children consumed for breakfast and at family meals. If the families used unhealthy cooking methods such as frying instead of baking, made unhealthy food choices such as waffles for breakfast instead of wheat toast, or ate more than the recommended serving size portions, these unhealthy habits would negate the supposed positive benefits of having family meals, eating breakfast regularly, and consuming lower levels of fast food.

Another possible explanation for the higher percentage of family meals and breakfast consumption along with the lower fast food consumption seen in the obese group, is that the parental respondents who answered the nutrition questions were 
overweight and may have wanted the researcher to think more positively of them in regards to their nutrition and therefore exaggerated their healthy eating habits. This possibility is supported by the fact that the obese group did have the highest percentage of obese parents. A recent on-line survey of 1,500 people found that $32 \%$ of the respondents reported lying to their doctor about diet and exercise habits in order to be seen as a "good" patient (Ravn, 2009).

Finally, a third possibility for the nutritional characteristic findings for the obese group is that they are an anomaly within the general population categorized as obese. The study subjects were obtained through convenience sampling which opens the study up to the possibility that the obese group had nutritional characteristics that are not within the norms for obese children. Studies with larger sample sizes $(\mathrm{N}>1,000)$ examining breakfast practices have found that overweight and obese children are more likely to skip breakfast than their normal weight peers (Dwyer et al., 2001; Pastore, Fisher, \& Friedman, 1996; Rampersaud et al., 2005). In addition, studies have found family meals to be associated with healthy nutritional practices such as higher fruit and vegetable consumption and less soft drink consumption, which should translate to normal BMI values (Krebs \& Jacobson, 2003).

Although the three possibilities above could explain the healthy nutritional practice results seen in the obese group, one further possibility does still exist, which is that breakfast consumption, fast food and family meals do not impact weight as strongly as believed. This rational is not only supported by the nutritional results seen in this study but by other studies as well. A 5-year longitudinal study of 2,516 adolescents 
found that eating family meals during high school did not protect against overweight (Fulkerson, Neumark-Sztainer, Hannan, \& Story, 2008). In addition, although some studies have found lower BMI values in children who regularly consume breakfast (Dwyer et al., 2001; Keski-Rahkonen et al., 2003), other studies have found no effect of breakfast consumption on body weight (Rampersaud et al., 2005; Sampson, Dixit, Meyers, \& Houser, 1995).

The results of this study found a higher frequency of family meals, higher percentage of daily breakfast consumption, and lower frequency of fast food intake in the obese children with asthma. Although these findings were not statically significant, they do show a clinical trend. The contradictory healthy eating behaviors seen in the obese group suggest that a complex relationship exists between body weight and nutritional practices.

\section{Asthma Severity}

Asthma is classified according to severity of symptoms. Three classifications were examined in this study: mild persistent, moderate persistent, and severe persistent. As expected, the obese children demonstrated the highest levels of asthma severity with $76.4 \%$ of the obese children having moderate or severe asthma classifications compared to the children classified as overweight (42.1\%) and normal weight (53.7\%).

Additionally, $23.5 \%$ of the obese children were ranked as having the highest level of asthma classification, severe persistent. Among the overweight children, only $5.3 \%$ had severe persistent asthma, and only $9.3 \%$ of the normal weight children had the highest possible severity level. Due to the small sample size $(\mathrm{N}=90)$, these findings did not 
reach statistical significance $(p=.190)$; however, they are remarkable in that they demonstrate a trend of comorbidity between asthma and obesity.

These results are consistent with other large-scale studies which have demonstrated that obese individuals are at higher risk of developing severe asthma symptoms (Akerman et al., 2004; Ford \& Mannino, 2005; Luder et al., 1998). This relationship between obesity and asthma severity has been found in both children and adults. A retrospective study, involving adults age $18-88$, found the prevalence of obesity increased along with increasing asthma severity $(\mathrm{r}=0.40, \mathrm{p}<0.0001)$ (Akerman et al., 2004). In a study examining children ages 2 to 18 years, the researchers found that the prevalence of overweight was higher in children with moderate to severe asthma compared to the non-asthma control group $(p=0.03)$. These findings suggest that obesity may be a potentially modifiable risk factor for asthma (Akerman et al., 2004).

Various explanations have been suggested for the link between asthma and obesity. One theory for this relationship is mechanical. Excess mass and adipose deposits over the chest and abdomen cause decrease movement in the chest wall and diaphragm which leads to increased chest wall stiffness, less flexibility in the lungs, and smaller total lung volumes (Nixon \& Honsinger, 2007). This makes it more difficult to breath in full breaths of air. Along with inhalation issues, chest wall stiffness and decreased lung flexibility also lead to more resistance in exhaling air as well (Nixon \& Honsinger, 2007).

Another possible explanation is related to endocrine function. Adipose tissue has recently been found not to be inert, as previously assumed, but an active endocrine organ, 
which produces and releases a variety of pro-inflammatory and anti-inflammatory mediators, including adipokines leptin, adiponectin, and resistin, as well as cytokines and chemokines, such as tumor necrosis factor- alpha (TNF- $\alpha$ ), interleukin 6 (IL-6), and monocyte chemoattractant protein 1 (Fantuzzi, 2005; Nixon \& Honsinger, 2007). In addition, eotaxin, a CC chemokine, which is produced during the late phase reaction in asthma, has shown to be significantly higher in obese mice and humans (Vasudevan et al., 2006). Many of these inflammatory mediators have been shown to decline with weight loss, which has lead to the suggestion that obesity is an inflammatory condition similar to asthma with possible common genetic components (Nixon \& Honsinger, 2007).

Although the existing research and the findings from this study demonstrate a trend and possible relationship between asthma severity and obesity, further research is needed to clarify how this relationship is formed in order to prevent the development of severe asthma symptoms. In addition, whether the relationship is indirect or direct warrants further inspection.

\section{$\underline{\text { Health Outcomes }}$}

Health outcomes were also examined using the sociodemographic questionnaire. The health outcomes examined included number of missed school days, emergency department (ED) visits, hospitalizations and unscheduled doctor or clinic visits over the last 6 months prior to their scheduled clinic appointment. Additional health outcomes included number of days the child wheezed and number of nights the child was awakened by coughing due to their asthma over the last two weeks prior to their clinic visit. These 
health outcomes were chosen because they have been shown to be strong indicators of asthma severity (National Asthma Education and Prevention Program, 2007).

Among the health outcomes, three did not demonstrate any statistically significant results or illustrate any trends between the three groups. These were missed number of school days, unscheduled doctor or clinic visits, and number of nights the child was awakened by coughing. However, the health outcomes reflecting the number of emergency department visits, hospitalizations, and days wheezing did demonstrate trends and statistical significance between the normal weight, overweight, and obese groups of children.

A trend was seen within two of the health outcomes, hospitalizations and number of days wheezing, but neither outcome reached a statistical significance. Children in the obese group had the highest percentage of hospitalizations in the last 6 months prior to their clinic appointment (17.7\%) compared to the overweight (5.3\%) and normal weight $(9.3 \%)$ children. In addition, the obese children showed a higher percentage of days wheezing in the last two weeks prior to their clinic appointment $(47.1 \%)$ compared to the overweight (21\%) and normal weight (38.9\%) children.

Of all the health outcomes, number of emergency department (ED) visits in the last 6 months demonstrated the most significant results. Obese children reported the highest percentage of ED visits (41.2\%) compared to overweight (15.8\%) and normal weight (14.9\%) children. Further analysis comparing the obese and normal weight children found the increased percentage of ED visits to be statistically significant ( $p=$ .037). 
These findings are similar to the results found in a study by Belamarich (2000) which examined 1525 inner-city children ages 4 to 9 years with asthma. The researchers found that the obese children with asthma used more medicine, wheezed more, and had a greater proportion of unscheduled ED visits (39\% vs 31\%) than the non-obese children (Belamarich et al., 2000). There were no differences found between the obese and nonobese groups in terms of frequency of hospitalization or in night time waking due to asthma (Belamarich et al., 2000). Unlike the study by Belamarich, the results from this study did demonstrate a trend in hospitalization frequency among the obese group, and did show a trend in the number of days wheezing. These trends combined with the statistically significant difference in ED visits in the obese children, indicates that these symptoms while not statistically significant alone, when combined are a good indicator of overall asthma severity.

The health outcomes examined by this study are all good indicators of asthma severity with the results validating the adequacy of these outcomes as indicators of asthma severity. Moreover, these symptoms, such as wheezing during the day and night time waking due to coughing, are all incorporated into the asthma classification system used to manage children with asthma, further validating their use (National Asthma Education and Prevention Program, 2007). When a child experiences increased asthma symptoms, such as wheezing and coughing, it can often lead to missed school days, unscheduled doctor or clinic visits, ED visits and in more severe cases, even hospitalization. By taking into account the broader spectrum of asthma symptoms and improving the quality of preventative care, these adverse effects on the social and 
educational realms of the child's life will be lessened and the child's overall quality of life will increase.

The obese children in this study had a higher percentage of days wheezing and hospitalizations and demonstrated a statistically significant higher number of ED visits compared to the overweight and normal weight groups. The obese children, as discussed earlier, also had the highest level of asthma severity compared to the overweight and normal weight groups. Together these findings support the fact that health outcomes such as days wheezing, ED visits and hospitalizations are indicators of asthma severity. It would seem logical that if a child wheezed more then they would need to go to the ED more which could possibly lead to more hospitalizations. Hospitalization rates for asthma have been declining since 1995 (American Lung Association, 2009). The majority of asthma exacerbations can be managed at home or briefly in the ED, however, more severe episodes require hospitalization. The often worsening progression of symptoms seen in children experiencing an asthma exacerbation is evident in the results of this study, which show higher percentages of days wheezing, ED visits and hospitalizations in obese children with higher levels of asthma severity, further supporting their consideration in overall treatment and prevention protocols.

\section{Quality of Life}

Quality of life (QOL) was measured using the Pediatric Asthma Quality of Life Questionnaire (PAQLQ) developed by Elizabeth Juniper. The PAQLQ has a total of 23 equally weighted items covering three domains: symptoms, emotional function, and 
activity limitation. For this study, the mean scores for each domain were examined as well as the overall quality of life score.

Mean scores for all three domains and overall QOL scores were similar for all three groups. Only one question, question 3 from the activity domain, approached statistical significance $(\mathrm{p}=.053)$. A regression analysis comparing the normal weight and obese groups found the only significant predictor of overall QOL was asthma severity $(\mathrm{p}=.002)$. Although the obese children in the study group had the highest proportion of asthma severity, the interaction between child size and asthma severity was found not to be a significant indicator of QOL $(\mathrm{p}=.912)$.

The study findings suggest that asthma severity is linked to quality of life, and that children with severe persistent asthma have lower overall quality of life. In addition, the study results validate the use of the PAQLQ tool in assessing how asthma severity affects a child's QOL. However, the results also demonstrate that weight does not appear to place an additional burden on a child's quality of life when combined with a diagnosis of asthma.

Studies examining asthma and QOL have mostly focused on children with mild to moderate asthma severity and have found asthma to have a minimal to moderate impact on QOL (Annett et al., 2001; Gibson, Henry et al., 1995; Okelo et al., 2004). In general, quality of life measures have been shown to correlate only moderately with clinical asthma status (National Asthma Education and Prevention Program, 2007). However, quality of life still continues to be a distinct component of asthma health status with its greatest impact seen more on the physical functioning component of quality of life than 
on the mental functioning (Adams et al., 2006; Juniper, Wisniewski et al., 2004; National Asthma Education and Prevention Program, 2007).

A study by Adams et al. (2006), which examined 834 adults with asthma, found that when asthma was present along with other chronic conditions such as diabetes, arthritis, heart disease, stroke, cancer, and osteoporosis, there was significant impairment in QOL in those over age 35, but not in younger adults. The findings by Adams et al. (2006) suggest that co-morbidities, such as obesity, may not impact QOL until later in life. The delayed impact of the effects of additional chronic conditions on the QOL of individuals with asthma may possibly explain why the obese children in this study did not report lower overall QOL scores when compared to overweight and normal weight children.

However, in a study by Schwimmer et al (2003), which examined QOL in overweight children, children with cancer, and healthy controls, the researchers found that overweight children were five times more likely to have "impaired" quality of life compared to healthy children $(\mathrm{p}<.001)$, and that the likelihood of an overweight child having impaired QOL was similar to a child diagnosed with cancer. The difference seen in the results obtained by Schwimmer et al. (2003) can be attributed to the degree of obesity. Schwimmer et al. (2003) examined children who were severely obese with a mean BMI of 34.7. The children observed in this study had a mean BMI of 29.8, and therefore a lower obesity severity so this factor may contribute to the lower perceived effect of obesity on their QOL. 
The impact of asthma on the physical functioning component of QOL is reflected in the results of question number 3 on the PAQLQ. Question 3, is part of the activity limitation domain, and asks the children how bothered by their asthma they have been doing activities with family and friends over the last week. As might be expected, the mean score for the obese children was $5.47(\mathrm{SD}=1.463)$, "bothered a bit", compared to the overweight $\mathrm{M}=6.16(\mathrm{SD}=1.068)$ and normal weight $\mathrm{M}=6.11(\mathrm{SD}=1.525)$ children who were "hardly bothered at all". This difference in scores approached statistical significance $(\mathrm{p}=.053)$, and implies a possible trend in physical limitation impairment in obese children with asthma.

A study by Annett et al. (2001), which examined 339 children with mild to moderate asthma, found that children with moderate asthma did report more activity limitations $(\mathrm{p}=.04)$. The obese children in this study did have higher levels of asthma severity and therefore their lower score on question 3 could be a reflection of the combined effects of their asthma severity and their weight. The mean scores for question 3 decreased with asthma severity for the obese children, which would support the results of the PAQLQ regression analysis which shows asthma severity to be the greatest predictor of QOL $(\mathrm{p}=.002)$.

What the findings of this study illustrate are that obesity may not currently affect QOL in children with asthma but it may impact an individual's health and QOL in the future if left unchecked. The very beginnings of this impact are apparent in the variation in scores seen in the obese children on question 3, which showed a slight decrease in the ability to enjoy activities with friends and family. The negative effect obesity has on 
health and QOL has been shown repeatedly in adults (Fontaine \& Barofsky, 2001).

However, in obese children the impact weight plays on QOL is mild or not evident at all unless they are severely obese (BMI > 99\% for age and gender) (Schwimmer et al., 2003). Based on the results of this study, obesity when combined with a chronic illness, such as asthma, does not affect QOL unless severity is considered.

\section{$\underline{\text { Spirometry Values }}$}

Six elements of spirometry testing were examined: FVC, FEV1, FEV1/FVC, FEF 25-75\%, and PEFR. None of the spirometry measurements demonstrated statistically significant difference between groups. The obese children did have a higher mean value for percentage of predicted FEV1 $(\mathrm{M}=96.53 \%)$ compared to the overweight $(\mathrm{M}=$ $88.58 \%)$ and normal weight $(\mathrm{M}=90.15 \%)$ groups. Although FEV1 measures airflow restriction, it is often normal in children with asthma when they are well (Spahn et al., 2008). A study by Bacharier et al. (2004) found FEV1 values to be normal even in severe persistent childhood asthma.

The obese children in this study had the highest percentage of moderate to severe asthma severity classifications compared to the overweight and normal weight groups. The phenomenon of normal FEV1 values seen even in severe persistent childhood asthma reported by Bacharier et al. (2004) can also be seen in the normal spirometry and higher FEV1 values obtained in this study. The normal spirometry values seen in all three groups could be due to the superior capability of the asthma clinic, where this study took place, to adequately manage and treat the asthma patient or this normalcy could be an anomaly. However, for this study, data on whether it was a first visit to the clinic or a 
follow-up visit was not recorded therefore, it would be difficult to accurately determine if the normal values were reflective of superior asthma management and treatment.

Studies have shown FEV1/FVC percentage, FEF 25-75\%, and PEFR to decline as asthma severity increases (Bacharier et al., 2004; Srivastava et al., 1995). These studies would suggest that just by having a higher percentage of children with severe to moderate asthma in the obese group, their spirometry values should have been lower, which was not demonstrated in the data. No statistical difference was seen in spirometry values between the three groups. Based on that lack of difference, obesity does not appear to directly affect lung function in childhood asthma.

\section{Theoretical Framework: Revised HRQOL Model}

The framework used to guide this study was the revised health-related quality of life (HRQOL) model developed by C. E. Ferrans and associates (2005). The revised HRQOL model contains five assessments of patient outcomes: biological function, symptoms, functional status, general health perceptions, and overall quality of life. These five measures of patient outcomes are influenced by the characteristics of the individual and the environment.

The characteristics of the individual are categorized as demographic, developmental, psychological and biological factors that influence health outcomes. The characteristics of the individuals examined in this study were measured using the sociodemographic questionnaire and the anthropometric measurements obtained the day of the clinic appointment: data collected included age, gender, race/ethnicity, height, and weight. The characteristics of the environment, categorized by Ferrans et al. (2005), as 
social and physical, and considers factors such as family, friends, healthcare providers, home, neighborhood, and workplace were also measured using the sociodemographic questionnaire. This data included nutritional characteristics of the family, such as meal patterns and BMI of the parents which would influence the child's environment.

As noted, the five types of patient outcomes were also measured. Biological function was measured using spirometric testing and asthma classification. Symptoms were assessed using the health outcome questions from the sociodemographic questionnaire and the symptoms domain scores of the PAQLQ. Functional status includes physical, psychological, social and role function with the focus on optimization of function (C. E. Ferrans, 2005). Functional status was measured using the percent of predicted measures for the six spirometry components and both the activity and emotional function domain scores of the PAQLQ.

The fourth component of the revised HRQOL model is general health perceptions, which represents a synthesis of all the various aspects of health from a subjective view. Ferrans et al. (2005) recommends this component be measured using a single global question asking people to rate their health on a Likert scale, ranging from poor to excellent. The overall QOL score from the PAQLQ was used to measure this component. The final component, overall quality of life, is also subjective measure and reflects how satisfied someone is with life as a whole. Ferrans et al. (2005) recommends a single global question to measure this component, asking how satisfied the individual was with life in general. This final component was not measured with a global question 
however, a combination of assessments could potentially measure this outcome: the overall PAQLQ score, health outcomes, and answers to the sociodemographic.

As demonstrated by the revised HRQOL model, quality of life is complex and involves many components that are directly and indirectly affected by the characteristics of the environment and the individual. When the measurements and findings from this study are integrated into the components of the revised HRQOL model the results show that QOL in children with asthma was not significantly affected or easily determined by a child's weight, which is a characteristic of the individual. Instead, overall QOL in children with asthma is affected more by the biological function (asthma classification and severity), symptoms (health outcomes and symptom domain scores), and functional status (activity and emotional domain scores) components of the model. A visual representation of the study variables represented by the revised HRQOL model can be seen in figure 2 . 
Figure 2. Revised HRQOL Model with Study Variables

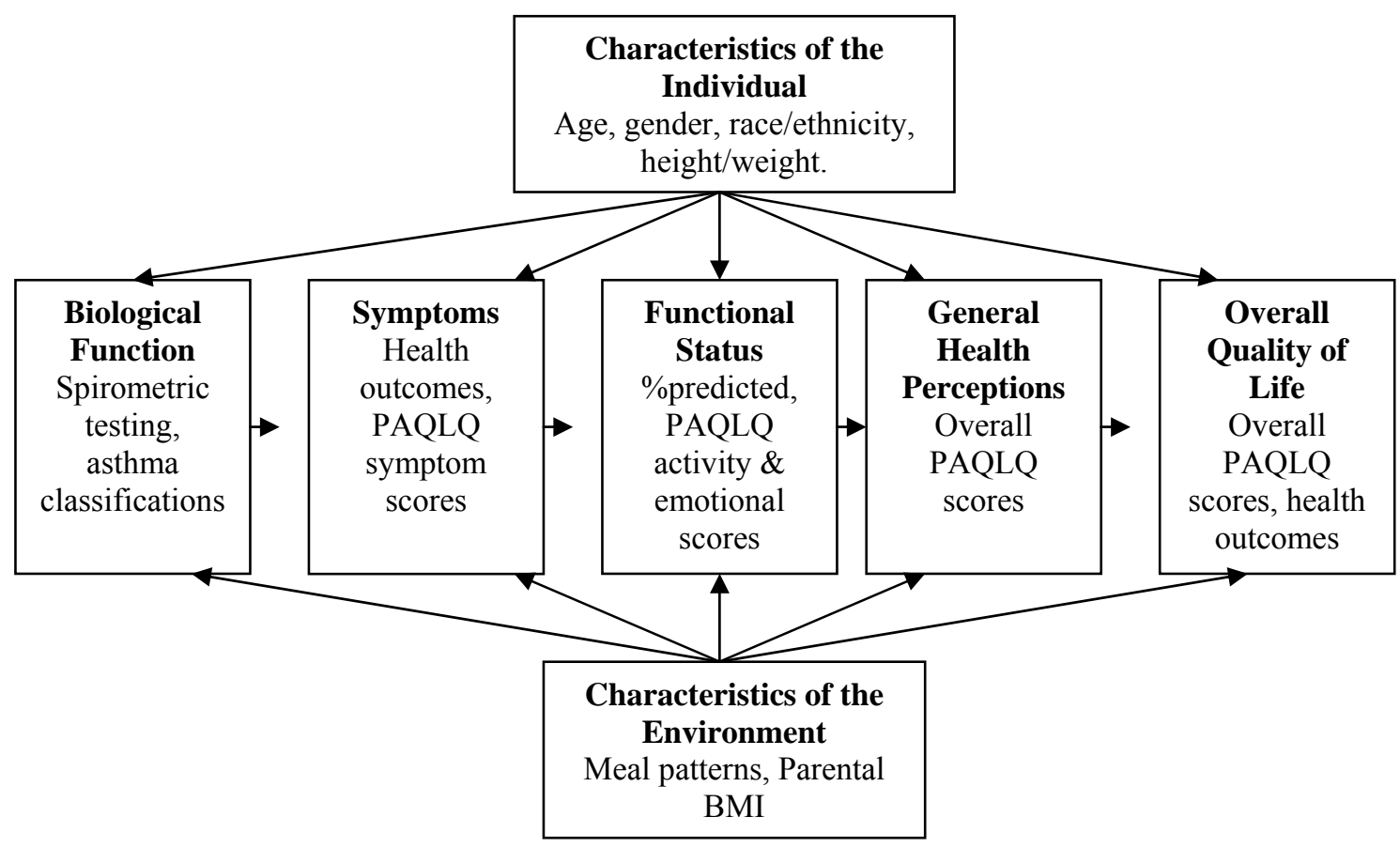

\section{$\underline{\text { Limitations }}$}

The main limitation of this study was sample size. The original power analysis for this study predicted that a total number of 100 subjects would be needed in order to detect a moderate effect size. However, due to time constraints and patient volume issues at the study setting, the number of subjects achieved was 90 . The study results (i.e., the trends showing a higher percentage of hospitalization and days wheezing in the obese children) suggest that a larger sample size would probably generate a statistically significant result in these areas.

Another limitation of the study was the obesity severity. Only 17 children out of the 90 subjects, approximately $18 \%$, were obese. Although this is equal to the obesity prevalence percentage currently seen among children in the United States, a larger 
number of obese children to compare to the normal weight children may have produced more significant results. In addition, the average BMI of the obese children in the study sample was 29.8 which is a lower level than what has been reported in the literature to affect QOL (Schwimmer et al., 2003). A larger number of morbidly obese or severely obese children might have helped to determine if higher levels of obesity severity would eventually impact the QOL of children with asthma.

The final limitation of this study was the lack of a global question for the general health perceptions and overall quality of life components of the revised HRQOL model as suggested by the work of Ferrans et al. (2005). Global questions for these two components could possibly have assisted in explaining why a child's weight did not appear to impact QOL in children with asthma like it has been shown to do in adults (Fontaine \& Barofsky, 2001). Offering children the opportunity to voice their feelings about their QOL would have been interesting as well as insightful.

\section{$\underline{\text { Conclusions }}$}

The results of this study demonstrate the complexity of the interaction between obesity and asthma in children. Higher percentages of hospitalizations and days wheezing were seen in the obese children compared to the overweight and normal weight children. In addition, the obese children demonstrated a statistically significant higher percentage of emergency department visits. However, despite a larger percentage of obese children in the study sample having higher levels of asthma severity, no differences were reported in lung function and quality of life between the obese, overweight, and 
normal weight children with asthma. Furthermore, asthma severity was found to be the best predictor of QOL based on the PAQLQ.

\section{Nursing Implications}

Even though the results of this study show that weight did not affect overall QOL in the obese children with asthma, the true beginnings of the future impact obesity plays on an individual's health are evident in the higher percentages of hospitalizations, days wheezing, ED visits, and asthma severity classifications seen in the obese group. It is well known that obesity in adults is associated with a multitude of health problems including cardiovascular disease, hypertension, stroke, type 2 diabetes, and certain forms of cancer (World Health Organization, 2005). However, it is hard for parents, caregivers, and even the child themselves to perceive and anticipate the impact the child's weight will have on their future health, when it seems so unaffected at the time. Even the obese parents in this study, the majority of whom were parents of obese children, may find it difficult to realize the future impact on health their weight will have in their own lives. In order to break the obesity cycle, nurses need to lead the way in prevention and treatment of obesity.

Obesity can be difficult to treat. The central cause of childhood obesity is eating too much and exercising too little (Mayo Clinic, 2009). The simple solution is to eat healthier foods and increase physical activity, but this can be difficult for a child to implement and maintain (Mayo Clinic, 2009). In order to be successful, establishing healthy habits should involve the whole family. Nurses are in the best position to work 
with families to establish healthy goals to prevent and treat childhood obesity. Nurses can educate parents and children about adopting healthy lifestyle changes by incorporating exercise into their everyday activities by walking to school, limiting television and computer time to 2 hours or less a day, and encouraging 5 servings of fruits and vegetables a day (CLOCC, 2009).

Nurses should not only lead the way in the treatment of obesity but also its prevention. Treating obesity is important but prevention is the key. The way to decrease the prevalence of obesity in children is to prevent it from occurring in the first place. The healthy habits already discussed are best taught before the issue of obesity develops. The majority of overweight adults were not overweight children, but the unhealthy habits, which led to their adult weight issues developed in childhood. Nurses can incorporate healthy behaviors into their everyday discussions about well-being with patients and their families.

Further nursing research is needed to better understand the relationship between obesity, asthma, and quality of life. Although this study found weight to have a limited affect on QOL of children with asthma, QOL is still an important factor to consider when managing and treating asthma (National Asthma Education and Prevention Program, 2007). Understanding the resilience of obese children, especially those with chronic illnesses such as asthma, may assist in the management of childhood obesity (PinhasHamiel et al., 2006) Nursing researchers are needed to guide future research directed at the development of effective interventions for treating and preventing obesity and asthma in children, which in the process, will improve overall child well-being. 
Summary

In summary, this study provides a glimpse into the worldwide obesity epidemic and its affects on chronic illnesses, such as asthma. Trends were found in increased hospitalization rates, number of days wheezing, and ED visits among obese children with asthma. A child's weight appears not to significantly affect the QOL of children with asthma. However, the worldwide obesity epidemic is currently showing no signs of slowing down. Therefore, it is imperative that further research be conducted in the area of childhood obesity. Asthma is the number one chronic illness among children, which puts it at the top of the list of chronic illnesses that are being impacted by obesity. Future research is needed to expand the findings of this study and to develop interventions to treat and prevent childhood obesity and improve management of childhood asthma. 
APPENDIX A:

ADULT CONSENT 


\section{CHILDREN'S MEMORIAL HOSPITAL Permission for a Child to Participate in a Research Project}

\section{Introduction:}

You are being asked to give permission for your child to take part in a research study, entitled "Quality of Life in Children with Asthma", being conducted by Amy Manion for a dissertation under the supervision of Barbara Velsor-Friedrich in the Department of Nursing at Loyola University of Chicago.

Your child is being asked to participate because they have shown symptoms of asthma.

Please read this form carefully and ask any questions you may have before deciding whether to allow your child to participate in the study.

\section{Purpose:}

The purpose of this study is to learn about how asthma symptoms affect a child's quality of life in order to determine more effective ways for treating asthma and improving overall well-being.

\section{Procedure:}

If you agree to allow your child to be in the study, he/she will be asked to fill out a quality of life questionnaire, which takes about 10 to 15 minutes to complete. Your child's height, weight, and breathing test results from today's visit will also be used for the study. In addition, you will also be asked to complete a demographic questionnaire.

\section{Risks/Benefits:}

There are no foreseeable risks involved in participating in this research beyond those experienced in everyday life. There are no direct benefits to you or your child for taking part in the study. However, the information gathered from this study will help to improve the management and treatment of children with asthma as well as developing a better understanding of quality of life.

If your child is injured, medical facilities and treatment will be available. However, you will be required to pay a reasonable fee for such care. Your child can still receive medical benefits if otherwise entitled. If you have any questions or desire further information concerning the availability of medical care, you may contact Dr. Edward Ogata, Chief Medical Officer, The Children's Memorial Hospital, 2300 Children's Plaza, no. 2, Chicago, Illinois, 60614-3394 (773/868-8056). 


\section{Compensation:}

For their participation in the study, children will be allowed to pick an item from an assortment of age appropriate stickers and pencils.

\section{Privacy:}

The investigators/researchers will need access to the medical records of all of the children who participate in this study. You and your child's protected health information that may be used and disclosed includes:

- Medical records including height, weight, gender, and spirometry (breathing test) results.

- In addition, your answers to the demographic questionnaire and your child's answers to the quality of life questionnaire will be used for this study.

If you sign this consent form, you are giving permission for your child's physician and Children's Memorial Hospital to provide your child's medical records to the following people, agencies or companies to review and use in this research study:

- Loyola University's Institutional Review Board

- Amy Manion RN, PNP, graduate student at Loyola University Chicago

- Dr. Barbara Velsor-Friedrich, faculty sponsor, Loyola's School of Nursing

- Dr. Rachel Story, Division of Allergy and Immunology Children's Memorial

Children's Memorial Hospital and your child's doctor will keep the records of this study confidential, and will release your child's medical information only to the people or companies listed above. In addition, to maintain confidentiality, no names will be used. All of the information collected from you and your child will be coded with an identification number, and will be used solely for this project. However, it is important for you to understand that, once your child's doctor or Children's Memorial Hospital releases your child's medical information to these people or companies, your child's doctor or Children's Memorial Hospital cannot guarantee that your child's information will remain confidential. It is possible that these other person's or companies could give your child's study information to others, without your permission.

The records of the study will be kept confidential with respect to any written or oral reports to the profession or the media, making it impossible to identify your child individually. At the end of the study all information will be destroyed.

\section{Voluntary Participation:}

By signing this consent form, you agree to have your child take part in this study. You are not giving up any of your or your child's legal rights or releasing this hospital from responsibility for carelessness.

You many cancel your consent and take your child out of this study at any time without penalty or loss of benefits. Your child's treatment by, and relations with the physician(s) and staff at The Children's Memorial Hospital, now and in the future, will not be affected 
in any way if you refuse to have your child take part, or if you enter your child into the study and then withdraw your child from it.

At any time, you can tell your child's doctor or Children's Memorial Hospital not to use or give out your child's study information or other information from your child's medical record to other people or companies. Withdrawal of this permission must be in writing. Any study information or other information from your child's medical record collected before your written notice of permission withdrawal may still be used for the study, if that information is necessary for the study. Your decision will not affect your child's regular care and your child's doctor will not change his or her feelings about you.

If you agree to let your child take part in this research study, you will not be able to look at or ask for a copy of your child's health information collected only for this study, while your child is taking part in the study. If you wish, you will be able to ask for this study research information when the study is over or when your child is no longer taking part in the study. This does not affect your right to see your child's medical records or the results of tests related to regular medical care that is given during the same time as the research study.

\section{Contacts and Questions:}

If you have questions about this research study, please feel free to contact, Dr. Rachel Story at (773) 327-3710, Amy Manion at (219) 313-3550 or manionar@yahoo.com or the faculty sponsor, Barbara Velsor-Friedrich, at bvelsor@1uc.edu.

If you have any questions about your child's rights as a research subject, you may take them to Philip V. Spina, Chief Administrative Officer, Children's Memorial Research Center, 2300 Children's Plaza, no. 205, Chicago, Illinois 60614-3394 [773/755-6301 (phone), 773/755-6533 (fax), pspina@childrensmemorial.org (email)].

\section{Statement of Consent:}

Your signature below indicates that you have read and understood the information provided above, have had an opportunity to ask questions, and agree to allow your child, copy of this form to keep for your records. , to participate in this research study. You will be given a 
I certify that I have explained the above to and believe that the signature was affixed freely. I also agree to answer any questions that may arise.

Signature of the Principal Investigator

Date or person presenting information

Amy Manion

Typed Name of Principal Investigator

or person presenting information

Printed Name of Person Providing Oral Translation:

Relationship of Translator to Subject, Parent, or Surrogate: 
APPENDIX B:

CHILD ASSENT 


\section{CHILDREN'S MEMORIAL HOSPITAL Adolescent's Agreement to Participate in a Research Study}

\section{Introduction:}

You are being asked to take part in a research study being done by Amy Manion a graduate student at Loyola University Chicago, entitled "Quality of Life in Children with Asthma”. We are trying to learn more about how asthma affects a person's life.

\section{Procedure:}

If you decide to be in this study, you will be asked to complete a questionnaire, which takes about 10 to 15 minutes to complete.

\section{Risks (Bad Things)/Benefits (Good Things):}

Sometimes things happen in research studies. Reading the items on the questionnaire may make you think more about asthma. If you find yourself getting upset or sad about a question, you should tell the doctor, nurse, or your parent right away. You do not have to answer any questions that upset you.

People also have good things happen to them when they are in research studies. The good things may be that by filling out the questionnaire you help others to learn more about asthma so they can help other kids just like you.

\section{Compensation:}

For taking part in this study, you will be able to pick out a sticker and pencil.

\section{Privacy:}

The investigators/researchers will need access to the medical records of all of the children who participate in this study. Your protected health information that may be used and disclosed includes:

- Medical records including your height, weight, gender, and spirometry (breathing test) results.

- In addition, your answers to the quality of life questionnaire and your parent/guardian's answers to the demographic questionnaire will be used for this study.

If you sign this assent form, you are giving permission for your physician and Children's Memorial Hospital to provide your medical records to the following people, agencies or companies to review and use in this research study:

- Loyola University's Institutional Review Board

- Amy Manion RN, PNP, graduate student at Loyola University Chicago

- Dr. Barbara Velsor-Friedrich, faculty sponsor, Loyola's School of Nursing

- Dr. Rachel Story, Division of Allergy and Immunology Children's Memorial 
Children's Memorial Hospital and your doctor will keep the records of this study confidential, and will release your medical information only to the people or companies listed above, and only when they have an explicit need to know about the effect of the study on you. In addition, to maintain confidentiality, no names will be used. All of the information collected from you will be coded with an identification number, and will be used solely for this project. However, it is important for you to understand that, once your doctor or Children's Memorial Hospital releases your medical information to these people or companies, your doctor or Children's Memorial Hospital cannot guarantee that that person or company will keep your information confidential. It is possible that these other person's or companies could give your study information to others, without your permission.

The records of the study will be kept confidential with respect to any written or oral reports to the profession or the media, making it impossible to identify you individually. At the end of the study all information will be destroyed.

\section{My Rights:}

By signing this assent form, you agree to take part in this study. You are not giving up any of your legal rights or releasing this hospital from responsibility for carelessness.

You may cancel your assent and take yourself out of this study at any time without penalty or loss of benefits. Your treatment by, and relations with the physician(s) and staff at The Children's Memorial Hospital, now and in the future, will not be affected in any way if you refuse to take part, or if you enter into the study and then withdraw from it.

At any time, you can tell your doctor or $\mathrm{CMH}$ not to use or give out your study information or other information from your medical record to other people or companies. Withdrawal of this permission must be in writing. Any study information or other information from your medical record collected before your written notice of permission withdrawal may still be used for the study, it that information is necessary for the study. Your decision will not affect your regular care and your doctor will not change his or her feelings about you. If you agree to take part in this research study, you will not be able to look at or ask for a copy of your health information collected only for this study, while you are taking part in the study. If you wish, you will be able to ask for this study research information when the study is over or when you are no longer taking part in the study. This does not affect your right to see your medical records or the results of tests related to regular medical care that is given during the same time as the research study. 
APPENDIX C:

BMI GROWTH CHARTS 
2 to 20 years: Girls

Body mass index-for-age percentiles

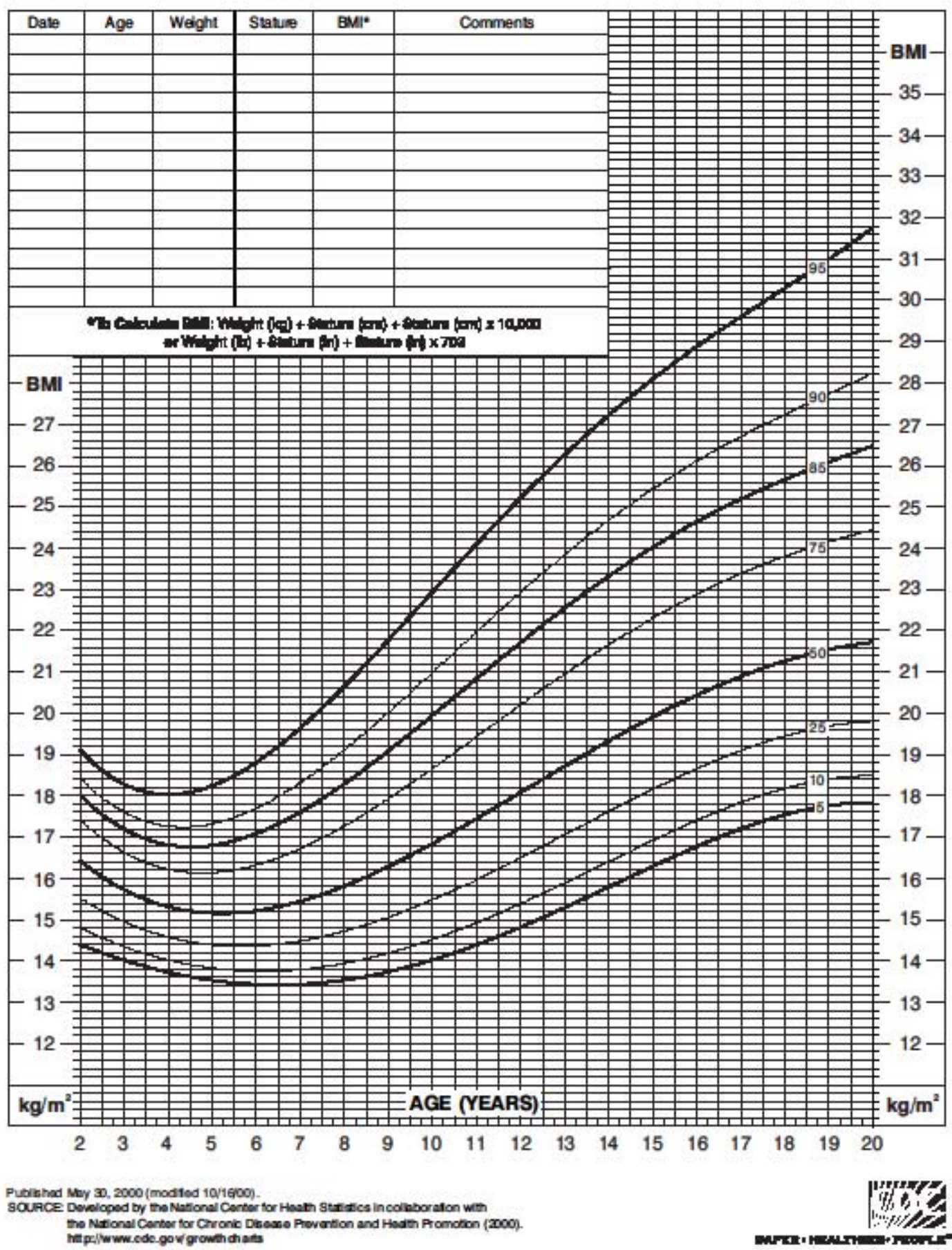


2 to 20 years: Boys

Body mass index-for-age percentiles

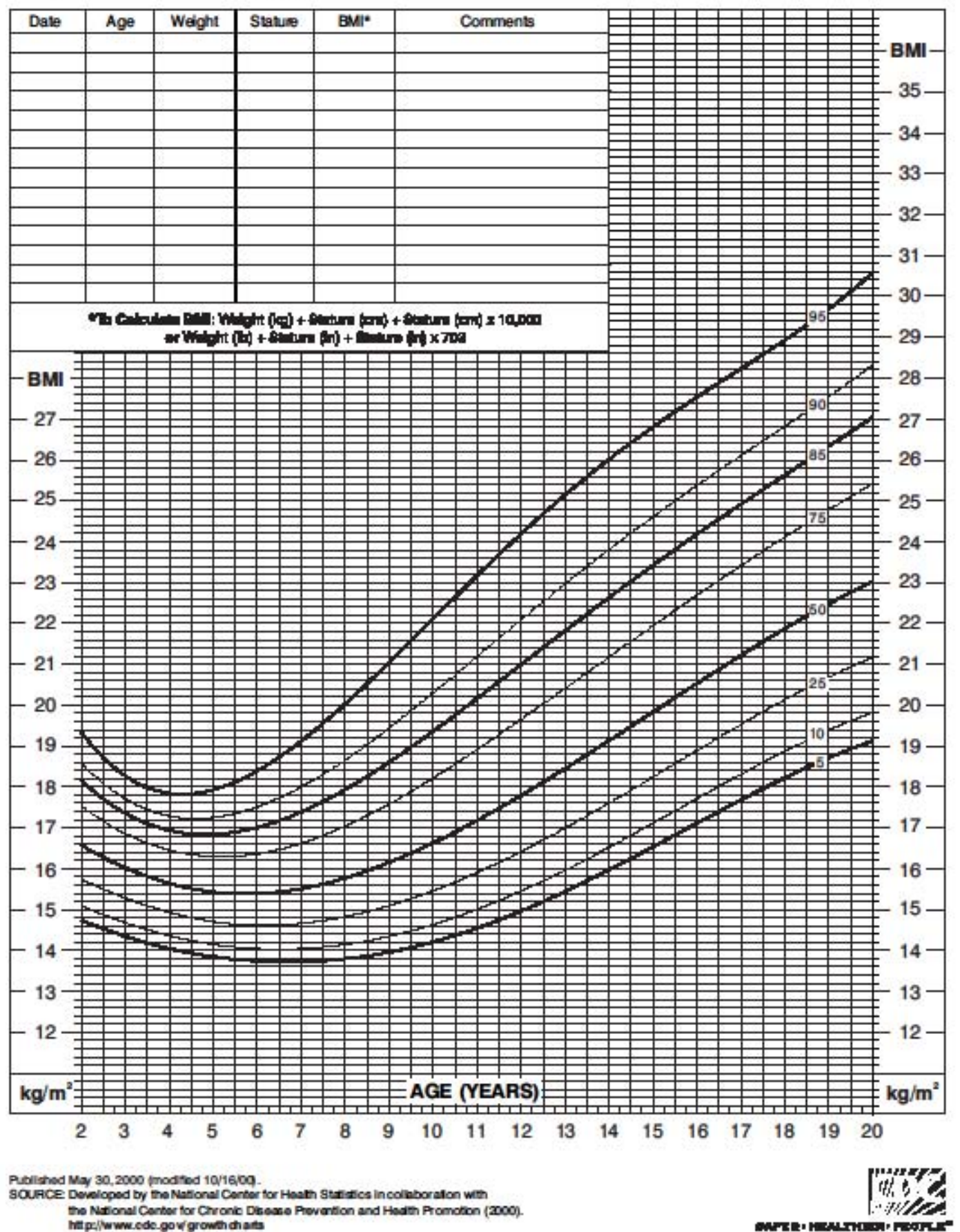


APPENDIX D:

SOCIODEMOGRAPHIC QUESTIONNAIRE 
ID\#

\section{Sociodemographic Questionnaire}

The purpose of this study is to learn more about how asthma symptoms affect a child's quality of life. This questionnaire will ask for information regarding you, your child, and factors related to asthma symptoms. Please fill in or circle the appropriate answer for each question. All of the information contained in this questionnaire will be kept private.

\section{Demographics:}

1. Please indicate the date of birth of the child who will be participating in the study by filling in the month, date, and year, in the space provided below.

\section{$\overline{\text { Month }} \overline{\text { Date }} \overline{\text { Year }}$}

2. Please circle the gender of the child that will be participating in the study.

Male or Female

3. What is your relationship to the child selected for this study?
a. Parent
b. Relative other than parent
c. Guardian
d. Other (please state)

4. Which of the following choices best describes the Race or Ethnicity of your child?
a. White (not Hispanic or Latino)
b. Black or African American (not Hispanic or Latino)
c. Hispanic or Latino
d. Asian
e. Native Hawaiian or other Pacific Islander
f. American Indian or Alaska Native
g. Other

5. Please indicate your highest level of education from the choices below.
a. Completed less than the $8^{\text {th }}$ grade.
b. High school diploma or GED.
c. Trade school.
d. Completed a 2 or 4 year college degree.
e. Graduate degree (M.D., PhD, J.D., Master's) 
6. Which of the following most accurately represents your current yearly family income?
a. Less than $\$ 25,000 /$ year
b. $\$ 25,000-49,999 /$ year
c. $\$ 50,000-74,999 /$ year
d. $\$ 75,000-99,999 /$ year
e. $\$ 100,000$ a year or more

7. If you know the approximate weight of the child's mother and father, please write it down in the spaces provided below.

$\overline{\text { Mother's weight (in pounds) }}$

$\overline{\text { Father's weight (in pounds) }}$
Mother's height (in feet \& inches)

Father's height (in feet \& inches)

8. Does your child usually eat breakfast in the morning? (Please circle your answer.)

Yes, my child always eats breakfast $\quad$ No, my child often skips breakfast

9. In an average week, how often does your family eat dinner together? days a week

10. In an average week, how often does your family eat at fast food restaurants? days a week

11. Does your child have a chronic illness, other than asthma. (Please circle all that apply.)

a. No, my child does not have a chronic illness, other than asthma.

b. Diabetes

c. Rheumatoid arthritis

d. Other (please state) 
Asthma questions:

1. How many school days did your child miss in the last 6 months due to their asthma?
a. None
b. 1 to 3 days
c. 4 to 6 days
d. 7 days or more

2. How many times in the last $\mathbf{6}$ months did you have to take your child to the Emergency Room (ER) because of their asthma?
a. None
b. 1 to 2 times
c. 3 or more times

3. How many times in the last $\mathbf{6}$ months has your child been hospitalized (stayed overnight in the hospital) because of their asthma?
a. None
b. 1 to 2 times
c. 3 or more times

4. How many times in the last 6 months did you have to take your child for an unscheduled doctor or clinic visit due to their asthma?
a. None
b. 1 to 2 times
c. 3 or more times

5. How many days in the last 2 weeks has your child wheezed?
a. None
b. 1 to 2 days
c. 3 to 5 days
d. 6 days or more

6. How many nights in the last 2 weeks has your child been awakened (woke up coughing) due to their asthma?
a. None
b. 1 to 2 nights
c. 3 to 5 nights
d. 6 nights or more

Thank you for taking the time to fill out this questionnaire 
APPENDIX E:

PEDIATRIC ASTHMA QUALITY OF LIFE QUESTIONNAIRE (PAQLQ) 


\section{PAEDIATRIC ASTHMA QUALITY OF LIFE QUESTIONAIRE WITH STANDARDISED ACTIVITIES \\ (PAQLQ(S))}

\section{SELF-ADMINISTERED \\ (C) 1999 \\ QOL TECHNOLOGIES LTD.}

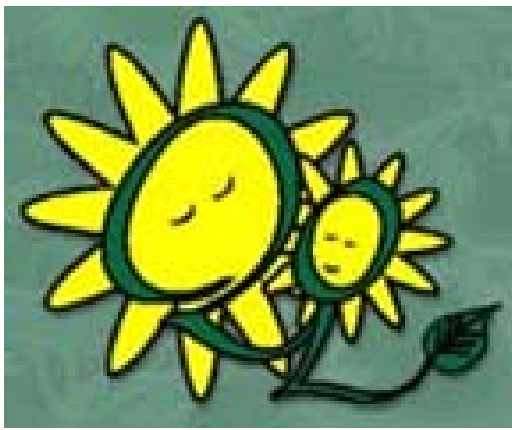

For Further Information:

Elizabeth Juniper, MCSP, MSc

Professor

20 Marcuse Fields,

Borsham

West Sussex,

P018 8NA, UK

Tel: + 44(0) 1243572124

Fax: + 44(0) 1243573680

E-mail: juniper@qoltech.co.uk

Web: www.qoltech.co.uk

() The PAQLQ(S) is copyrighted. It may not be altered, sold (paper or electronic), translated or adapted for another medium without the permission of Elizabeth Juniper. 
ID

QUALITY OF LIFE QUESTIONAIRE (S)

SELF ADMINISTERED

DATE

Page 1 of 4

Please complete all questions by circling the number that best describes how you have been during the past week as a result of your asthma.

HOW BOTHERED HAVE YOU BEEN DURING THE LAST WEEK DOING:

$\begin{array}{ccccccc}\begin{array}{c}\text { Extremely } \\ \text { Bothered }\end{array} & \begin{array}{c}\text { Very } \\ \text { Bothered }\end{array} & \begin{array}{c}\text { Quite } \\ \text { Bothered }\end{array} & \begin{array}{c}\text { Somewhat } \\ \text { Bothered }\end{array} & \begin{array}{c}\text { Bothered } \\ \text { A Bit }\end{array} & \begin{array}{c}\text { Hardly } \\ \text { Bothered }\end{array} & \begin{array}{c}\text { Not } \\ \text { Bothered }\end{array}\end{array}$

1. PHYSICAL ACTIVITIES

(such as running,

swimming, sports, walking uphill/upstairs

1

2

3

4

5

6

7

and bicycling)?

2. BEING WITH ANIMALS

(such as playing with pets and looking after animals)?

3. ACTIVITIES WITH FRIENDS AND FAMILY (such as playing at recess and doing things with your friends and family)?

4. COUGHING

1

2

3

3

4

5

6

7

IN GENERAL, HOW OFTEN DURING THE LAST WEEK DID YOU:

All of the Most of Quite Some Once in Hardly Any None Time the Time Often the Time a While of the Time the Time

5. Feel FRUSTRATED because of your asthma?

1

2

3

4

5

6

7

6. Feel TIRED because of your asthma

1

2

3

4

5

6

7

7. Feel WORRIED, CONCERNED OR TROUBLED because of your asthma

1

2

3

4

5

6 
PAEDIATRIC ASTHMA

QUALITY OF LIFE QUESTIONAIRE (S) SELF ADMINISTERED
PATIENT ID

DATE

Page 2 of 4

HOW BOTHERED HAVE YOU BEEN DURING THE LAST WEEK BY?

\begin{tabular}{|c|c|c|c|c|c|}
\hline $\begin{array}{l}\text { Extremely } \\
\text { Bothered }\end{array}$ & $\begin{array}{c}\text { Very } \\
\text { Bothered }\end{array}$ & $\begin{array}{c}\text { Quite } \\
\text { Bothered }\end{array}$ & $\begin{array}{r}\text { Somewhat } \\
\text { Bothered }\end{array}$ & $\begin{array}{c}\text { Bothered } \\
\text { A Bit }\end{array}$ & $\begin{array}{c}\text { Hardly } \\
\text { Bothered }\end{array}$ \\
\hline
\end{tabular}

$\begin{array}{llllllll}\text { 8. ASTHMA ATTACKS } & 1 & 2 & 3 & 4 & 5 & 6 & 7\end{array}$

IN GENERAL, HOW OFTEN DURING THE LAST WEEK DID YOU:

All of the Most of Quite Some Once in Hardly Any None Time the Time Often the Time a While of the Time the Time

9. Feel ANGRY because

of your asthma

1

$$
2
$$

34

5

6

7

HOW BOTHERED HAVE YOU BEEN DURING THE LAST WEEK BY?

$\begin{array}{ccccccc}\text { Extremely } & \text { Very } & \text { Quite } & \text { Somewhat } & \text { Bothered } & \text { Hardly } & \text { Not } \\ \text { Bothered } & \text { Bothered } & \text { Bothered } & \text { Bothered } & \text { A Bit } & \text { Bothered } & \text { Bothered }\end{array}$

10. WHEEZING

1

2

3

4

5

6

7

IN GENERAL HOW OFTEN DURING THE LAST WEEK DID YOU:

All of the Most of $\begin{gathered}\text { Quite } \\ \text { Time }\end{gathered}$ the Time Often the Time a While of the Time the Time

11.Feel IRRITABLE

(cranky/grouchy) because of your asthma

1

2

3

4

56

7

HOW BOTHERED HAVE YOU BEEN DURING THE LAST WEEK BY?

$\begin{array}{ccccccc}\text { Extremely } & \text { Very } & \text { Quite } & \text { Somewhat } \\ \text { Bothered } & \text { Bothered } & \begin{array}{c}\text { Bothered } \\ \text { Bothered }\end{array} & \begin{array}{c}\text { Hardly } \\ \text { Bothered }\end{array} & \begin{array}{c}\text { Not } \\ \text { A Bit }\end{array} & \begin{array}{c}\text { Bothered } \\ \text { Bothered }\end{array}\end{array}$

12. TIGHTNESS IN YOUR CHEST

1

2

3

4

5

6

7 
PAEDIATRIC ASTHMA

QUALITY OF LIFE QUESTIONAIRE (S)

SELF ADMINISTERED
PATIENT ID

DATE

Page 3of 4

IN GENERAL, HOW OFTEN DURING THE LAST WEEK DID YOU:

All of the $\begin{gathered}\text { Most of Quite Some } \\ \text { Time }\end{gathered}$ the Time Often the Time a While of the Time the Time
Time

13. Feel DIFFERENT OR

LEFT OUT because of

1

$2 \quad 3 \quad 4$

5

6

7 your asthma

HOW BOTHERED HAVE YOU BEEN DURING THE LAST WEEK BY?

$\begin{array}{ccccccc}\text { Extremely } & \text { Very } & \text { Quite } & \text { Somewhat } & \text { Bothered } & \text { Hardly } & \text { Not } \\ \text { Bothered } & \text { Bothered } & \text { Bothered } & \text { Bothered } & \text { A Bit } & \text { Bothered Bothered }\end{array}$

14. SHORTNESS OF

BREATH

1

2

3

4

5

6

7

IN GENERAL, HOW OFTEN DURING THE LAST WEEK DID YOU:

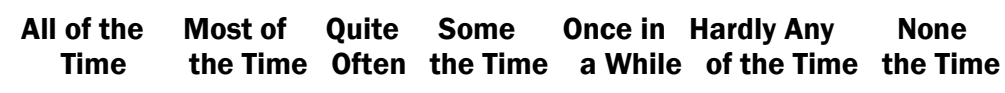

15. FeeI FRUSTRATED BECAUSE YOU COULDN'T KEEP UP WITH OTHERS

16. WAKE UP DURING THE NIGHT because of your asthma

1

17. Feel UNCOMFORTABLE Because of your asthma?

1

2

3

4

5

6

7

18. Feel OUT OF BREATH because of your asthma?

$2 \quad 3 \quad 4$

5

6

7

19. Feel YOU COULDN'T KEEP UP WITH OTHERS because of your asthma?

$2 \quad 3 \quad 4$

5

6 
PAEDIATRIC ASTHMA

QUALITY OF LIFE QUESTIONAIRE (S)

SELF ADMINISTERED
PATIENT ID

DATE

Page 4of 4

IN GENERAL, HOW OFTEN DURING THE LAST WEEK DID YOU:

All of the Most of $\begin{gathered}\text { Quite Some } \\ \text { Once in Hardly Any }\end{gathered}$ None
Time the Time Often the Time a While of the Time the Time

20. Have trouble SLEEPING AT NIGHT because of your asthma?

1

$$
2
$$

$3 \quad 4$

5

6

7

21. Feel FRIGHTENED BY AN ASTHMA ATTACK?
1

2

3

4

5

6

7

THINK ABOUT ALL THE ACTIVITIES THAT YOU NDID IN THE PAST WEEK:

$\begin{array}{ccccccc}\begin{array}{c}\text { Extremely } \\ \text { Bothered }\end{array} & \begin{array}{c}\text { Very } \\ \text { Bothered }\end{array} & \begin{array}{c}\text { Quite } \\ \text { Bothered }\end{array} & \begin{array}{c}\text { Somewhat } \\ \text { Bothered }\end{array} & \begin{array}{c}\text { Bothered } \\ \text { A Bit }\end{array} & \begin{array}{c}\text { Hardly } \\ \text { Bothered }\end{array} & \begin{array}{c}\text { Not } \\ \text { Bothered }\end{array}\end{array}$

22. How much were you bothered by your asthma during these activities?

1

$$
2
$$

3

4

5

6

7

IN GENERAL, HOW OFTEN DURING THE LAST WEEK DID YOU:

All of the Most of Quite Some Once in Hardly Any $\begin{gathered}\text { None } \\ \text { Time the Time Often the Time a While of the Time the Time }\end{gathered}$

23. Have difficulty taking a DEEP BREATH?

1

2

3

4

5

6

7 
APPENDIX F:

\section{PERMISSION LETTERS}


Amy Becker Manion- HRQOL model Use Request

RE: HRQOL model

Wednesday, October 28, 2009 3:39 PM

From:

"Carol Ferrans" cferrans@uic.edu

To:

"Amy Becker" <manionar@yahoo.com> Hello Amy,

Congratulations on the completion of your dissertation study! Yes, I am happy to give you permission to include my model in your dissertation.

Good luck!

Carol Ferrans

Carol Estwing Ferrans, PhD, RN, FAAN

Professor and Associate Dean for Research

University of Illinois at Chicago

College of Nursing (MC 802)

845 S. Damen Avenue

Chicago, IL 60612

Phone (312) 996-8445

Fax (312) 996-4979

Email cferrans@uic.edu

QLI website: www.uic.edu/orgs/qli 
Amy Becker Manion- Permission to Print PAQOL Tool

Re: permission to print

Wednesday, October 14, 2009 5:49 AM

From:

"Elizabeth Juniper" <juniper@qoltech.co.uk>

To:

"Amy Becker" <manionar@yahoo.com>

Dear Amy,

Congratulations on completing your dissertation. You are very welcome to included the PAQLQ in your dissertation (please indicate, with my permission, but it must not be included in any publication.

With good wishes

Liz Juniper

----- Original Message ----- From: "Amy Becker" <

To: "juniper" <juniper@qoltech.co.uk>

Sent: Tuesday, September 29, 2009 5:48 AM

Subject: permission to print

Dear Professor Juniper,

I wrote to you back in 2003 about my dissertation study using your PAQLQ tool. You were kind enough to send me a copy and wish me luck with my research. I have finished data collection and I am planning on presenting my oral defense of my dissertation, QOL and Health Outcomes in Overweight and Non-Overweight Children with Asthma, in November. I need to submit my dissertation to Loyola University for publication and was wondering if I have your permission to include your tool in the final submission of my dissertation. I will understand if you do not want it included in the final copy.

Sincerely,

Amy Becker Manion RN, CPNP

$\mathrm{PhD}$ candidate, Loyola University Chicago 


\section{BIBLIOGRAPHY}

Aaronson, N. K. (1988). Quality of life: What is it? How should it be measured? Oncology, 2, 69-74.

Adams, R. J., Wilson, D. H., Taylor, A. W., Daly, A., Tursan d'Espaignet, E., Dal Grande, E., et al. (2006). Coexistent chronic conditions and asthma quality of life. Chest, 129, 285-291.

Akerman, M. J., Calacanis, C. M., \& Madsen, M. K. (2004). Relationship between asthma severity and obesity. Journal of Asthma, 41(5), 521-526.

Akinbami, L. J., \& Schoendorf, K. C. (2002). Trends in childhood asthma: prevalence, health care utilization, and mortality. 315-322.

American Heart Association. (2006). Metabolic Syndrome. Retrieved July 18, 2006, from http://www.americanheart.org

American Lung Association. (2005). Asthma \& Children Fact Sheet. Retrieved May 27, 2006, from http://www.lungusa.org

American Lung Association. (2009). Trends in asthma morbidity and mortality. Retrieved August 8, 2009, from http://www.lungusa.org

Anavian, J., Brenner, D. J., Fort, P., \& Speiser, P. W. (2001). Profiles of obese children presenting for metabolic evaluation. Journal of Pediatric Endocrinology, 14(8), 1145-1150.

Andersen, R. E., Crespo, C. J., Bartlett, S. J., Cheskin, L. J., \& Pratt, M. (1998). Relationship of physical activity and television watching with body weight and level of fatness among children: results from the Third National Health and Nutrition Examination Survey.[see comment]. JAMA. 279(12):938-42.

Annett, R., Bender, B. G., Lapidus, J., Duhamel, T. R., \& Lincoln, A. (2001). Predicting children's quality of life in an asthma clinical trial: what do children's reports tell us? Journal of Pediatrics. 139(6):854-61.

Apter, A. J., \& Szefler, S. J. (2004). Advances in adult and pediatric asthma. Journal of Allergy and Clinical Immunology, 113(3), 407-414. 
Arnall, D. (1999). Pulmonary function testing. Retrieved September 15, 2009, from http://www2.nau.edu/ daa/lecture/pft.htm

Bacharier, L. B., Strunk, R. C., Mauger, D., White, D., Lemanske, R. F., \& Sorkness, C. A. (2004). Classifying asthma severity in children. American Journal of Respiratory and Critical Care Medicine, 170, 426-432.

Belamarich, P. F., Luder, E., Kattan, M., Mitchell, H., Islam, S., Lynn, H., et al. (2000). Do obese inner-city children with asthma have more symptoms than nonobese children with asthma? Pediatrics, 106(6), 1436-1441.

Bergner, M. (1985). Measurement of health status. Medical Care, 23, 696-704.

Bernstein, D. I. (2008). ABCs of Asthma. Clinical Cornerstone, 8(4), 9-22.

Bibi, H., Shoseyov, D., Feigenbaum, D., Genis, M., Friger, M., Peled, R., et al. (2004). The relationship between asthma and obesity in children: is it real or a case of over diagnosis? Journal of Asthma, 41(4), 403-410.

Blandon Vijil, V., Del Rio Navarro, B., Berber Eslava, A., \& Sienra Monge, J. J. L. (2004). Quality of life in pediatric patients with asthma with or without obesity: a pilot study. Allergologia et Immunopathologia, 32(5), 259-264.

Bloom, B., \& Cohen, R. A. (2007). Summary health statistics for U.S. children: National Health Interview Survey, 2006. Vital and Health Statistics, 10(234), 1-87.

Bradley, C. B., McMurray, R. G., Harrell, J. S., \& Deng, S. (2000). Changes in common activities of 3rd through 10th graders: the CHIC study. Medicine \& Science in Sports \& Exercise, 32(12), 2071-2078.

Brink, P. J., \& Wood, M. J. (1998). Advanced Design in Nursing Research (2nd ed.). Thousand Oaks, CA: Sage Publications.

Brownell, K. D., \& Horgen, K. B. (2004). Food Fight. Chicago: Contemporary Books.

Brunner, H. I., Taylor, J., Britto, M. T., Corcoran, M. S., Kramer, S. L., Melson, P. G., et al. (2006). Differences in disease outcomes between medicaid and privately insured children: possible health disparities in juvenile rheumatoid arthritis. Arthritis and Rheumatism, 55(3), 378-384.

Burns, C. E., Dunn, A. M., Brady, M. A., Barber Star, N., \& Blosser, C. G. (2009). Atopic and Rheumatic Disorders. In Pediatric Primary Care (pp. 555-567). St. Louis: Saunders. 
Camargo, C. A., Weiss, S. T., Zhang, S., Willett, W. C., \& Speizer, F. E. (1999). Prospective study of body mass index, weight change, and risk of adult-onset asthma in women. Archives of Internal Medicine, 159(21), 2582-2588.

Castro-Rodriguez, J. A., Holberg, C. J., Morgan, W. J., Wright, A. L., \& Martinez, F. D. (2001). Increased incidence of asthmalike symptoms in girls who become overweight or obese during the school years. American Journal of Respiratory \& Critical Care Medicine, 163(6), 1344-1349.

CDC. (2002). Asthma Prevalence, Health Care Use and Mortality, 2002. Retrieved March 3, 2006, from http://www.cdc.gov/nchs/data/asthmahealthestat1.pdf

CDC. (2005). National Center for Health Statistics- Health E-Stats-Prevalence of overweight among children and adolescents: United States, 1999-2002.

Retrieved May 30, 2006, from http://www/cdc.gov/nchs/products/pubs/pubd/hestats/overwght99.htm

CDC. (2006). Asthma prevalence, health care use and mortality: United States, 2003-05. Retrieved August 15, 2009, from http://www.cdc.gov/nchs

CDC. (2009a). Defining Overweight and Obesity. Retrieved August 26, 2009, from http://www.cdc.gov/obesity/defining.html

CDC. (2009b). NHANES Surveys (1976-1980 and 2003-2006). Retrieved August 25, 2009, from http://www.cdc.gov/obesity/childhood/prevalence.html

Centers for Disease Control and Prevention. (2004). Participation in high school physical education- United States, 1991-2003. Morbidity \& Mortality Weekly Report, 53(36), 844-847.

Chagnon, Y. C., Perusse, L., Weisnagel, S. J., Rankinen, T., \& Bouchard, C. (2000). The Human Obesity Gene Map: The 1999 Update. Obesity Research, 8, 89-117.

Chen, A. Y., Kim, S. E., Houtrow, A. J., \& Newacheck, P. W. (2009). Prevalence of obesity among children with chronic conditions. Obesity, 17(6), 1-4. doi: 10.1038/oby.2009.1185.

Chicago Public Schools. (2004, June 21). Chicago Public Schools new vending policy to restrict junk food. Retrieved July 18, 2006, from www.isds.org/newsroom/articles/CPSvend.pdf

Chinn, S., \& Rona, R. J. (2001). Can the increase in body mass index explain the rising trend in asthma in children? Thorax, 56(11), 845-850. 
Chipps, B. E. (2008). Asthma in infants and children. Clinical Cornerstone, 8(4), 44-58.

Chu, Y. T., Chen, W. Y., Wang, T. N., Tseng, H. I., Wu, J. R., \& Ko, Y. C. (2009). Extreme BMI predicts higher asthma prevalence and is associated with lung function impairment in school-aged children. Pediatric Pulmonology, 44, 472479.

CLOCC. (2009). CLOCC: 5-4-3-2-1 Go! Retrieved September 30, 2009, from http://www.clocc.net

Crister, G. (2003). Fat Land. Boston: Houghton Mifflin Company.

Daniels, S. R. (2006). The consequences of childhood overweight and obesity. Future of Children, 16(1), 47-67.

Daniels, S. R., Arnett, D. K., Eckel, R. H., Gidding, S. S., Hayman, L. L., Kumanyika, S., et al. (2005). Overweight in children and adolescents: pathophysiology, consequences, prevention, and treatment. Circulation, 111(15), 1999-2012.

Dey, A. N., \& Bloom, B. (2005). Summary health statistics for U.S. children: National Health Interview Survey, 2003. Vital and Health Statistics. Series 10., 223, 1-78.

Dietz, W. H. (1995). Does hunger cause obesity? Pediatrics, 95(5), 766-767.

Dietz, W. H., \& Robinson, T. N. (2005). Overweight children and adolescents. New England Journal of Medicine, 352(20), 2100-2109.

Ditesheim, J. A., \& Templeton, J. M. (1987). Short-term v long-term quality of life in children following repair of high imperforate anus. Journal of Pediatric Surgery, 22, 581-587.

Draper, P. (1997). Nursing perspectives on quality of life. New York: Routledge.

Dwyer, J. T., Evans, M., Stone, E. J., Feldman, H. A., Lytle, L., Hoelscher, D., et al. (2001). Adolescent eating patterns influence their nutrient intakes. Journal of the American Dietetic Association, 101, 798-802.

Eaton, D. K., Kann, L., Kinchen, S., Ross, J., Hawkins, J., Harris, W. A., et al. (2006). Youth risk behavior surveillance- United States, 2005. Morbidity \& Mortality Weekly Report. Surveillance Summaries., 55(5), 1-108.

Eggleston, P. A. (1993). Childhood Asthma: A guide for parents. San Ramon, CA: HIN, Inc. 
Eiser, C., Eiser, J. R., \& Stride, C. B. (2005). Quality of life in children newly diagnosed with cancer and their mothers. Health \& Quality of Life Outcomes, 3(1), 29.

Eiser, C., \& Morse, R. (2001). The measurement of quality of life in children: past and future perspectives. Journal of Developmental \& Behavioral Pediatrics, 22(4), 248-256.

Fagot-Campagna, A., Pettitt, D. J., Engelgau, M., Burrows, N. R., Geiss, L. S., Valdez, R., et al. (2000). Type 2 diabetes among North American children and adolescents: An epidemiologic review and a public health perspective. The Journal of Pediatrics, 136(5), 664-672.

Fantuzzi, G. (2005). Adipose tissue, adipokines, and inflammation. Journal of Allergy and Immunology, 115(5), 911-919.

Farshchi, H. R., Taylor, M. A., \& Macdonald, I. A. (2005). Deleterious effects of omitting breakfast on insulin sensitivity and fasting lipid profiles in healthy lean women. American Journal of Clinical Nutrition, 81, 388-396.

Faul, F., \& Erdfelder, E. (1992). G Power: A priori, post-hoc, and compromise power analyses for MS-DOS. (Version 2) [Computer Program]. Bonn, Federal Republic of Germany: Bonn University.

Ferrans, C., \& Powers, M. (1985). Quality of life index: Development and psychometric properties. Advances in Nursing Science, 8, 15-24.

Ferrans, C. E. (1996). Development of a conceptual model of quality of life. Scholarly Inquiry for Nursing Practice: An International Journal, 10(3), 293-304.

Ferrans, C. E. (2005). Definitions and conceptual models of quality of life. In C. C. Gotay \& C. Snyder (Eds.), Outcomes research in cancer: Measures, methods, and applications. (pp. 14-30). Cambridge, UK: Cambridge University Press.

Ferrans, C. E., Zerwic, J. J., Wilbur, J. E., \& Larson, J. L. (2005). Conceptual Model of Health-Related Quality of Life. Journal of Nursing Scholarship, 37(4), 336-342.

Figueroa-Munoz, J. I., Chinn, S., \& Rona, R. J. (2001). Association between obesity and asthma in 4-11 year old children in the U.K. Thorax, 56, 133-137.

Finkelstein, E. A., Fiebelkorn, I. C., \& Wang, G. (2003). National medical spending attributable to overweight and obesity. How much, and who's paying? Health Affairs Web Exclusive, W3, 219-226, http://content.healthaffairs.org/cgi/content/full/hlthaff.w213.219v211/DC211. 
Fontaine, K. R., \& Barofsky, I. (2001). Obesity and health-related quality of life. Obesity Reviews, 2(3), 173-182.

Ford, E. S., \& Mannino, D. M. (2005). Time trends in obesity among adults with asthma in the United States: findings from three national surveys. Journal of Asthma, $42(2), 91-95$.

Freedman, D. S., Dietz, W. H., Srinivasan, S. R., \& Berenson, G. S. (1999). The relation of overweight to cardiovascular risk factors among children and adolescents: The Bogalusa Heart Study. Pediatrics, 103(6), 1175-1182.

Freedman, D. S., Khan, L. K., Dietz, W. H., Srinivasan, S. R., \& Berenson, G. S. (2001). Relationship of childhood obesity to coronary heart disease risk factors in adulthood: The Bogalusa Heart Study. Pediatrics, 108(3), 712-718.

French, S. A., Lin, B. H., \& Guthrie, J. F. (2003). National trends in soft drink consumption among children and adolescents age 6 to 17 years: prevalence, amounts, and sources, 1977/1978 to 1994/1998. Journal of the American Dietetic Association, 103(10), 1326-1331.

Friedlander, S. L., Larkin, E. K., Rosen, C. L., Palermo, T. M., \& Redline, S. (2003). Decreased quality of life associated with obesity in school-aged children. Archives of Pediatrics and Adolescent Medicine, 157, 1206-1211.

Fry, E. (1977). Elementary Reading Instruction: The McGraw-Hill Companies.

Fulkerson, J. A., Neumark-Sztainer, D., Hannan, P. J., \& Story, M. (2008). Family meal frequency and weight status among adolescents: Cross-sectional and 5-year longitudinal associations. Obesity, 16(11), 2529-2534.

Galatzer-Levy, J. (2003, April 27). Asthma's ground zero. The Chicago Tribune (Magazine), pp. 10-15.

Gennuso, J., Epstein, L. H., Paluch, R. A., \& Cerny, F. (1998). The relationship between asthma and obesity in urban minority children and adolescents. Archives of Pediatrics \& Adolescent Medicine, 152(12), 1197-1200.

Gerharz, E. W., Eiser, C., \& Woodhouse, C. R. (2003). Current approaches to assessing the quality of life in children and adolescents. BJU International, 91(2), 150-154.

Gibson, P. G., Henry, R. L., Vimpani, G. V., \& Halliday, J. (1995). Asthma knowledge, attitudes, and quality of life in adolescents. Archives of Disease in Childhood, 73(4), 321-326. 
Gibson, P. G., Talbot, P. I., Toneguzzi, R. C., \& Population Medicine Group 91C. (1995). Self-management, autonomy, and quality of life in asthma. Chest, 107(4), 10031008.

Gill, T. M., \& Feinstein, A. R. (1994). A critical appraisal of the quality-of-life measurements. Journal of the American Medical Association, 272, 619-626.

Gilmartin, M. E. (2005). Asthma management: a pharmacologic approach. The American Journal of Nurse Practitioners, editorial supplement, 20-30.

Goran, M. I., Ball, G. D., \& Cruz, M. L. (2003). Cardiovascular endocrinology 2: Obesity and risk of type 2 diabetes and cardiovascular disease in children and adolescents. The Journal of Clinical Endocrinology \& Metabolism, 88(4), 14171427.

Gordon-Larsen, P., McMurray, R. G., \& Popkin, B. M. (2000). Determinants of adolescent physical activity and inactivity patterns. Pediatrics, 105(6), E83.

GovTrack.us. (2009). H.R. 1324: Child Nutrition Promotion and School Lunch Protection Act of 2009. Retrieved August 26, 2009, from http://www.govtrack.us/congress/bill.

Griffiths, M., Rivers, J. P., \& Payne, P. R. (1987). Energy intake in children at high and low risk of obesity. Human Nutrition - Clinical Nutrition, 41(6), 425-430.

Grunbaum, J. A., Kann, L., Kinchen, S., Ross, J., Hawkins, J., Lowry, R., et al. (2004). Youth risk behavior surveillance- United States, 2003. Morbidity \& Mortality Weekly Report, 53(SS-2), 844-847.

Guo, S. S., \& Chumlea, W. C. (1999). Tracking of body mass index in children in relation to overweight in adulthood. American Journal of Clinical Nutrition, $70(1), 145 \mathrm{~S}-148 \mathrm{~S}$.

Guyatt, G. H., \& Cook, D. J. (1994). Health status, quality of life, and the individual patient. Journal of the American Medical Association, 272, 630-631.

Guyatt, G. H., Juniper, E. F., Griffith, L. E., Feeny, D. H., \& Ferrie, P. J. (1997). Children and adult perceptions of childhood asthma. Pediatrics, 99(2), 165-168.

Guyatt, G. H., Veldhuyzen Van Zanten, S. J., Feeny, D. H., \& Patrick, D. L. (1989). Measuring quality of life in clinical trials: a taxonomy and review. Canadian Medical Association Journal, 140, 1441-1448. 
Hagarty, M. A., Schmidt, C., Bernaix, L., \& Clement, J. M. (2004). Adolescent obesity: Current trends in identification and management. Journal of the American Academy of Nurse Practitioners, 16(11), 481-489.

Harrell, J. S., Gansky, S. A., Bradley, C. B., \& McMurray, R. G. (1997). Leisure time activities of elementary school children. Nursing Research, 46(5), 246-253.

Harrison, M. B., Juniper, E. F., \& Mitchell-DiCenso, A. (1996). Quality of life as an outcome measure in nursing research. "May you have a long and healthy life". Canadian Journal of Nursing Research, 28(3), 49-68.

Heller, L. (2006). No go for junk food ban in Illinois schools. Retrieved August 26, 2009, from http://www.foodnavigator-usa.com

Hellmich, N. (2004). School vending rated as junk. Retrieved July 18, 2006, from http://www.keepmedia.com/pibs/USATODAY/2004/5/12

Herndon, D. N., LeMaster, J., Beard, S., Bernstein, N., Lewis, S. R., \& Rutan, T. C. (1986). The quality of life after major thermal injury in children: An analysis of 12 survivors with $>80 \%$ total body, $70 \%$ third-degree burns. The Journal of Trauma, 26, 609-617.

Howard, T. D., Meyers, D. A., \& Bleecker, E. R. (2000). Mapping susceptibility genes for athma and allergy. Journal of Allergy and Clinical Immunology, 105, S477S481.

International Study of Asthma and Allergies in Childhood. (1998). Worldwide variation in prevalence of symptoms of asthma, allergic rhinoconjunctivitis, and atopic eczema: ISAAC. Lancet, 351(9111), 1225-1232.

Janse, A. J., Sinnema, G., Uiterwaal, C. S., Kimpen, J. L., \& Gemke, R. J. (2004). Quality of life in chronic illness: perceptions of parents and paediatricians. Archives of Disease in Childhood, 90, 486-491.

Juniper, E. F. (1997). How important is quality of life in pediatric asthma? Pediatric Pulmonology - Supplement, 15, 17-21.

Juniper, E. F. (2005). Measurement of Health-Related Quality of Life. Retrieved February 1, 2007, from http://www.qoltech.co.uk/PaedAsthma.htm

Juniper, E. F., Guyatt, G. H., Feeny, D. H., Griffith, L. E., \& Ferrie, P. J. (1997). Minimum skills required by children to complete health-related quality of life instruments for asthma: comparison of measurement properties. European Respiratory Journal, 10(10), 2285-2294. 
Juniper, E. F., Svensson, K., Mork, A. C., \& Stahl, E. (2004). Measuring health-related quality of life in adults during an acute asthma exacerbation. Chest, 125(1), 93-97.

Juniper, E. F., Wisniewski, M. E., Cox, F. M., Emmett, A. H., Nielsen, K. E., \& O'Byrne, P. M. (2004). Relationship between quality of life and clinical status in asthma: a factor analysis. European Respiratory Journal, 23, 287-291.

Kabesch, M., Schedel, M., Carr, D., Woitsch, B., Fritzsch, C., Weiland, S. K., et al. (2006). IL-4/IL-13 pathway genetics strongly influence serum IgE levels and childhood asthma. Journal of Allergy and Clinical Immunology, 117(2), 269-274.

Keski-Rahkonen, A., Kaprio, J., Rissanen, A., Virkkunen, M., \& Rose, R. J. (2003). Breakfast skipping and health-compromising behaviors in adolescents and adults. European Journal of Clinical Nutrition, 57, 842-853.

Kimm, S. Y., Glynn, N. W., Kriska, A. M., Fitzgerald, S. L., Aaron, D. J., Similo, S. L., et al. (2000). Longitudinal changes in physical activity in a biracial cohort during adolescence. Medicine \& Science in Sports \& Exercise, 32(8), 1445-1454.

Kimm, S. Y., \& Obarzanek, E. (2006). Childhood Obesity: A New Pandemic of the New Millennium. Pediatrics, 110(5), 1003-1007.

King, C. R., \& Hinds, P. S. (2003). Quality of life from nursing and patient perspectives. (2nd ed.). Sudbary, MA: Jones and Bartlett Publishers.

Koeppen-Schomerus, G., Wardle, J., \& Plomin, R. (2001). A genetic analysis of weight and overweight in 4-year-old twin pairs. International Journal of Obesity \& Related Metabolic Disorders: Journal of the International Association for the Study of Obesity, 25(6), 838-844.

Koscik, R. L., Douglas, J. A., Zaremba, K., Rock, M. J., Splaingard, M. L., Laxova, A., et al. (2005). Quality of life of children with cystic fibrosis. Journal of Pediatrics, 147(3 Suppl), S64-68.

Krebs, N. F., \& Jacobson, M. S. (2003). American Academy of Pediatrics. Committee on Nutrition. Prevention of pediatric overweight and obesity. Pediatrics. 112(2):424-30.

Krebs-Smith, S. M., Cook, A., Subar, A. F., Cleveland, L., Friday, J., \& Kahle, L. L. (1996). Fruit and vegetable intakes of children and adolescents in the United States. Archives of Pediatrics \& Adolescent Medicine, 150(1), 81-86.

Kuczmarski, R. J., Ogden, C. L., Grummer-Strawn, L. M., Flegal, K. M., Guo, S. S., Wei, R., et al. (2000). CDC Growth Charts: United States. Advance Data(314), 1-28. 
Lai, C. K., Douglass, C., Ho, S. S., Chan, J., Lau, J., Wong, G., et al. (1996). Asthma epidemiology in the Far East. Clinical \& Experimental Allergy, 26(1), 5-12.

Lake, J. K., Power, C., \& Cole, T. J. (1997). Child to adult body mass index in the 1958 British birth cohort: associations with parental obesity.[see comment]. Archives of Disease in Childhood, 77(5), 376-381.

Lansky, L. L., List, M. A., Lansky, S. B., Cohen, M. E., \& Sinks, L. F. (1985). Toward the development of a play performance scale for children (PPSC). Cancer, 56(suppl. 7), 1837-1840.

Lansky, S. B., List, M. A., Lansky, L. L., Ritter-Sterr, C., \& Miller, D. R. (1987). The measurement of performance in childhood cancer patients. Cancer, 60, 16511656.

Lemanske, R. F., Nayak, A., McAlary, M., Everhard, F., Fowler-Taylor, A., \& Gupta, N. (2002). Omalizumab improves asthma-related quality of life in children with allergic asthma. Pediatrics, 110(5), e55.

Leplege, A., \& Hunt, S. (1997). The problem of quality of life in medicine. JAMA, 278(1), 47-50.

Li, Z., Bowerman, S., \& Heber, D. (2005). Health ramifications of the obesity epidemic. Surgical Clinics of North America, 85(4), 681-701.

Liu, A. H., Spahn, J. D., \& Leung, D. Y. M. (2004). Childhood Asthma. In R. E. Behrman, R. M. Kliegman \& H. B. Jenson (Eds.), Nelson Textbook of Pediatrics (17th ed., pp. 760-778). International Edition: Saunders.

Luder, E., Ehrlich, R. I., Lou, W. Y., Melnik, T. A., \& Kattan, M. (2004). Body mass index and the risk of asthma in adults. Respiratory Medicine, 98(1), 29-37.

Luder, E., Melnik, T. A., \& DiMaio, M. (1998). Association of being overweight with greater asthma symptoms in inner city black and Hispanic children. Journal of Pediatrics, 132(4), 699-703.

Ludwig, D. S., Peterson, K. E., \& Gortmaker, S. L. (2001). Relation between consumption of sugar-sweetened drinks and childhood obesity: A prospective, observational analysis. Lancet, 357, 505-508.

Lugogo, N. L., Kraft, M., \& Castro, M. (2008). Epidemiology of Asthma. In M. Castro \& M. Kraft (Eds.), Clinical Asthma (pp. 3-12). Philadelphia: Mosby.

Maffeis, C., \& Tato, L. (2001). Long-term effects of childhood obesity on morbidity and mortality. Hormone Research, 55 Suppl 1, 42-45. 
Mannino, D. M., Homa, D. M., Akinbami, L. J., Moorman, J. E., Gwynn, C., \& Redd, S. C. (2002). Surveillance for asthma--United States, 1980-1999. Morbidity \& Mortality Weekly Report Surveillance Summaries, 51(1), 1-13.

Mannino, D. M., Homa, D. M., Pertowski, C. A., Ashizawa, A., Nixon, L. L., Johnson, C. A., et al. (1998). Surveillance for asthma--United States, 1960-1995. Morbidity \& Mortality Weekly Report CDC Surveillance Summaries, 47(1), 1-27.

Mannino, D. M., Mott, J., Ferdinands, J. M., Camargo, C. A., Friedman, M., Greves, H. M., et al. (2006). Boys with high body masses have an increased risk of developing asthma: findings from the National Longitudinal Survey of Youth (NLSY). International Journal of Obesity, 30(1), 6-13.

Masoli, M., Fabian, D., Holt, S., \& Beasley, R. (2004). The Global Burden of Asthma Report. Retrieved August 14, 2009, from http://www.ginastha.org

Mayo Clinic. (2009). Childhood obesity: Make weight loss a family affair. Retrieved September 24, 2009, from http://www.mayoclinic.com

McDaniel, M., Paxson, C., \& Waldfogel, J. (2006). Racial disparities in childhood asthma in the United States: Evidence from the National Health Interview Survey, 1997 to 2003. Pediatrics, 117(5), 868-877.

McGill, H. C., McMahan, C. A., Herderick, E. E., Zieske, A. W., Malcom, G. T., Tracy, R. E., et al. (2002). Obesity accelerates the progression of coronary atherosclerosis in young men. Circulation, 105, 2712-2718.

Miller, M. R., Hankinson, J., Brusasco, V., Burgos, F., Casaburi, R., Coates, A., et al. (2005). ATS/ERS task force: Standardization of lung function testing. Standardization of spirometry. European Respiratory Journal, 26, 319-338.

Morland, K., Wing, S., Diez Roux, A., \& Poole, C. (2002). Neighborhood characteristics associated with the location of food stores and food service places. American Journal of Preventive Medicine, 22(1), 23-29.

Mullen, A. L. W. (2005). Asthma: An overview. The American Journal of Nurse Practitioners, Editorial supplement(June), 4-8.

Munoz, K. A., Krebs-Smith, S. M., Ballard-Barbash, R., \& Cleveland, L. E. (1997). Food Intakes of US children and adolescents compared with recommendations. Pediatrics, 100, 323-329.

Murphy, K. R., Fitzpatrick, S., Cruz-Rivera, M., Miller, C. J., \& Parasuraman, B. (2003). Effects of budesonide inhalation suspension compared with cromolyn sodium 
nebulizer solution on health status and caregiver quality of life in childhood asthma. Pediatrics, 112((3 Pt 1)), E212-219.

Musaad, S. M., Patterson, T., Ericksen, M., Lindsey, M., Dietrich, K., Succop, P., et al. (2009). Comparison of anthropometric measures of obesity in childhood allergic asthma: central obesity is most relevant. Journal of Allergy \& Clinical Immunology, 123(6), 1321-1327.

Musschenga, A. W. (1997). The relation between concepts of quality-of-life, health, and happiness. The Journal of Medicine and Philosophy, 22, 11-28.

Nair, S. J., \& Cloutier, M. M. (2003). Managing severe asthma exacerbations in children. The Journal of Respiratory Diseases for Pediatricians, 5(1), 12-21.

National Association for Sport and Physical Education \& American Heart Association. (2006). 2006 Shape of the nation report: Status of physical education in the USA. Reston, VA: National Association for Sport and Physical Education.

National Asthma Education and Prevention Program. (2003). Guidelines for the diagnosis and management of Asthma- Update on Selected Topics 2002: Expert Panel Report. Retrieved June 10, 2006, from http://www.nhlbi.nh.gov/guidelines/asthma/asthgdln.htm

National Asthma Education and Prevention Program. (2007). Expert Panel Report 3: Guidelines for the diagnosis and management of asthma. (No. NIH publication no. 07-4051). Bethesda, MD: National Heart Lung and Blood Institute.

National Heart Lung and Blood Institute. (1999). Data Fact Sheet: Asthma Statistics. Retrieved March 3, 2006, from http://www.nhlbi.nih.gov/health/prof/lung/asthma/asthstat.pdf.

National Institutes of Health. (2005). NIH News: Bacteria in household dust may trigger asthma symptoms. Retrieved June 28, 2006, from http://www.nih.gov/news/pr/sep2005/niehs-07.htm

Nixon, A. Y., \& Honsinger, R. (2007). Asthma and obesity. Retrieved September 26, 2009, from http://www.aaaai.org/patients/advocate/2007/fall/asthma obesity.asp

Odame, I., Duckworth, J., Talsma, D., Beaumont, L., Furlong, W., Webber, C., et al. (2006). Osteopenia, physical activity and health-related quality of life in survivors of brain tumors treated in childhood. Pediatric Blood \& Cancer, 46(3), 357-362.

Ogden, C. L., Carroll, M. D., Curtin, L. R., McDowell, M. A., Tabak, C. J., \& Flegal, K. M. (2006). Prevalence of overweight and obesity in the United States, 1999-2004. JAMA, 295(13), 1549-1555. 
Ogden, C. L., Carroll, M. D., McDowell, M. A., \& Flegal, K. M. (2007). Obesity among adults in the United States- no change since 2003-2004. Hyattsville, MD: National Center for Health Statistics.

Ogden, C. L., Flegal, K. M., Carroll, M. D., \& Johnson, C. L. (2002). Prevalence and trends in overweight among US children and adolescents, 1999-2000. JAMA, 288(14), 1728-1732.

Okelo, S. O., Wu, A. W., Krishnan, J. A., Rand, C. S., Skinner, E. A., \& Diette, G. B. (2004). Emotional quality-of-life and outcomes in adolescents with asthma. Journal of Pediatrics, 145(4), 523-529.

Okie, S. (2005). Fed Up! Washington, D.C.: Joseph Henry Press.

Olshansky, S. J., Passaro, D. J., Hershow, R. C., Layden, J., Carnes, B. A., Brody, J., et al. (2005). A potential decline in life expectancy in the United States in the $21 \mathrm{st}$ century.[see comment]. New England Journal of Medicine, 352(11), 1138-1145.

Paeratakul, S., Ferdinand, D. P., Champagne, C. M., Ryan, D. H., \& Bray, G. A. (2003). Fast-food consumption among US adults and children: dietary and nutrient intake profile. Journal of the American Dietetic Association, 103(10), 1332-1338.

Pastore, D. R., Fisher, M., \& Friedman, S. B. (1996). Abnormalities in weight status, eating attitudes, and eating behaviors among urban high school students:

Correlations with self-esteem and anxiety. Journal of Adolescent Health, 18, 312319.

Pereira, M. A., Jacobs, D. R., VanHorn, L., Slattery, M. L., Kartashov, A. I., \& Ludwig, D. S. (2002). Dietary consumption, obesity and the insulin resistence syndrome in young adults: the CARDIA study. JAMA, 287, 2081-2089.

Pereira, M. A., Kartashov, A. I., Ebbling, C. B., Van Horn, L., Slattery, M. L., \& Jacobs, D. R. (2005). Fast-food habits, weight gain, and insulin resistance (the CARDIA study): 15-year prospective analysis. Lancet, 365(9453), 36-42.

Pinhas-Hamiel, O., Singer, S., Pilpel, N., Fradkin, A., Modan, D., \& Reichman, B. (2006). Health-related quality of life among children and adolescents: associations with obesity. International Journal of Obesity, 30, 267-272.

Raat, H., Bueving, H. J., de Jongste, J. C., Grol, M. H., Juniper, E. F., \& van der Wouden, J. C. (2005). Responsiveness, longitudinal- and cross-sectional construct validity of the Pediatric Asthma Quality of Life Questionnaire (PAQLQ) in Dutch children with asthma. Quality of Life Research, 14(1), 265-272. 
Rachelefsky, G. S., Kennedy, S., \& Stone, A. (2006). Enhancing the role of the emergency department in the identification and management of childhood asthma. Pediatrics, 117(4), S57-S62.

Rampersaud, G. C., Pereira, M. A., Girard, B. L., Adams, J., \& Metzel, J. D. (2005). Breakfast habits, nutritional status, body weight, and academic performance in children and adolescents. Journal of the American Dietetic Association, 105(5), 743-760.

Ravens-Sieberer, U., Redegeld, M., \& Bullinger, M. (2001). Quality of life after inpatient rehabilitation in children with obesity. International Journal of Obesity \& Related Metabolic Disorders: Journal of the International Association for the Study of Obesity, 25 Suppl 1, S63-65.

Ravn, K. (2009). Body of lies: Patients aren't 100\% honest with doctors. Retrieved September 24th, 2009, from http://articles.latimes.com

Rees, J. (2005). ABC of asthma. Prevalence. BMJ, 331(7514), 443-445.

Riddle, R., Ryser, C. N., Morton, A. A., Sampson, J. D., Browne, R. H., Punaro, M. G., et al. (2006). The impact on health-related quality of life from non-steroidal antiinflammatory drugs, methotrexate, or steroids in treatment for juvenile idiopathic arthritis. Journal of Pediatric Psychology, 31(3), 262-271.

Ritchie, L., Ivey, S., Masch, M., Woodward-Lopez, G., Ikeda, J., \& Crawford, P. (2001). Pediatric overweight: A review of the literature. Retrieved June 24, 2005, from http://CNR.berkeley.edu/cwh/PDFS/bw-weighing.pdf.

Robinson, T. N. (1999). Reducing children's television viewing to prevent obesity: a randomized controlled trial. JAMA, 282(16), 1561-1567.

Rodriguez, M. A., Winkleby, M. A., Ahn, D., Sundquist, J., \& Kraemer, H. C. (2002). Identification of population subgroups of children and adolescents with high asthma prevalence: findings from the Third National Health and Nutrition Examination Survey. Archives of Pediatrics \& Adolescent Medicine, 156(3), 269275.

Roger, A. (1999). Quality of life in the severity of asthma. Alergol Inmunol Clin, 14(6), 354-363.

Roy, A. J. (2005). Sound the alarm: Childhood obesity and the emergence of type 2 diabetes. Advance for Nurse Practitioners, August, 37-42. 
Russell, K. M., Hudson, M., Long, A., \& Phipps, S. (2006). Assessment of health-related quality of life in children with cancer: consistency and agreement between parent and child reports. Cancer, 106(10), 2267-2274.

Sampson, A. E., Dixit, S., Meyers, A. F., \& Houser, R. (1995). The nutritional impact of breakfast consumption on the diets of inner-city African-American elementary school children. Journal of the American Medical Association, 87, 195-202.

Satter, E. (2005). Your Child's Weight: Helping Without Harming. Madison, WI: Kelcy Press.

Sawyer, M. G., Carbone, J. A., Whitham, J. N., Roberton, D. M., Taplin, J. E., Varni, J. W., et al. (2005). The relationship between health-related quality of life, pain, and coping strategies in juvenile arthritis- a one year prospective study. Quality of Life Research, 14(6), 1585-1598.

Schrock, K. (1995). Kathy Schrock's Guide for Educators. Retrieved June 20, 2007, from http://discoveryschool.com/schrockguide/

Schwimmer, J. B., Burwinkle, T. M., \& Varni, J. W. (2003). Health-related quality of life of severely obese children and adolescents.[see comment]. JAMA, 289(14), 18131819.

Shaheen, S. O. (1999). Obesity and asthma: cause for concern? Clinical and Experimental Allergy, 29(3), 291-293.

Siega-Riz, A. M., Popkin, B. M., \& Carson, T. (1998). Trends in breakfast consumption for children in the United States from 1965-1991. American Journal of Clinical Nutrition, 67(suppl), 748S-756S.

Sinha, R., Fisch, G., Teague, B., Tamborlane, W. V., Banyas, B., Allen, K., et al. (2002). Prevalence of impaired glucose tolerance among children and adolescents with marked obesity. The New England Journal of Medicine, 346(11), 802-810.

Sithole, F., Douwes, J., Burstyn, I., \& Veugelers, P. (2008). Body mass index and childhood asthma: A linear association? Journal of Asthma, 45, 473-477.

Smyth, R. L. (2002). Asthma: a major pediatric health issue. Respiratory Research, 3(suppl 1), S3-S7.

Spahn, J. D., Stewart, L., \& Chipps, B. (2008). How do you diagnose asthma in the child? In M. Castro \& M. Kraft (Eds.), Clinical Asthma (pp. 57-66). Philadelphia, PA: Elsevier Mosby. 
Spivak, H., Hewitt, M. F., Onn, A., \& Half, E. E. (2005). Weight loss and improvement of obesity-related illness in 500 U.S. patients following laparoscopic adjustable gastric banding procedure. American Journal of Surgery, 189(1), 27-32.

Srivastava, A., Kapoor, R. K., Misra, P. K., Srivastava, K. L., Thakur, S., \& Shukla, N. (1995). Pulmonary function tests in normal Indian children and changes in respiratory disorders. Indian Pediatrics, 32, 629-634.

Swallen, K. C., Reither, E. N., Haas, S. A., \& Meier, A. M. (2005). Overweight, obesity, and health-related quality of life among adolescents: the National Longitudinal Study of Adolescent Health. Pediatrics, 115(2), 340-347.

Szeftel, A., \& Schiffman, G. (2009). Myths, facts, and statistics about asthma. Retrieved August 18, 2009, from http://www.medicinenet.com/asthma/article.htm

Tattersfield, A. E., Knox, A. J., Britton, J. R., \& Hall, I. P. (2002). Asthma. Lancet, 360, 1313-1322.

Tauler, E., Vilagut, G., Grau, G., Gonzalez, A., Sanchez, E., Figueras, G., et al. (2001). The spanish version of the paediatric asthma quality of life questionnaire (PAQLQ): metric characteristics and equivalence with the original version. Quality of Life Research, 10(1), 81-91.

Teach, S. J., Guagliardo, M. F., Crain, E. F., McCarter, R. J., Quint, D., Shao, C., et al. (2006). Spatial accessibility of primary care pediatric services in an urban environment: association with asthma management and outcome. Pediatrics, 117, S78-S85.

Testa, M. A., \& Simonson, D. C. (1996). Assessment of quality of life outcomes. The New England Journal of Medicine, 334, 835-840.

Thomas, C., Mitchell, P., O'Rourke, P., \& Wainwright, C. (2006). Quality-of-life in children and adolescents with cystic fibrosis managed in both regional outreach and cystic fibrosis center settings in Queensland. Journal of Pediatrics, 148(4), 508-516.

Thorpe, K. E., Florence, C. S., Howard, D. H., \& Joski, P. (2004). The impact of obesity on rising medical spending. Retrieved July 3, 2006, from http://content.healthaffairs.org

To, T., Vydykhan, T., Dell, S., Tassoudji, M., \& Harris, J. K. (2004). Is obesity associated with asthma in young children? The Journal of Pediatrics, 144, 162168. 
Toriano, R. P., Briefel, R. R., Carroll, M. D., \& Bialostosky, K. (2000). Energy and fat intake of children and adolescents in the United States: Data from the National Health and Nutrition Examination Surveys. American Journal of Clinical Nutrition, 72, 1343S-1353S.

Townsend, M. S., Peerson, J., Love, B., Achterberg, C., \& Murphy, S. P. (2001). Food insecurity is positively related to overweight in women. Journal of Nutrition, $131(6), 1738-1745$.

Treuth, M. S., Butte, N. F., \& Wong, W. W. (2000). Effects of familial predisposition to obesity on energy expenditure in multiethnic prepubertal girls. American Journal of Clinical Nutrition, 71(4), 893-900.

Trochim, W. (2001). The Research Methods Knowledge Base (2nd ed.). Cincinnati, OH: Atomic Dog Publishing.

US Department of Health and Human Services. (2000). Healthy People 2010: With Understanding and Improving Health and Objectives for Improving Health, Vol. 2. Retrieved June 18, 2006, from http://www.healthypeople.gov

US Preventive Services Task Force. (2005). Screening and interventions for overweight in children and adolescents: recommendation statement. Pediatrics, 116(1), $205-$ 209.

Van Gent, R., van der Ent, C. K., Rovers, M. M., Kimpen, J. L., van Essen-Zandvliet, L., \& de Meer, G. (2007). Excessive body weight is associated with additional loss of quality of life in children with asthma. Journal of Clinical Immunology, 119(3), 591-596.

Vasudevan, A. R., Wu, H., Xydakis, A. M., Jones, P. H., O'Brian Smith, E., Sweeney, J. F., et al. (2006). Eotaxin and obesity. The Journal of Clinical Endocrinology \& Metabolism, 91(1), 256-261.

Vignola, A. M., Mirabella, F., Costanzo, G., Di Giorgi, R., Gjomarkaj, M., Bellia, V., et al. (2003). Airway remodeling in asthma. Chest, 123(3), 417S-422S.

Vincent, K. A., \& Higginson, I. J. (2003). Assessing quality of life in children. In A. J. Carr, I. J. Higginson \& P. G. Robinson (Eds.), Quality of Life (pp. 40-53). London: BMJ Books.

Wardle, J. (2005). Understanding the aetiology of childhood obesity: implications for treatment. Proceedings of the Nutrition Society, 64, 73-79. 
Weight-Control Information Network. (2007). Statistics related to overweight and obesity. Retrieved August 25, 2009, from http://win.niddk.nih.gov/statistics/index.htm\#econ

Weiss, K. B., \& Sullivan, S. D. (2001). The health economics of asthma and rhinitis. I. Assessing the economic impact. Journal of Allergy and Clinical Immunology, 107, 3-8.

Weiss, K. B., \& Wagener, D. K. (1990). Changing patterns of asthma mortality: identifying target populations at high risk. JAMA, 264, 1683-1687.

Weiss, R., Dziura, J., Burgert, T. S., Tamborlane, W. V., Taksali, S. E., Yeckel, C. W., et al. (2004). Obesity and the metabolic syndrome in children and adolescents. New England Journal of Medicine, 350(23), 2362-2374.

Whitaker, R. C., Wright, J. A., Pepe, M. S., Seidel, K. D., \& Dietz, W. H. (1997). Predicting obesity in young adulthood from childhood and parental obesity. New England Journal of Medicine, 337(13), 869-873.

Williams, J., Wake, M., Hesketh, K., Maher, E., \& Waters, E. (2005). Health-related quality of life of overweight and obese children. JAMA, 293(1), 70-76.

Wilson, I. B., \& Cleary, P. D. (1995). Linking Clinical Variables With Health-Related Quality of Life: A Conceptual Model of Patient Outcomes. JAMA, 273, 59-65.

Wolf, A. M., \& Colditz, G. A. (1998). Current estimates of the economic cost of obesity in the United States.[see comment]. Obesity Research, 6(2), 97-106.

Woodruff, S. J., \& Hanning, R. M. (2009). Association between family dinner frequency and specific food behaviors among grade six, seven, and eight students from Ontario and Nova Scotia. Journal of Adolescent Health, 44, 431-436.

World Health Organization. (2000). Obesity: preventing and managing the global epidemic. Report of a WHO consultation. World Health Organization Technical Report Series, 894, i-xii.

World Health Organization. (2005). World Health Statistics 2005. Retrieved July 2, 2006, from http://www.who.int/healthinfo/statistics/en/

World Health Organization. (2006a). Obesity and Overweight. Retrieved July 2, 2006, from http:///www.who.int/kietphysicalactivity/publications/facts/obesity/en/print.html

World Health Organization. (2006b). Obesity and Overweight. Retrieved August 24, 2009, from http://www.who.int/mediacentre/factsheets/fs311/en/index.html 
World Health Organization. (2006c). WHO: Global Database on Body Mass Index. Retrieved July 2, 2006, from http://www.who.int/bmi/index.jsp

World Health Organization Division of Mental Health. (1993). WHO-QOL Study protocol: The development of the World Health Organization quality of life assessment instrument. Geneva, Switzerland: WHO.

Zemel, M. B. (2002). Regulation of adiposity and obesity risk by dietary calcium: mechanisms and implications. Journal of the American Colllege of Nutrition, 21, 146S-151S.

Zemel, M. B. (2003). Mechanisms of dairy modulation of adiposity. Journal of Nutrition, $133,252 \mathrm{~S}-256 \mathrm{~S}$. 
VITA

Amy Becker Manion grew up in Hinsdale, Illinois. She graduated from Northern Illinois University in 1989 with the degree of Bachelor of Science in Nursing. Her first employment as a registered nurse was at Mercy Hospital in Chicago, Illinois in pediatrics. She returned to school in 1991 and graduated with the degree of Masters of Science in Nursing, Pediatric Clinical Nurse Specialist, from Loyola University Chicago in 1995. She started working at Children's Memorial Hospital in the Pediatric Intensive Care Unit in 1994 and remained employed there until 2002. Immediately following her graduation from Loyola University, she enrolled in the Post-Graduate Pediatric Nurse Practitioner Program at Rush University and completed the program in 1996. Since graduating from Rush University she has been employed as a pediatric nurse practitioner at Northwestern Children's Practice in Chicago, Illinois. In addition, Amy Becker Manion has held a clinical faculty position at Rush University since 2007. She is an active member of the National Association of Pediatric Nurse Practitioners and a medical round table member at the Pathways Awareness Foundation. She currently lives in Munster, Indiana with her husband, Mike, and their two children. 
